\title{
Doing Well by Doing Good?
}

\author{
New Insights into the \\ Firm Value Implications of \\ Corporate Social Responsibility
}

\author{
Dissertation \\ zur Erlangung des Doktorgrades \\ der Wirtschaftswissenschaftlichen Fakultät \\ der Georg-August-Universität Göttingen \\ (Dr. rer. pol.) \\ vorgelegt von \\ Isabell Lenz, M.A. \\ geboren in Lahnstein
}

Göttingen, Oktober 2016 

Erstgutachter:

Prof. Dr. Maik Hammerschmidt, Professor für Marketing und Innovationsmanagement, Georg-August-Universität Göttingen

Zweitgutachterin:

Prof. Dr. Yasemin Boztuğ, Professorin für Marketing und Konsumentenforschung, GeorgAugust-Universität Göttingen

Drittgutachter:

Prof. Dr. Till Dannewald, Professor für Business Analytics/Business Intelligence, Hochschule RheinMain Wiesbaden

Tag der mündlichen Prüfung: 04. November 2016 



\section{Table of Content}

Table of Content V

List of Figures VII

List of Tables VIII

1. General Introduction 1

1.1 Relevance 1

1.2 Literature Review 4

1.3 Research Outline 7

1.4 Abstracts 14

2. How Can CSR be Used to Compensate Stakeholders for Corporate Misconduct:

The Role of Marketing Levers 17

2.1 Study 1: Introduction 18

2.2 Study 1: Classification of Compensation Strategies 21

2.3 Study 1: Firm Value Effects of Compensation Strategies 23

2.4 Study 1: The Role of Marketing Levers 25

2.5 Study 1: Data and Variables___ 28

2.6 Study 1: Analysis and Results __ 32

2.7 Study 1: Discussion __ 35

3. Can Doing Good Lead to Doing Poorly? Firm Value Implications of CSR in the Face of CSI

3.1 Study 2: Introduction __ 42

3.2 Study 2: An Instrumental Stakeholder Theory Perspective on CSR ___ 48

3.3 Study 2a: The Role of CSI for Firm Value Effects of CSR _ 50

3.3.1 Study 2a: CSR and CSI _ 50

3.3.2 Study 2a: The Interactive Effect of CSR and CSI on Firm Value _ 50

3.3.3 Study 2a: Data and Variables ___ 51

3.3.4 Study 2a: Analysis and Results __ 56

3.3.5 Study 2a: Discussion _ 59

3.4 Study 2b: Firm Value Effects of Different CSR Activities in the Presence of CSI__ 61

3.4.1 Study 2b: Engaging in CSR in the Face of CSI __ 61 
3.4.2 Study 2b: Firm Value Effects of CSR Activities 63

3.4.3 Study 2b: The Role of CSI Context 64

3.4.4 Study 2b: Data and Variables 68

3.4.5 Study 2b: Analysis and Results __ 70

3.4.6 Study 2b: Discussion __ 80

3.5 Study 2: Discussion __ 80

4. Firm Value Effects of Different CSR Types: The Role of Strategic Emphasis 89

4.1 Study 3: Introduction __ 90

4.2 Study 3: Literature Review and Contributions ___ 92

4.3 Study 3: The Agency Cost and Benefit Perspective on CSR __ 95

4.4 Study 3: The Role of Strategic Emphasis for Firm Value Effects of CSR Types ___ 97

4.5 Study 3: Data and Variables___ 107

4.6 Study 3: Analysis and Results __ 115

4.7 Study 3: Discussion _ 124

5. General Discussion _ 131

Appendix _ 137

References _ 139 


\section{List of Figures}

Figure 1: Framework Comprising Three Distinct Studies ............................................ 8

Figure 2: Share of All Firms that Engage in CSR and Faced CSI ......................................43

Figure 3: Moderating Role of CSI Proneness for CSR Types..............................................78

Figure 4: Moderating Effect of CSI Externalization for OD-CSR ........................................79

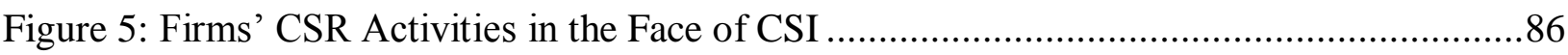

Figure 6: Three Approaches to Differentiate CSR ..................................................... 102

Figure 7: Moderating Effect of Strategic Emphasis for Secondary Doing Good and Primary Avoiding Bad 


\section{List of Tables}

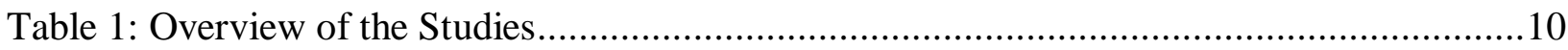

Table 2: Data, Sample, and Methodology of the Studies ........................................................13

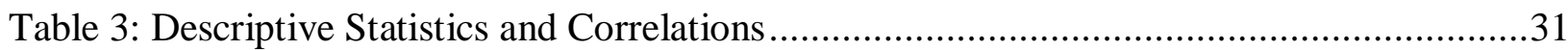

Table 4: The Impact of Social Compensation Strategies on Firm Value ...................................34

Table 5: Studies that Focus the Effects of CSR and CSI on Firm Value ................................47

Table 6: Measurement and Literature Support .........................................................55

Table 7: Descriptive Statistics and Correlations of Variables in Study 2a Sample ....................56

Table 8: Moderating Effect of CSI for the CSR-Firm Value Relationship .............................60

Table 9: Descriptive Statistics and Correlations of Variables in Study 2b Sample ....................72

Table 10: Estimation of a Firm's Probability for CSI ............................................................73

Table 11: Effects of CSR Types on Firm Value ............................................................ 77

Table 12: Measurement and Literature Support ...................................................... 113

Table 13: Descriptive Statistics and Correlations ....................................................... 114

Table 14: Moderating Effect of Strategic Emphasis for CSR Types Based on Three

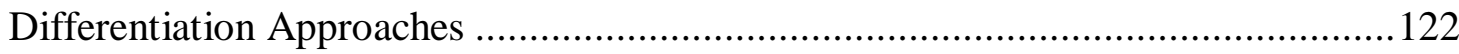



"The Price of Greatness is Responsibility."

—Winston Churchill—

\section{General Introduction}

\subsection{Relevance}

Firms are more than ever before required to take responsibility for stakeholders and society at large. Several trends lead to growing societal expectations on firms. First, society recognizes governments' failure to resolve social problems and becomes increasingly concerned with environmental topics such as climate change and resource scarcity. Second, globalization increases the power and influence of firms leading to frequent occurrence of negative impacts on society and hence less trust into business in general. Third, firms' negative practices become more transparent as nongovernmental organizations are eager to detect social drawbacks while advances in information technology allow exposing these information to a larger and wide-reaching audience (Bielak, Bonini, and Oppenheim 2007; Pricewaterhouse Coopers 2014; Smith 2003). According to a McKinsey survey among CEO's whose firms are members of the UN Global Compact ${ }^{1}$, nearly all respondents believe that the societal expectations on firms' responsibilities have increased in the past years and half see that this trend will continue in the future (Bielak, Bonini, and Oppenheim 2007).

To account for the growing societal expectations, firms engage in corporate social responsibility (CSR) which is broadly defined as firm action that links to the fulfillment of stakeholder or societal obligations (Brown and Dacin 1997; Luo and Bhattacharya 2006; Sen and Bhattacharya 2001). The variety of initiatives that fall under the umbrella of CSR is large and ranges from activities that mitigate the firm's negative social impacts (e.g., pollution and

\footnotetext{
${ }^{1}$ The UN Global Compact is a voluntary, global collaboration between firms and the United Nations intended to promote and implement social and environmental policies into business (UN Global Compact 2016).
} 
waste reduction) to activities that contribute to societal well-being (e.g., employee volunteer programs that serve community needs, charitable giving). Such CSR activities already receive considerable attention in practice. For instance, for half of the Fortune Global 500 companies, CSR ranks among the top three CEO priorities and their yearly CSR spending already represents \$20 billion (Economic Policy Group 2015; McKinsey \& Company 2014).

While these facts are clearly favorable from a societal point of view, the shareholder value implications of CSR, i.e., whether doing good aligns with doing well, is still a topic of hot debate in practice and research alike. In practice, there is still uncertainty whether CSR is valued by shareholders. A survey reveals that the lack of recognition from the investor community represents one of the largest CSR implementation barriers (Accenture 2010; McKinsey\&Company 2009). In research, the question of the financial returns of CSR remains equally unclear. More than three decades of scholarly work on this topic were not enough to provide a clear answer as studies found positive, neutral or negative firm value effects of CSR (Mattingly 2015; Mishra and Modi 2016).

Reflecting the lack of consensus in practice and research, the financial impact of CSR investments can be viewed from two opposing theoretical angles. Agency theory (Jensen and Meckling 1976) provides arguments against CSR by suggesting that CSR represents an agency problem between managers (the agency) and shareholders (the principals). Managers may be inclined to devote resources to CSR projects for personal gains such as to improve their own social standing in the community or to enhance their self-image and such "ego trips" diminish profits (Friedman 1970; Jensen and Meckling 1976). The agency view on CSR thus suggests that CSR may not create shareholder wealth which is also reflected in the following quotation: 
"Shareholders do not hire CEOs to be the U.N., to act like a government or to be a charity. They were hired to make money for shareholders. Business is society's wealth-creation machine. If these guys stick to what they should do-make money - they will create wealth that will benefit the rest of society."

(Steve Milloy, Action Fund Management; Forbes 2008)

The view on CSR as agency costs has been challenged by stakeholder theory (Freeman 1984) which argues in favor of CSR. Proponents of the stakeholder view of the firm suggest that CSR initiatives indirectly affect firm value by establishing strong and trustful stakeholder relationships that foster the achievement of business goals (e.g., Barnett 2007; Hillman and Keim 2001). According to this view, CSR is a wise investment in the enlightened self-interest of the firm as highlighted in the following quotation:

"Creating a strong business and building a better world are not conflicting goals - they are both essential ingredients for long-term success."

(William Clay Ford Jr., Ford Motor Company; Forbes 2008)

These theoretical perspectives suggest either positive or negative firm value effects of CSR. Given the variety of CSR engagement and a firm's specific characteristics and environmental settings in which CSR decisions are embedded, the relationship between CSR and firm value may be too complex as to find a single answer to the question whether CSR is financially beneficial. Rather, the truth may lie between these extreme views in that it depends on the nature of CSR engagement and the firm's specific context whether CSR pays off or not. Thus, the question is not whether firms should engage in CSR but how and when firms can do well by doing good. 
To shed light on the how- and when-question, this dissertation centers on the examination of the impact of different CSR types on firm value under consideration of contingency factors. The dissertation contains three studies that contribute to research and practice alike. For research, the studies provide a more nuanced view on the CSR-firm value link by examining distinct CSR types from three different perspectives. The findings of the studies deliver new insight into what constitutes the heterogeneity of the firm value effects of CSR. More specifically, the findings show that whether certain CSR types contribute to shareholder wealth is intertwined with contextual factors and thus answering the howquestion is inseparable from answering the when-question. For practice, the findings show that firms can reap financial benefits from CSR; however, managers must cautiously choose their CSR engagement under consideration of the specific firm context. Overall, the findings enable managers to make the right CSR decisions, help justifying CSR investments and after all may convince those that still resist from contributing to society. The next chapter gives an overview of the relevant CSR literature and serves to highlight the importance to answer the how- and when-question.

\subsection{Literature Review}

As a multitude of review articles and meta-analyses indicates, there is a long history of scholarly work on the relationship between CSR and firm value (Margolis and Walsh 2003; Mattingly 2015; Orlitzky, Schmidt, and Rynes 2003; Peloza and Shang 2011; Wang, Dou, and Jia 2015). However, more than three decades of research on this topic have only produced equivocal results with evidence for a positive (Luo and Bhattacharya 2006), a negative (Wright and Ferris 1997), and a neutral relationship (Servaes and Tamayo 2013). Margolis and Walsh (2003) review that almost half of the 109 studies on the CSR-financial 
performance link between 1972 and 2002 detected a positive relationship between CSR and financial performance. Seven studies indicate a negative relationship, 28 studies a neutral and 20 studies reveal mixed relationships. In their meta-study of 52 studies from 1979 to 2002, Orlitzky, Schmidt, and Rynes (2003) conclude that a positive influence of CSR on financial performance exists. The most recent meta-study bases on 42 studies and 119 effect sizes after 2003 and likewise found an overall positive effect of CSR on financial performance (Wang, Dou, and Jia 2015).

Although a positive financial effect of CSR seems to dominate the academic literature, several scholars conclude that the results are such fragmented that a universal relationship in which every CSR actions generates the same financial returns for every firm in every condition is unlikely (Barnett 2007) and even "theoretically untenable" (Rowley and Berman 2000, p. 406). Similarly, Rowley and Berman (2000, p. 406) suggest that "only the most naive (or blindly hopeful) among us will assume that poor (good) social behavior will always have negative (positive) financial implications".

In order to relieve the tension in the debate over doing well by doing good and to explain the heterogeneous findings of prior work, research has been developing into two directions: Recent studies consider the multifaceted nature of the CSR construct by differentiating CSR types (i.e., differentiation approach). Such approach suggests that different CSR types may bear different financial implications. Other research focuses on examining contingency factors in the CSR-financial performance relationship (i.e., contingency approach). This approach builds on the idea that the financial performance effects of CSR differ by firms' individual context.

Differentiation approach. Studies examining different CSR types attempt to answer the question how a firm should design its CSR engagement for reaping financial benefits. 
Paving the way for a more fine-grained differentiation of CSR, scholars suggest that CSR and its counterpart corporate social irresponsibility (CSI), mirror distinct patterns of firm action and should not be commingled into an overall CSR construct as has been done in the majority of CSR studies (Mattingly and Berman 2006). Recent seminal studies find evidence for the importance to extract CSI from the overall CSR measure and to explicitly account for CSI in the CSR-firm value relationship (Jayachandran, Kalaignanam, and Eilert 2013; Kang, Germann, and Grewal 2016). Other pioneering studies focus on a pragmatic differentiation of CSR by simply distinguishing CSR with respect to domains in which they are accomplished (e.g., natural environment, diversity, employee relations, product, community relations, human rights or corporate governance). For instance, Hillman and Keim (2001) suggest that only CSR in the community domain is linked to firm value. Jayachandran, Kalaignanam, and Eilert (2013) find that CSR in the product domain enhances firm value while CSR engagement towards the natural environment remains unconsidered from the investor community. Mishra and Modi (2016) even find no direct effect of any CSR domain. Taking these findings together, a disaggregated analysis on such pragmatic domain-level may lead to equally fragmented findings in the CSR-firm value relationship and calls for alternative, conceptually driven differentiations of CSR.

Contingency approach. By considering contingency factors in the CSR-firm value link, other research has moved towards answering the question when does it payoff to be socially responsible (Barnett 2007; Dixon-Fowler et al. 2013). Recent studies in this area reveal that in some context the positive performance impact of CSR is strengthened and in other contexts it is mitigated or even turns into a negative relationship. For example, Luo and Bhattacharya (2006) show that the effect of CSR on firm value is strengthened for innovative firms but that CSR backfires for firms with low product quality. Recent research suggests that 
whether CSR has a direct impact on firm value at all is contingent on marketing variables (Mishra and Modi 2016; Servaes and Tamayo 2013). These studies provide first insight that a firm reaps financial returns from CSR only when customer awareness is high pointing to the importance of creating marketing capabilities to boost CSR success. In sum, these findings suggest examining the moderating role of the marketing function in the CSR-firm value relationship as fruitful area of research.

Accounting for both approaches in CSR literature, this dissertation provides unique differentiations of CSR engagements and examines the firm value effect of these CSR facets under consideration of contingency factors, such as the influence of functional and strategic marketing factors. The next chapter explains the dissertation's research outline.

\subsection{Research Outline}

The dissertation comprises three studies in which the firm value effects of distinct CSR types are examined from three different perspectives. Figure 1 gives an overview of the dissertation's framework showing that CSR types are examined from a compensation, a CSI, and an obligation/stakeholder perspective. 


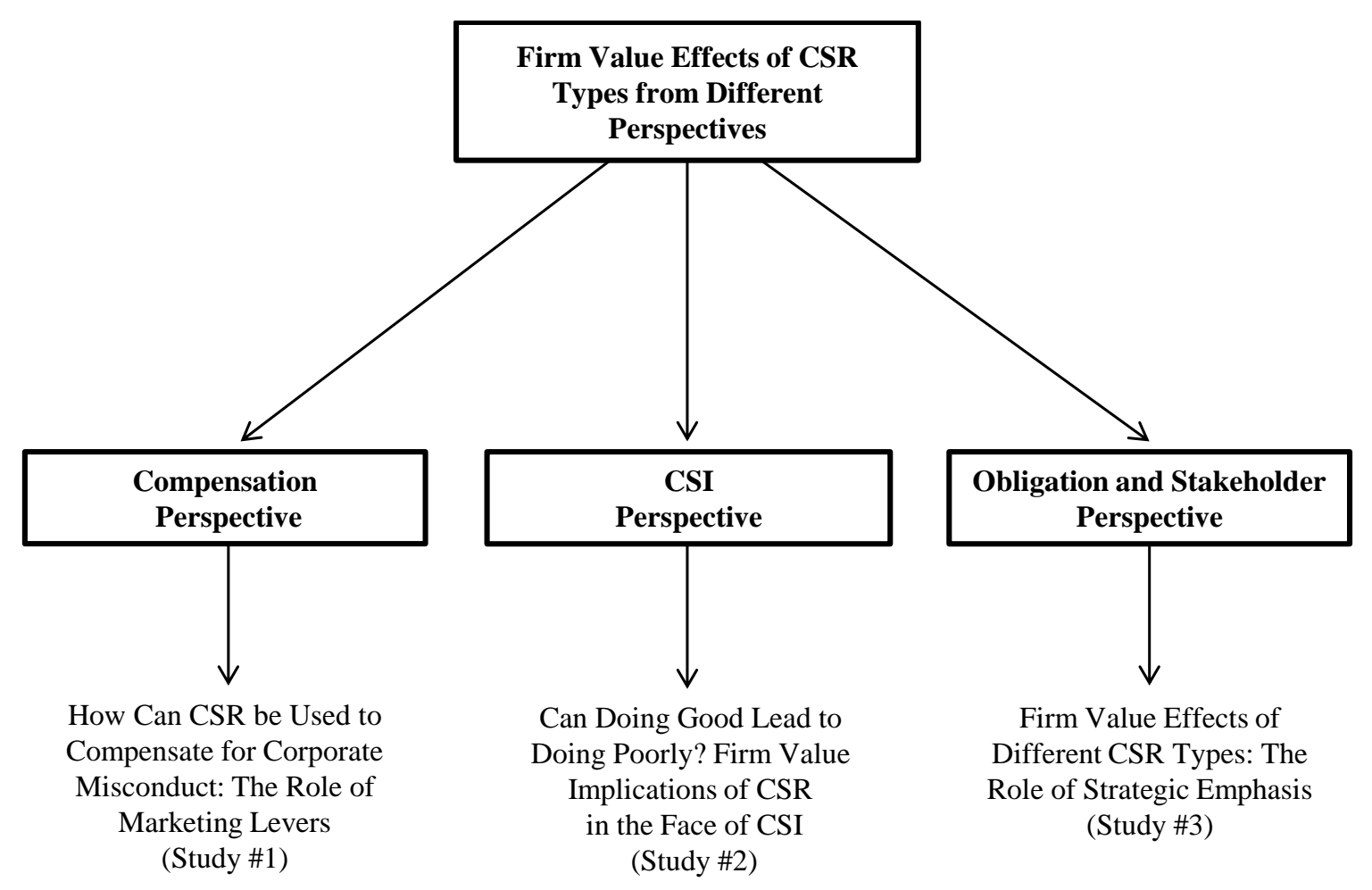

Study 1 takes a compensation perspective by focusing on CSR as a means for compensating stakeholders for the harm caused by prior corporate misconduct. More specifically, the study centers on the examination of the firm value effects of two distinct ways to engage in CSR as a response to preceding corporate misconduct and the role of the marketing function (i.e., $R \& D$ and advertising) in these relationships. The study gives a first indication of the relevancy of a firm's irresponsible behavior for the evaluation of CSR and also underlines the pivotal role of marketing in the CSR-firm value relationship. Both issues receive deeper elaboration in Study 2 and Study 3.

Study 2 centers on CSI, the antithesis of CSR. The study comprises two empirical examinations that take a CSI-perspective and explore the financial performance effects of 
CSR initiatives that are employed simultaneously with CSI occurrence. The goal of Study 2a is to establish the importance of CSI for shaping the CSR-firm value relationship. By referring to firms affected by CSI, Study $2 \mathrm{~b}$ takes a more fine-grained perspective on CSR by examining whether distinct CSR types that vary in their domain overlap to CSI pay off financially and how CSI characteristics moderate their relationship to firm value.

Study 3 brings three CSR differentiation approaches into the focus of the analysis, i.e., an obligation-based approach, a stakeholder-based approach and an approach that integrates the obligation and stakeholder dimensions. The study provides an examination of how a firm's strategic emphasis between value creation and value appropriation influences firm value effects of the CSR types that are derived through these CSR differentiation approaches. Comparing the findings across the approaches informs about the benefits and the hazards of the differentiation approaches, while the examination of the role of a firm's prioritization in marketing strategy sheds further light on how the marketing function helps capitalizing on CSR. Table 1 summarizes the key interests, research questions and contributions of the studies. 
Table 1: Overview of the Studies

\begin{tabular}{|c|c|c|c|c|}
\hline Study & Key Interest & Research Questions & Key Findings & Contributions \\
\hline \multirow{3}{*}{$\begin{array}{l}\# 1 \text { : How Can CSR be } \\
\text { Used to Compensate } \\
\text { for Corporate } \\
\text { Misconduct: The Role } \\
\text { of Marketing Levers }\end{array}$} & \multirow{3}{*}{$\begin{array}{l}\text { Examination of the firm } \\
\text { value effects of } \\
\text { compensation } \\
\text { strategies. Exploring the } \\
\text { role of functional } \\
\text { marketing factors for } \\
\text { influencing these } \\
\text { effects. }\end{array}$} & $\begin{array}{l}\text { (1) How can firms compensate } \\
\text { stakeholders for past corporate } \\
\text { misconduct through CSR? }\end{array}$ & $\begin{array}{l}\text { (1) Differentiation of compensation } \\
\text { strategies by their relatedness to } \\
\text { misconduct. }\end{array}$ & $\begin{array}{l}\text { (1) Clarifies which CSR opportunities } \\
\text { firms can embrace in order to respond } \\
\text { after misconduct occurrence and to offset } \\
\text { for the damage caused by misconduct. }\end{array}$ \\
\hline & & $\begin{array}{l}\text { (2) Are these social compensation } \\
\text { strategies successful in terms of } \\
\text { firm value enhancements? }\end{array}$ & $\begin{array}{l}\text { (2) Related compensation backfires on } \\
\text { firm value, unrelated compensation } \\
\text { enhances firm value. }\end{array}$ & $\begin{array}{l}\text { (2) Insight into the heterogeneity of the } \\
\text { firm value effects of CSR. }\end{array}$ \\
\hline & & $\begin{array}{l}\text { (3) Which role do functional } \\
\text { marketing factors play in shaping } \\
\text { the effectiveness of those } \\
\text { compensation strategies? }\end{array}$ & $\begin{array}{l}\text { (3) Advertising and R\&D intensity } \\
\text { leverage the main effects of both } \\
\text { compensation strategies. }\end{array}$ & $\begin{array}{l}\text { (3) Support for the interdependence } \\
\text { between marketing and CSR. }\end{array}$ \\
\hline \multirow{3}{*}{$\begin{array}{l}\text { \#2: Can Doing Good } \\
\text { Lead to Doing Poorly? } \\
\text { Firm Value } \\
\text { Implications of CSR in } \\
\text { the Face of CSI }\end{array}$} & \multirow{3}{*}{$\begin{array}{l}\text { Evaluation of the firm } \\
\text { value effects of CSR } \\
\text { that coincides with CSI. } \\
\text { Exploring the role of } \\
\text { CSI characteristics for } \\
\text { these effects. }\end{array}$} & $\begin{array}{l}\text { (1) How can CSR activities be } \\
\text { distinguished to account for CSI? }\end{array}$ & $\begin{array}{l}\text { (1) Distinguishing CSR activities that } \\
\text { vary by the domain overlap to CSI. }\end{array}$ & $\begin{array}{l}\text { (1) CSR and CSI are not only } \\
\text { conceptually different constructs; they } \\
\text { also interact in deriving firm value. }\end{array}$ \\
\hline & & $\begin{array}{l}\text { (2) Do these CSR activities differ in } \\
\text { their firm value effects? }\end{array}$ & $\begin{array}{l}\text { (2) Same-domain CSR has no effect on } \\
\text { firm value; Other-domain CSR has a } \\
\text { positive impact. }\end{array}$ & $\begin{array}{l}\text { (2) Conceptually founded distinction of } \\
\text { CSR efforts that varies by the domain } \\
\text { overlap to CSI. }\end{array}$ \\
\hline & & $\begin{array}{l}\text { (3) Do these effects depend on CSI } \\
\text { characteristics? }\end{array}$ & $\begin{array}{l}\text { (3) CSI context can strengthen/weaken } \\
\text { the effect of other-domain CSR and } \\
\text { determines whether same-domain CSR is } \\
\text { beneficial or even harmful. }\end{array}$ & $\begin{array}{l}\text { (3) Adjusting CSR efforts with the firm's } \\
\text { CSI pattern facilitates concrete managerial } \\
\text { CSR decision making. }\end{array}$ \\
\hline \multirow[t]{3}{*}{$\begin{array}{l}\text { \#3: Firm Value Effects } \\
\text { of Different CSR } \\
\text { Types: The Role of } \\
\text { Strategic Emphasis }\end{array}$} & \multirow{3}{*}{$\begin{array}{l}\text { Examination of firm } \\
\text { value effects of CSR } \\
\text { types based on three } \\
\text { differentiation } \\
\text { approaches. Exploring } \\
\text { the role of strategic } \\
\text { emphasis for these } \\
\text { effects. }\end{array}$} & $\begin{array}{l}\text { (1) How can CSR types be } \\
\text { conceptually distinguished? }\end{array}$ & $\begin{array}{l}\text { (1) CSR types can be distinguished by an } \\
\text { obligation-based approach, a stakeholder- } \\
\text { based approach and an integrative } \\
\text { approach. }\end{array}$ & $\begin{array}{l}\text { (1) Comparing different approaches } \\
\text { allows insight into the benefits and the } \\
\text { hazards of such approaches. }\end{array}$ \\
\hline & & $\begin{array}{l}\text { (2) Do these CSR types influence } \\
\text { firm value? }\end{array}$ & $\begin{array}{l}\text { (2) Across the differentiation approaches, } \\
\text { none CSR type has a significant main } \\
\text { effect on firm value. }\end{array}$ & $\begin{array}{l}\text { (2) The choice of the differentiation } \\
\text { approach is not decisive for detecting } \\
\text { main effects of CSR on firm value but for } \\
\text { detecting precise moderating } \\
\text { relationships. }\end{array}$ \\
\hline & & $\begin{array}{l}\text { (3) Does the strategic emphasis in } \\
\text { marketing moderate these CSR } \\
\text { types? }\end{array}$ & $\begin{array}{l}\text { (3) Strategic emphasis moderates some } \\
\text { CSR types. Depending on the } \\
\text { prioritization, some CSR types } \\
\text { enhance/destroy firm value. }\end{array}$ & $\begin{array}{l}\text { (3) Support of the pivotal role of } \\
\text { marketing for capitalizing on CSR but } \\
\text { findings also point to the limits for the } \\
\text { effectiveness of marketing efforts. }\end{array}$ \\
\hline
\end{tabular}


Common to all studies, firm value is operationalized as Tobin's q which is a wellestablished measure in marketing, management and finance literature (Jiao 2010; Luo and Bhattacharya 2006; Servaes and Tamayo 2013). Tobin's q is the ratio of the market value of a firm to the replacement costs of its assets. Values higher than 1 where the market value exceeds the replacement costs of the assets suggest an efficient use of a firm's resources, values smaller than 1 refer to an inefficient use respectively and values equal to 0 indicate no incremental value from a firm's assets (Anderson, Fornell, and Mazvancheryl 2004). By including market value in the numerator, Tobin's q is forward looking and reflects future expectations about the cash flows and the growth opportunities of a firm. Compared to accounting measures of firm value (e.g., return on asset), Tobin's q is risk-adjusted and less affected from distortions due to tax laws and arbitrary accounting methods, and thus comparable across industries. By using accounting data in the denominator, Tobin's q reflects levels of firm value instead of changes in firm value as it is the case with purely market-based measures (i.e., stock return; Montgomery and Wernerfelt 1988). By combining market and accounting data, Tobin's q is thus considered as the best measure for firm value (Anderson, Fornell, and Mazvancheryl 2004; Srinivasan and Hanssens 2009). In the context of CSR, such forward looking measure is particularly appropriate as CSR is expected to unfold its impact in the long run (Jayachandran, Kalaignanam, and Eilert 2013). In all studies, Tobin's $\mathrm{q}$ is constructed as follows:

(1) Tobin's q $=(\mathrm{MVE}+\mathrm{PS}+\mathrm{DEBT}) / \mathrm{TA}$,

where MVE $=($ closing price of share at the end of the financial year $) \times($ number of common shares outstanding); PS = liquidating value of the firm's outstanding preferred stock; DEBT $=($ current liabilities - current assets $)+($ book value of inventories $)+($ book value of long-term debt), and TA = book value of total assets. 
Table 2 gives an overview of the data, sample, and methodology of the studies. For testing the conceptual frameworks of the studies, two secondary panel data sources were used. KLD data which includes ratings of socially-relevant behavior of the largest publicly traded U.S. firms was used to measure the CSR variables and other related constructs. Nearly all publications on CSR, including those in top-tier journals, draw on KLD data which underlines that KLD is the de-facto standard for measuring CSR (e.g., Kang, Germann, and Grewal 2016; Mishra and Modi 2016; Servaes and Tamayo 2013). Data on firm value and other financially-related variables were derived from Compustat. Compustat provides market and fundamental data including industry classifications, cash flow, and balance sheet data for more than 30,000 publicly traded firms in North America (Barnett and Salomon 2012). As it is the case with KLD, Compustat represents the most widely used data base when examining the financial performance of U.S. firms. While the data sources and the examined time period is the same in each study, the sample composition differs in order to address the specific key research interests in the studies. Likewise, each study challenges different methodological issues. A detailed description is provided in the data and methodology sections of the studies. The next chapter provides the abstracts of the studies. 
Table 2: Data, Sample, and Methodology of the Studies

\begin{tabular}{|c|c|c|c|c|c|}
\hline Study & Data Sources & Time Period & $\begin{array}{l}\text { Observations } \\
\quad \text { (Firms) }\end{array}$ & $\begin{array}{l}\text { Modelling } \\
\text { Approach }\end{array}$ & $\begin{array}{c}\text { Further Methodological } \\
\text { Considerations }\end{array}$ \\
\hline $\begin{array}{l}\text { \#1: How Can CSR be Used } \\
\text { to Compensate for } \\
\text { Corporate Misconduct: The } \\
\text { Role of Marketing Levers }\end{array}$ & KLD, Compustat & 1991-2009 & $3,667(884)$ & $\begin{array}{l}\text { Ordinary-least square } \\
\text { regression }\end{array}$ & $\begin{array}{l}\text { - Cluster-robust estimates } \\
\text { - Time fixed effects for unobserved } \\
\text { longitudinal heterogeneity }\end{array}$ \\
\hline $\begin{array}{l}\text { \#2: Can Doing Good Lead } \\
\text { to Doing Poorly? Firm } \\
\text { Value Implications of CSR } \\
\text { in the Face of CSI }\end{array}$ & KLD, Compustat & 1991-2009 & $\begin{array}{l}\text { Study 2a: } \\
\text { 17,345 }(3,041) \\
\text { Study 2b: } \\
13,411(2,682)\end{array}$ & Linear mixed model & $\begin{array}{l}\text { - Random effects for unobserved } \\
\text { cross-sectional heterogeneity } \\
\text { - Time fixed effects for unobserved } \\
\text { longitudinal heterogeneity } \\
\text { - Gaussian copula approach for } \\
\text { - } \text { remaining endogeneity } \\
\text { - Sample selection bias correction } \\
\text { - Hoodlight analysis } \\
\text { Holdout-sampling }\end{array}$ \\
\hline $\begin{array}{l}\text { \#3: Firm Value Effects of } \\
\text { Different CSR Types: The } \\
\text { Role of Strategic Emphasis }\end{array}$ & KLD, Compustat & 1991-2009 & $21,481(3,572)$ & Fixed effects model & $\begin{array}{l}\text { - Firm fixed effects for unobserved } \\
\text { cross-sectional heterogeneity } \\
\text { - Time fixed effects for unobserved } \\
\text { longitudinal heterogeneity } \\
\text { - Gaussian Copula approach for } \\
\text { remaining endogeneity } \\
\text { - Floodlight analysis }\end{array}$ \\
\hline
\end{tabular}




\subsection{Abstracts}

Study 1:

When firms encounter misconduct, they often respond by compensating stakeholders for the harmful behavior through CSR activities. Firms can employ such social compensation strategies in domain(s) where misconduct occurred (i.e., misconduct-related compensation) or in domain(s) in which no misconduct occurred (i.e., misconduct-unrelated compensation). This study contributes to CSR research by (1) introducing different strategies for compensating past misconduct through CSR, (2) investigating how the compensation strategies affect firm value, and (3) how the marketing function (i.e., R\&D and advertising) moderates these relationships. The empirical results reveal that misconduct-unrelated compensation can help to stimulate firm value and the effect is boosted for advertising and R\&D intensive firms. Contrary, misconduct-related compensation hurts firm value, particularly for firms with high advertising and $R \& D$ spending. For managers, the findings suggest that misconduct-unrelated compensation is the preferable strategy for enhancing firm value.

Study 2:

CSR activities enhance firm value via strengthened stakeholder relationships. However, many firms that employ CSR initiatives are also contemporaneously involved in Corporate Social Irresponsibility (CSI), which could lead stakeholders to judge CSR actions as hypocritical and insincere, subsequently damaging firm value. This study examines the pivotal role of CSI for CSR's firm value effects. As an initial finding, the results indicate that CSR's firm value effect is significantly attenuated by the presence of CSI. Offering a more fine-grained analysis, the authors elaborate on the effectiveness of CSR that relates to the same (SD-CSR) 
or another domain (OD-CSR) as CSI. The results indicate that only OD-CSR enhances firm value. Depending upon the CSI context, however, SD-CSR may destroy or benefit firm value and OD-CSR might be more or less beneficial. By adding new aspects to the swelling discussion about how to align doing good with doing well, the results speak to both theorists and practitioners.

\section{Study 3:}

Choosing CSR activities that contribute to firm value is a major challenge for managers. The authors argue that aligning CSR with a firm's strategic emphasis (SE) - the trade-off between value creation and value appropriation-helps to decide on appropriate CSR engagement. Therefore, the authors examine the moderating role of SE for firm value effects of CSR types that are derived through three CSR differentiation approaches: an obligation-based approach (i.e., doing good and avoiding bad), a stakeholder-based approach (i.e., primary and secondary stakeholder-related CSR), and an integrated approach. Comparing the results across the approaches reveals that only a differentiation of CSR by the integrated approach precisely captures the moderating effect of SE. The authors find significant moderating effects of SE for doing good activities addressing secondary stakeholders and avoiding bad activities targeting primary stakeholders. Interestingly, contrary strategic foci complement these CSR types in deriving firm value. For managers, our findings allow concrete advice which CSR engagement should be preferred given their prioritization in marketing strategy. For research, our findings inform about the benefits and hazards of using these CSR differentiation approaches. 



\section{How Can CSR be Used to Compensate Stakeholders for Corporate Misconduct: The Role of Marketing Levers}

(with Hauke Wetzel and Maik Hammerschmidt) ${ }^{2}$

A prior version of the manuscript is published as:

How Companies Should React to Social Misconduct: The Role of In- and Extra-Domain Compensation, in: AMA Summer Educators Conference Proceedings, Chicago, IL, USA, 2012.

Keywords:

corporate misconduct, corporate social responsibility, compensation strategy, advertising and $\mathrm{R} \& \mathrm{D}$, firm value

\footnotetext{
${ }^{2}$ This paper was created in cooperation with the listed co-authors. I was responsible for the literature review, the theoretical foundation, the hypotheses development, the data management, the methodology, and the empirical analysis. My co-responsibilities comprised the positioning, the contribution statement, the conceptual framework, and the implication section.
} 


\subsection{Study 1: Introduction}

Most firms engage in corporate misconduct (KPMG 2014)-firm action that appears unjustifiable from an ethical point of view (Harris and Bromiley 2007). For instance, CocaCola and Pepsi have both drawn negative attention with beverages that were contaminated with pesticides (Gentleman 2006). Representing another severe wrongdoing, products of Nestle have been recently found to contain small pieces of glass (Almasy 2016). The frequency of corporate misconduct points to the difficulties to monitor every course of action and business process. Particularly, when firms' operations are spread around the world, misconduct often becomes uncontrollable and thus unpreventable. Along with nongovernmental organizations' eagerness to reveal firms' misbehavior, investors are increasingly sensitive to negative firm behavior because it indicates controversies with stakeholders which hazard the achievement of business goals (Frooman 1997; Shrieves, Murphy, and Tibbs 2009). In order to compensate stakeholders for the harm caused by their bad deeds, firms frequently engage in corporate social responsibility (CSR; Kang, Germann, and Grewal 2016) - firm action that links to the fulfillment of stakeholder or societal obligations (Brown and Dacin 1997; Sen and Bhattacharya 2001).

Indeed, studies reveal that CSR often trails corporate misconduct temporally as a firm's attempt to make amends for their missteps (Kang, Germann, and Grewal 2016; Kotchen and Moon 2012). However, these studies do not investigate which CSR initiatives for compensating stakeholders are financially beneficial for the firm. This lack is surprising as CSR research suggests that ,engaging in the right initiatives enhances firm performance” (Luo and Bhattacharya 2009, p. 198) but the question what constitutes the right initiatives has been largely unexplored in literature yet (Du, Bhattacharya, and Sen 2007; Smith 2003). Consequently, research has urgently requested a differentiation of unique CSR-related 
compensation strategies (Basu and Palazzo 2008; Bhattacharya, Korschun, and Sen 2011). Pioneering studies have differentiated CSR activities in terms of the targeted stakeholder groups (Godfrey, Merrill, and Hansen 2009; Homburg, Stierl, and Bornemann 2013; Torres et al. 2012), however, there is no study that examines the financial implications of different CSR strategies for compensating stakeholders after misconduct. This research attempts to fill this gap.

Specifically, we investigate (1) how firms can compensate stakeholders for corporate misconduct through CSR, (2) whether these social compensation strategies are successful in terms of firm value enhancements, and (3) the role functional marketing levers play in shaping the effectiveness of the compensation strategies.

We draw on associative network theory in a stakeholder context to conceptualize distinct social compensations strategies and to derive hypotheses. Associative network theory suggests that stakeholders do not evaluate information about a firm's action (e.g., socially responsible action) in isolation but evaluate it collectively with other information (e.g., misconduct) that is related to the focal information via a thematic association (Lei, Dawar, and Lemmink 2008). In turn, we distinguish two social compensation strategiesmisconduct-related compensation and misconduct-unrelated compensation-which vary in terms of the relatedness between CSR and misconduct, and we evaluate their firm value impact.

The contributions of this research are manifold. First, we contribute to the discussion on strategic thinking about CSR (Hildebrand, Sen, and Bhattacharya 2011; Maignan and Ferrell 2004; Porter and Kramer 2006) by considering distinct strategic approaches for employing CSR to compensate stakeholders after misconduct occurrence. Our differentiation of social compensation strategies builds upon the penance mechanism which suggests that firms 
engage in CSR to make amends for prior misbehavior (Kang, Germann, and Grewal 2016) but extends this perspective by clarifying which opportunities firms face to compensate stakeholders with CSR.

We also present a model that accounts for the firm value effects of both compensation strategies. Empirical examination of this model clearly demonstrates that compensation strategies have unique implications for firm value in that not both strategies are financially favorable. Our findings confirm notions in CSR literature that the firm value effects of CSR are heterogeneous and we deliver first insight into what explains such heterogeneity (Barnett 2007; Rowley and Berman 2000).

Lastly, with CSR initiatives understood as strategic response to misconduct, CSR very likely interplays with functional marketing levers, a notion confirmed by recent studies (e.g., Servaes and Tamayo 2013). Thus, we examine whether on a strategic level the effectiveness of CSR is moderated by functional marketing levers of which advertising and research and development $(\mathrm{R} \& \mathrm{D})$ are the most important. While advertising may accomplish value appropriation strategies fostering brand and customer equity; it also plays a crucial role for the visibility of the firm's compensation efforts (Servaes and Tamayo 2013). Likewise, R\&D is linked to value creation efforts and strongly determines stakeholder expectations towards a firm's moral responsibilities. The empirical results show that these marketing levers fuel the impact of the compensation strategies on firm value.

In the following section, we introduce a conceptual framework and develop a set of hypotheses. We then test our framework with longitudinal data spanning 19 years (19912009). We conclude with implications for research and practice and the study's limitations. 


\subsection{Study 1: Classification of Compensation Strategies}

By corporate misconduct, we mean firm action that stakeholders perceive as unjustifiable from an ethical point of view and that harm stakeholders (Harris and Bromiley 2007). As a mean to make amends for corporate misconduct, firms often engage in CSR (Kang, Germann, and Grewal 2016) which is generally defined as firm action that links to the fulfillment of stakeholder or societal obligations (Brown and Dacin 1997; Luo and Bhattacharya 2006). This perspective is known as the penance mechanism and has gained momentum in CSR literature (Kang, Germann, and Grewal 2016; Kotchen and Moon 2012; Muller and Kräussl 2011). Indeed, recent studies find that firms that are doing more harm are also doing more good (Kang, Germann, and Grewal 2016; Kotchen and Moon 2012). In this research, we build on the penance mechanism and understand the misconduct-responding orientation in CSR activities as a firm's social compensation strategy.

Firms have many opportunities to engage in socially responsible initiatives after misconduct and these initiatives vary in how much they relate to preceding misconduct. Relatedness of information has been shown to be meaningful in explaining behavioral and financial outcomes for a wide array of marketing activities, including branding (Lei, Dawar, and Lemmink 2008; Morrin 1999), sponsoring (Johar and Pham 1999; Simmons and BeckerOlsen 2006), and communication (Janney and Gove 2011; Wagner, Lutz, and Weitz 2009). We suggest such relatedness is also meaningful for better understanding the firm value effects of compensation efforts.

Associative network theory (Collins and Loftus 1975) serves to theoretically ground relatedness and has previously been applied in a CSR context (Luo and Bhattacharya 2009). The theory posits that a memory node captures different informational pieces about a mental concept - a representation of a word or a phrase — in human memory. Both a firm's CSR 
action and an incident of misconduct represent such nodes. One node (i.e., CSR action) can be associatively related to another node (i.e., misconduct) in memory, whereby the relatedness is high when the nodes share informational attributes that allow for a clear thematic connection (Chapman and Aylesworth 1999). Their relatedness is low when the nodes share less attributes and thus a thematic connection is unlikely. A CSR action that is accomplished in a domain were prior misconduct occurred (e.g., environment) is thematically related to misconduct, and a CSR action that avoids a thematic connection to previous misconduct by addressing a domain (e.g., employee relations) other than the one affected by misconduct (e.g., environment) is unrelated to misconduct. We apply this reasoning to distinguish two social compensation strategies: misconduct-related and misconduct-unrelated compensation.

Misconduct-related compensation comprises offsetting misconduct by CSR activities in domains in which misconduct occurred. For example, Nestlé, a global food maker has been associated with the deforestation of rainforest in Indonesia since a nongovernmental organization had steered public focus on this concern. After all, Nestlé championed diverse projects for the rural development in third world countries of suppliers, where the dissemination of sustainable commodity production methods is only one example amongst others.

In contrast, misconduct-unrelated compensation refers to making amends for misconduct by CSR actions in domains in which no incident of misconduct occurred. For instance, Heidelberg Cement AG, a global player in manufacturing construction material belongs to the top 10 of the $\mathrm{CO}_{2}$ emitting companies in Europe. While competitors reduced their $\mathrm{CO}_{2}$ emission to tolerable levels, Heidelberg Cement struggles to downsize its emission. 
Instead, Heidelberg Cement is setting up medical camps in Bangladesh, and thus, tries to offset its environmental pollution with social efforts in the community domain.

\subsection{Study 1: Firm Value Effects of Compensation Strategies}

CSR literature proposes that the mechanism by which CSR influences a firm's financial performance lies in the ability to trigger favorable stakeholder responses and actions (Rowley and Berman 2000). The reasoning includes all key stakeholders that have the potential to affect the firm's business goals via the support of valuable resources (e.g., customers, employees, community). ${ }^{3}$ In the context of corporate misconduct, we suggest that favorable stakeholder actions to CSR depend on whether stakeholders combine CSR and misconduct information and which motive attributions stakeholder make when evaluating the compensation strategies.

According to associative network theory, the strength of relatedness between nodes drives the probability of combining certain information in memory with other information when forming judgments (Collins and Loftus 1975). If one node (e.g., CSR action) is triggered, activation spreads to a related node (e.g., incident of misconduct) and provokes the retrieval of information stored in it (Roehm and Tybout 2006). The resulting mix of mentally activated information provides input for stakeholders' evaluation of compensation strategies.

CSR research also suggests that the favorability of stakeholder reactions to CSR depends on the attributions stakeholders make about the firm's motives to engage in CSR (Forehand and Grier 2003; Menon and Kahn 2003). Extrinsic motives are attributed when

\footnotetext{
${ }^{3}$ For instance, CSR enhances customer satisfaction (Luo and Bhattacharya 2006), strengthens customer loyalty (Du, Bhattacharya, and Sen 2007) which leads to increased sales (Waddock and Graves 1997) and higher willingness to pay a premium price (Creyer and Ross 1996). Likewise, CSR attracts more talented job seekers (Greening and Turban 2000), results in better productivity and superior customer service (Korschun, Bhattacharya, and Swain 2014). In the community domain, CSR can result in tax advantages, decreased regulatory burden and improvement in the quality of local labor. Ultimately, all such outcomes lead to higher financial performance.
} 
stakeholders believe that enhancing firm welfare by increasing sales or improving the firm's image is the main driver of CSR action. The attribution of extrinsic motives leads to the perception that the firm does not genuinely act socially responsible which potentially hinders favorable stakeholder actions leading to lower firm value. Stakeholders attribute intrinsic motives when they assume that firms follow the goal to enhance stakeholders or societies welfare. Thus, intrinsic motive attributions elicit the perception that the firm has genuine concern for stakeholder issues potentially leading to favorable stakeholder responses and higher firm value (Du, Bhattacharya, and Sen 2007; Ellen, Webb, and Mohr 2006).

Misconduct-related compensation refers to CSR compensation in the domain(s) of misconduct. Because of the strong thematic connection to misconduct, such compensation efforts lead stakeholders to retrieve misconduct information and to direct attention to misconduct which triggers stakeholders' suspicion (Fein and Hilton 1994; Forehand and Grier 2003). Stakeholders likely attribute such engagement to extrinsic motives and in turn perceive such compensation as ambiguous interest in social issues. After all, stakeholders may view misconduct-related compensation solely as a problem-driven intent to polish the firm's bad image (Wagner, Lutz, and Weitz 2009; Yoon, Gürhan-Canli, and Schwarz 2006). Overall, these perceptions hinder favorable stakeholders' actions harming firm value in turn.

$\mathrm{H}_{1}$ : Misconduct-related compensation has a negative impact on firm value.

Misconduct-unrelated compensation refers to a firm's attempt to compensate stakeholders with CSR activities in other domains. As the exhibited behaviors fall into different domains, misconduct-unrelated compensation unlikely activates generalization from the CSR action to preceding misconduct. Because the retrieval of misconduct information is not provoked, stakeholders are less suspicious and skeptical. Consequently, stakeholders rather attribute intrinsic motives for such engagement and view it as genuine attempts to 
enhance stakeholder welfare. Overall, misconduct-unrelated compensation functions as subliminal and thus less obvious compensation of misconduct. Given our arguments, we propose that misconduct-unrelated compensation leads to favorable stakeholder responses leading to higher firm value.

$\mathrm{H}_{2}$ : Misconduct-unrelated compensation has a positive impact on firm value.

\subsection{Study 1: The Role of Marketing Levers}

CSR literature suggests heterogeneous firm value effects of CSR depending upon firmspecific context (Barnett 2007; Berman et al. 1999). More specifically, CSR research points to the pivotal role of the marketing function in the CSR-financial performance link (e.g., McWilliams and Siegel 2001; Mishra and Modi 2016). In this research, we focus on advertising and R\&D because these are important functional marketing factors (Currim, Lim, and Kim 2012; Krasnikov and Jayachandran 2008) and should interplay with strategic considerations on CSR (i.e., compensation strategies).

Advertising and compensation strategies. Marketing literature suggests that advertising creates intangible assets such as brand awareness and brand esteem (Boyd, Chandy, and Cunha 2010; Joshi and Hanssens 2010). Empirical evidence further shows that these advertising effects influence stakeholder groups beyond the customer (Joshi and Hanssens 2010; Luo and Bhattacharya 2009). For instance, in the investor domain, studies find that investors often invest in familiar stocks and stocks with strong brands (Joshi and Hanssens 2010). Such spill overs are likely to occur in other stakeholder domains because advertising increases the firm's general visibility and awareness, engenders information transfer and thus mitigates the information gap between a firm and its stakeholders (Luo and Bhattacharya 2009). Overall, advertising ensures that stakeholders find out about CSR-related 
compensation efforts (Servaes and Tamayo 2013). Indeed, a well-articulated concern in CSR research is that firms must create awareness for their engagements to ensure stakeholder responses to CSR that eventually drive firm value (e.g., Bhattacharya and Sen 2004; Du, Bhattacharya, and Sen 2010; Schuler and Cording 2006). Likewise, advertising is crucial to communicate a firm's identity (Bhattacharya and Sen 2003). As CSR provides insight into the firm's identity (Du, Bhattacharya, and Sen 2007), advertising enhances the salience of the identity-related CSR information through repetition and ensures that stakeholders easily retrieve such information from memory (Luo and Bhattacharya 2009). Overall, advertising increases the visibility and awareness of CSR among stakeholders, and thus, advertising and CSR should interplay in their outcome on firm value.

Because with high advertising intensity stakeholders more likely find out about a firm's compensation efforts, stakeholders' interpretation of misconduct-related compensations as extrinsically motivated and misconduct-driven is more likely to occur. Moreover, high advertising intensity makes more salient that the firm explicitly and repeatedly hawks with its CSR activities via advertising campaigns, which further fuels stakeholders' perceptions that the firm solely engages in CSR to polish their negative image. These arguments lead to the following hypothesis:

$\mathrm{H}_{3}$ : Advertising intensity negatively interacts with misconduct-related compensation in influencing firm value.

Misconduct-unrelated compensation is not clearly connected to a firm's wrongdoing in stakeholders' mind and thus they perceive such compensation efforts as genuine attempt to enhance stakeholders' welfare. As is the case for misconduct-related compensation, advertising enhances the chance that stakeholder find out about these compensation efforts and thus favorable stakeholder actions for such compensation efforts are more likely to occur. 
As such efforts demonstrate values of the firm that do not clash with prior misconduct, it helps to create a coherent firm identity which becomes more salient to stakeholders when the firm repeatedly communicates such information. Overall, we propose the following:

$\mathrm{H}_{4}$ : Advertising intensity positively interacts with misconduct-unrelated compensation in influencing firm value.

$R \& D$ and compensation strategies. $\mathrm{R} \& \mathrm{D}$ spending can be seen as technical investment that fosters product and process innovations (Currim, Lim, and Kim 2012). In the first place innovations help to satisfy current and emerging customer needs and thereby provide tangible benefits to stakeholders (Wang and Qian 2011). For instance, employees link the outcome of such investments to a more secure workplace and customers receive direct benefits through innovative product (Luo and Bhattacharya 2009). For stakeholders, innovativeness thus demonstrates that the firm fulfills some of their core responsibilities. By showing that the firm fulfills its core responsibilities, stakeholders have higher expectations on the firm's moral responsibilities, i.e., CSR engagement (Suchman 1995).

Misconduct-related compensation directs the attention to misconduct. Such engagement not only shows that the firm has violated social norms with their misbehavior, it also creates an ambiguous picture of what the firm values by conducting good deeds that clash with misconduct in the same domain. As such conflicting engagement underlines the problem-driven intent of the firm, it is unlikely to serve the higher expectations that stakeholders have on the firm's good deeds when R\&D intensity is high. As a consequence of the unrealized expectations and the subsequent disappointment, stakeholders evaluate misconduct-related compensation even more negative. We suggest the following:

$\mathrm{H}_{5}: \mathrm{R} \& \mathrm{D}$ intensity negatively interacts with misconduct-related compensation in influencing firm value. 
The contrary effect can be expected for misconduct-unrelated compensation. We argued that stakeholders are less skeptical on the firm's motive to engage in misconductunrelated compensation because such engagement refers to domains that are spotless from misconduct and thus avoids a connection to misconduct. As such engagement is viewed as the firm's genuine attempts to enhance stakeholder welfare, it more likely addresses stakeholders' higher CSR expectations that come with high R\&D intensity. Moreover, as innovative firms face a higher risk for firm misbehavior (Flammer 2014), compensation efforts that are untainted from misconduct positively surprise stakeholders. Overall, we thus hypothesize the following:

$\mathrm{H}_{6}: \mathrm{R} \& \mathrm{D}$ intensity positively interacts with misconduct-unrelated compensation in influencing firm value.

\subsection{Study 1: Data and Variables}

\section{Data Sample}

We use ratings from Kinder, Lydenberg and Domini (KLD) for information on CSR and corporate misconduct. KLD measures strength (i.e., CSR actions) and concern (i.e., incidences of misconduct) indicators in several domains (i.e., community relations, employee relations, corporate governance, diversity, environment, human rights, and product) for more than 3,000 of the largest U.S. firms. The complete list of indicators appears in the Appendix 1. The yearly KLD ratings, starting with 1991, rely on multiple sources such as surveys, financial statements, and articles on companies in press, academic journals and government reports (McWilliams and Siegel 2000). By referring "to a consistent, largely objective set of screening criteria" (Graves and Waddock 1994, p.1038), the KLD data source is considered 
as the de-facto standard for measuring socially responsible (CSR) and irresponsible (misconduct) behavior (Waddock 2003).

KLD has modified their measurement procedure after 2009 and thus our sampling period is restricted to 1991-2009. Because compensation requires the occurrence of corporate misconduct, we exclude firms with no incidence of misconduct in $\mathrm{t}-1$. Moreover, we model a time lag between misconduct (in t-1) and CSR (in t) as we consider CSR as compensatory response to misconduct. Finally, we match KLD data with marketing, financial and accounting data from Compustat. The sample size drops to 3,667 firm-year observations including 884 firms after missing values were removed. ${ }^{4}$

\section{Variable Construction}

Compensation Strategies. Misconduct-related compensation is operationalized as the difference between a firm's strengths and concerns in domains with at least one concern. We measure misconduct-unrelated compensation as the difference between a firm's strengths and concerns in domains without concern. To subtract concerns from strengths is a wellestablished procedure in prior CSR literature (e.g., Hull and Rothenberg 2008). Because the number of rated strength and concern indicators differs between domains and years, we scale the actual number of strengths (concerns) for each relevant domain by the maximum possible number of strengths (concerns) within each domain in the respective year before we subtract the concerns from the strengths for each compensation strategy (Servaes and Tamayo 2013).

Firm Value. We measure firm value as Tobin's q which is a forward looking measure reflecting capital market's future expectations about the value of the firm (Anderson, Fornell, and Mazvancheryl 2004). As the ratio of the market value of a firm to the replacement costs

\footnotetext{
${ }^{4}$ A large reduction of sample size mainly results from missing data on advertising and R\&D spending because firms are not under legal compulsion to disclose such information.
} 
of its assets, Tobin's q states intangible firm value. We construct Tobin's q as shown in Equation (1).

Marketing Levers. We measure advertising intensity as adverting spending scaled by the book value of total assets and $R \& D$ intensity as the ratio of $R \& D$ spending to the book value of total assets (Luo and Bhattacharya 2009).

Controls. We control for several factors that potentially affect firm value. To control for the influence of profitability, we use return on asset because of possible information impact on future cash flow (Chauvin and Hirschey 1993). As a measure of financial leverage we estimate the ratio of long-term debt to the book value of total assets, which has been used in numerous finance studies (Denis and Kruse 2000). For measuring firm size, we use the logarithm of the number of employees (Luo and Bhattacharya 2006). We further control for industry concentration by including the Herfindahl index which is computed as the sum of squared market shares of the firms in the industry derived from sales (Luo and Homburg 2007). To control for year-specific effects, we use time dummies (Jayachandran, Kalaignanam, and Eilert 2013). Table 3 contains descriptive statistics and correlations of all variables in the model. 
Table 3: Descriptive Statistics and Correlations

\begin{tabular}{|c|c|c|c|c|c|c|c|c|c|c|c|}
\hline Variable & $\mathbf{M}$ & SD & 1. & 2. & 3. & 4. & 5. & 6. & 7. & 8. & 9. \\
\hline 1. Firm value & 1.81 & 1.32 & 1 & & & & & & & & \\
\hline 2. Misconduct-related compensation & -.44 & .34 & .041 & 1 & & & & & & & \\
\hline 3. Misconduct-unrelated compensation & -.32 & .50 & .137 & .727 & 1 & & & & & & \\
\hline 4. Advertising intensity & .03 & .06 & .091 & .007 & .071 & 1 & & & & & \\
\hline 5. R\&D intensity & .05 & .07 & .190 & .082 & .079 & -.070 & 1 & & & & \\
\hline 6. Profitability & .03 & .17 & .189 & .002 & .039 & -.188 & -.381 & 1 & & & \\
\hline 7. Financial leverage & .16 & .20 & -.015 & -.086 & -.081 & .046 & -.016 & -.268 & 1 & & \\
\hline 8. Firm size & 1.90 & 1.85 & -.031 & -.201 & -.093 & .074 & -.397 & .209 & .136 & 1 & \\
\hline 9. Industry concentration & .24 & .19 & -.139 & -.042 & -.024 & .059 & -.155 & -.007 & -.022 & .095 & 1 \\
\hline
\end{tabular}

Notes: Correlations greater than or equal to $|.020|$ are statistically significant $(p<.05$, two-tailed). $\mathrm{N}=3,667$. 


\subsection{Study 1: Analysis and Results}

\section{Analysis Approach}

We test our hypotheses using ordinary least square regression. Because we use panel data characterized by yearly firm observations, we cluster standard errors for each firm to incorporate that these observations are not independent (i.e., observations that belong to the same firm are more similar than observations of different firms; Rogers 1993). The equation for testing the hypotheses is as follows:

$$
\begin{aligned}
\text { Firm value }_{\text {it }}= & \mu+\beta_{1} \times M-R_{\text {it }}+\beta_{2} \times M-\mathrm{UR}_{\mathrm{it}}+\beta_{3} \times \mathrm{AD}_{\mathrm{it}}+\beta_{4} \times \mathrm{M}-\mathrm{R}_{\mathrm{it}} \times \mathrm{AD}_{\mathrm{it}} \\
& +\beta_{5} \times \mathrm{M}-\mathrm{UR}_{\mathrm{it}} \times \mathrm{AD}_{\mathrm{it}}+\beta_{6} \times \mathrm{RD}_{\mathrm{it}}+\beta_{7} \times \mathrm{M}-\mathrm{UR}_{\mathrm{it}} \times \mathrm{RD}_{\mathrm{it}}+\beta_{8} \times \mathrm{M}-\mathrm{R}_{\mathrm{it}} \times \mathrm{RD}_{\mathrm{it}} \\
& +\beta_{9} \times \mathrm{PROF}_{\mathrm{it}}+\beta_{10} \times \mathrm{LEV}_{\mathrm{it}}+\beta_{11} \times \mathrm{SIZE}_{\mathrm{it}}+\beta_{12} \times \mathrm{CONC}_{\mathrm{it}}+\sum_{\mathrm{t}} \alpha_{\mathrm{t}} \mathrm{TIME}_{\mathrm{t}}+\varepsilon_{\mathrm{it}},
\end{aligned}
$$

where $\mathrm{i}=$ firms $; \mathrm{t}=$ year $; \mu=$ constant $; \mathrm{M}-\mathrm{R}=$ misconduct-related compensation; $\mathrm{M}$ $\mathrm{UR}=$ misconduct-unrelated compensation; $\mathrm{AD}=$ advertising intensity; $\mathrm{R} \& \mathrm{D}=\mathrm{R} \& \mathrm{D}$ intensity; $\mathrm{PROF}=$ profitability LEV = financial leverage; $\mathrm{SIZE}=$ firm size; $\mathrm{CONC}=$ industry concentration; TIME = time dummies.

\section{Hypotheses Testing}

Table 4 shows a main-effects-only model first whereas the second model also includes the moderating effects. ${ }^{5}$ We test our hypotheses based on the second model. As predicted by $\mathrm{H}_{1}$, misconduct-related compensation lowers firm value significantly $(\beta=-.32, p<.05)$. Contrary, misconduct-unrelated compensation has a significant positive effect on firm value $(\beta=.33, p<.01)$, lending support for $\mathrm{H}_{2} . \mathrm{H}_{3}$ states that the interaction between misconduct-

\footnotetext{
${ }^{5}$ We mean-centered all independent variables to avoid multicollinearity. After mean-centering, we tested for multicollinearity by estimating variance inflation factors. The highest variance inflation factor is 2.63 indicating no threat to our results (Hair et al. 2010).
} 
related compensation and advertising is negative and we found support for this assumption $(\beta=-3.73, p<.01) . \mathrm{H}_{4}$ predicts a positive interaction between misconduct-unrelated compensation and advertising. The findings shows that the interaction is only borderline in its significance $(\beta=3.75, p<.10)$, thus $\mathrm{H}_{4}$ is weakly supported. The results provide support for $\mathrm{H}_{5}$, because the interaction between misconduct-related compensation and $\mathrm{R} \& \mathrm{D}$ is negative and significant $(\beta=-9.59, p<.01) . \mathrm{H}_{6}$ states a positive interaction between misconductunrelated compensation and $\mathrm{R} \& \mathrm{D}$. The findings shows that the interaction is positive and significant $(\beta=4.16, p<.05)$ which lends support for $\mathrm{H}_{6}$. 
Table 4: The Impact of Social Compensation Strategies on Firm Value

\begin{tabular}{|c|c|c|c|c|c|c|c|}
\hline \multirow[b]{2}{*}{ Independent Variable } & \multirow[b]{2}{*}{$\begin{array}{l}\text { Hypotheses } \\
\text { (Expected } \\
\text { Sign) }\end{array}$} & \multicolumn{3}{|c|}{ Model 1} & \multicolumn{3}{|c|}{ Model 2} \\
\hline & & Coef. & & Sig. & Coef. & & Sig. \\
\hline Constant & & 1.49 & $(.10)$ & $* * *$ & 1.44 & $(.11)$ & $* * *$ \\
\hline \multicolumn{8}{|l|}{ Social compensation strategies } \\
\hline $\begin{array}{l}\text { Misconduct-related compensation } \\
\text { Misconduct-unrelated compensation }\end{array}$ & $\begin{array}{l}\mathrm{H}_{1}(-) \\
\mathrm{H}_{2}(+)\end{array}$ & $\begin{array}{r}-.32 \\
.37\end{array}$ & $\begin{array}{l}(.14) \\
(.10)\end{array}$ & $\begin{array}{l}* * \\
* * *\end{array}$ & $\begin{array}{r}-.32 \\
.33\end{array}$ & $\begin{array}{l}(.13) \\
(.10)\end{array}$ & $\begin{array}{l}* * \\
* * * \\
* *\end{array}$ \\
\hline \multicolumn{8}{|l|}{ Moderators and interactions } \\
\hline $\begin{array}{l}\text { Advertising intensity } \\
\text { Misconduct-related compensation } \\
\times \text { Advertising intensity }\end{array}$ & $\mathrm{H}_{3}(-)$ & 3.31 & $(.68)$ & $* * *$ & $\begin{array}{r}2.63 \\
-3.73\end{array}$ & $\begin{array}{l}(.57) \\
(1.41)\end{array}$ & $\begin{array}{l}* * * \\
* * *\end{array}$ \\
\hline $\begin{array}{l}\text { Misconduct-unrelated compensation } \\
\times \text { Advertising intensity }\end{array}$ & $\mathrm{H}_{4}(+)$ & & & & 3.75 & $(2.14)$ & $*$ \\
\hline $\begin{array}{l}\text { R\&D intensity } \\
\text { Misconduct-related compensation } \\
\times \text { R\&D intensity }\end{array}$ & $\mathrm{H}_{5}(-)$ & 5.87 & $(.72)$ & $* * *$ & $\begin{array}{r}5.96 \\
-9.59\end{array}$ & $\begin{array}{l}(.70) \\
(3.26)\end{array}$ & $\begin{array}{l}* * * \\
* * *\end{array}$ \\
\hline $\begin{array}{l}\text { Misconduct-unrelated compensation } \\
\times \text { R\&D intensity }\end{array}$ & $\mathrm{H}_{6}(+)$ & & & & 4.16 & $(2.04)$ & $* *$ \\
\hline \multicolumn{8}{|l|}{ Control variables } \\
\hline $\begin{array}{l}\text { Profitability } \\
\text { Financial leverage } \\
\text { Firm Size } \\
\text { Industry concentration }\end{array}$ & & $\begin{array}{r}2.52 \\
.52 \\
-.02 \\
-.59\end{array}$ & $\begin{array}{l}(.49) \\
(.34) \\
(.02) \\
(.19)\end{array}$ & $* * *$ & $\begin{array}{r}2.61 \\
.50 \\
-.02 \\
-.57\end{array}$ & $\begin{array}{l}(.49) \\
(.31) \\
(.02) \\
(.18)\end{array}$ & $* * *$ \\
\hline $\begin{array}{l}\mathrm{R}^{2} \\
\mathrm{~N}\end{array}$ & & & $\begin{array}{r}.24 \\
3,667\end{array}$ & & & $\begin{array}{r}.25 \\
3,667\end{array}$ & \\
\hline
\end{tabular}

$* p<.10 ; * * p<.05 ; * * * p<.01$.

Notes: Standard errors are adjusted for firm clusters and shown in parentheses. Time dummies are included in the model but not reported. 


\subsection{Study 1: Discussion}

In this study, we examined how firms can employ CSR to compensate stakeholders for corporate misconduct, whether these social compensation efforts pay off in terms of firm value and which role functional marketing levers (i.e., advertising and R\&D) play in these relationships. By introducing two distinct compensation strategies-misconduct-related and misconduct-unrelated compensation - this study detects opposing firm value effects of the compensation strategies that are each intensified through advertising and R\&D spending. The results yield valuable insight both for researchers and managers, which we discuss next.

\section{Theoretical Implications}

Recent CSR literature suggests that the question is no longer whether firms should engage in CSR for financial value generation but how (Smith 2003). Although scholars have urgently requested a differentiation of unique CSR strategies (Basu and Palazzo 2008; Bhattacharya, Korschun, and Sen 2011), research has barely considered a disaggregation of CSR yet. Our research enriches the general discussion of the how-question and provides new answers. We distinguish two compensation strategies instead of commingling CSR efforts in one construct as it is the case in most CSR studies (e.g., Hull and Rothenberg 2008; Luo and Bhattacharya 2006). The empirical findings show that misconduct-related compensation stimulates firm value, whereas misconduct-unrelated compensation backfires on firm value. Without distinguishing between distinct compensation strategies, these heterogeneous firm value implications of CSR responses to misconduct would have been masked. We recommend further research, no matter whether examining CSR in general or as a response to misconduct, to treat CSR as a multifaceted construct which requires a differentiation into 
conceptually meaningful CSR initiatives. Only then, the financial benefits and drawbacks of CSR can be fully revealed and concrete answers to the how-question can be delivered.

By centering our study on the effectiveness of CSR for compensating stakeholders after misconduct, this study underlines the importance to acknowledge that often firms are doing good after doing bad and that they need profound knowledge which kind of doing good pays off. In fact, the penance perspective gains momentum in CSR research, however, the few studies concerned with this topic do not explicitly examine the firm value effects of CSR following misconduct (Kotchen and Moon 2012; Muller and Kräuss1 2011). An exception is the study of Kang, Germann, and Grewal (2016), which relate CSR after misconduct to firm value, but like most other CSR studies, the authors consider an overall measure of CSR. The findings of the study suggest that the penance mechanism is ineffective because stakeholders interpret firms' CSR efforts following CSI as "unauthentic or even as deceitful, seeking to greenwash their past mistakes" (Kang, Germann, and Grewal 2016, p. 73). Our research pinpoints that engaging in the right compensation strategy is key in the context of firm wrongdoing. Specifically, we show that a penance mechanism can be beneficial for firms if implemented through misconduct-unrelated CSR efforts. Future research should therefore go beyond establishing the case that firms engage in CSR as a way to make amends and rather examine how firms respond with CSR and whether these CSR responses pay back financially.

By investigating marketing moderators (i.e., advertising and R\&D), this study confirms prior research on the importance of the marketing function in the CSR-firm value relationship (e.g., Luo 2009; Mishra and Modi 2016; Servaes and Tamayo 2013). Importantly, the findings show that marketing activities not always yield preferable outcomes. While current literature highlights the beneficial influence of advertising in the 
CSR-firm value relationship (Servaes and Tamayo 2013), our research is the first to show that a negative interaction with advertising is possible and which CSR efforts are affected (i.e., misconduct-related compensation). For $R \& D$, current findings on the interaction with CSR are mixed. Hull and Rothenberg (2008) reveal a negative interaction between R\&D and overall CSR on firm financial performance, suggesting that a firm with the best products has little reason to build an outstanding reputation as a responsible firm. Luo and Bhattacharya (2006), however, find a positive interaction suggesting that a minimum product quality must be ensured to justify CSR investments in the eyes of stakeholders. Our findings suggest that the chosen compensation strategy determines the direction of the moderating impact of R\&D. Therefore, our findings point out that using an aggregated CSR measure which commingles CSR actions with potentially differing firm value effects may produce the inconclusive findings on the moderating role of R\&D. Overall, our research shows that the compensation strategy determines whether R\&D (advertising) has negative or positive interaction effects which further enhances the relevancy to distinguish between CSR efforts.

\section{Managerial Implications}

Although misconduct seems omnipresent in practice and most firms respond with CSR activities, managers often lack knowledge about promising compensation strategies yielding the highest financial return. Our research shows that it matters to do good in the right things because not all CSR activities after misconduct pay out financially.

First, our findings suggest that managers need to consider that their CSR actions draw attention to misconduct to different degrees. Misconduct-related compensation refers to CSR in the same domain as misconduct and thus stakeholders very likely connect these good deeds with misconduct. In turn, such CSR activities enhance stakeholders' suspicion about the motives of engaging in CSR triggering perceptions that the CSR engagement is solely 
problem-driven in order to whitewash the firm's negative image. Contrary, misconductunrelated compensation suggests a less obvious compensation effort as it is not linked to misconduct and rather leads to intrinsic motive attributions. By revealing that misconductunrelated compensation enhances firm value while misconduct-related compensation harms firm value, firms should favor the former as an unobtrusive compensation strategy.

Second, our results suggest that managers can influence the firm value effects of the compensation strategies through functional marketing levers. In general, advertising increases the firms' visibility among stakeholders and thus stakeholders more likely get to know about the firm's CSR engagement. For heavily advertising firms, the decision on which compensation strategy to employ becomes even more decisive. Choosing the wrong strategy, that is misconduct-related compensation, lead to even more detrimental firm value effects for heavy advertisers. However, choosing misconduct-unrelated compensation turns out to be even more financially rewarding under such circumstances. Likewise, managers should consider that high R\&D spending increases stakeholder expectations towards compensation efforts. As is the case for advertising, misconduct-unrelated compensation further contributes to the bottom line because it satisfies these expectations while misconduct-related compensation further backfires as a result of stakeholders' disappointment. Overall, the findings reveal how CSR strategies are interwoven with marketing decisions and thus hopefully foster a collaboration of the respective organizational authorities in order to align strategic decisions as to maximize financial returns.

\section{Limitations and Future Research}

This study has limitations that pave the way for further research. First, we solely captured a firm's strategic CSR reaction to misconduct based on the mere temporal sequence between CSR and misconduct. However, a time lag between CSR and misconduct may not ensure that 
a firm's CSR efforts are a strategic and intentional response to prior misconduct. Second, while we investigated the moderating role of advertising and R\&D separately in the CSRfirm value relationship, some studies have also established the importance of the relative allocation of resources to both marketing levers for financial outcomes (Josephson, Johnson, and Mariadoss 2015; Mizik and Jacobson 2003). Future research should therefore investigate how trade-offs between the two levers moderate the CSR-firm value relationship. Lastly, we do not account for possible unobserved heterogeneity and endogeneity of CSR with respect to firms' financial performance that should be accounted for (e.g., Flammer 2015). 



\section{Can Doing Good Lead to Doing Poorly? Firm Value Implications of CSR in the Face of CSI}

(with Hauke Wetzel and Maik Hammerschmidt) ${ }^{6}$

The manuscript has been conditionally accepted in Journal of the Academy of Marketing Science.

The project was founded by the Deutsche Forschungsgemeinschaft (DFG)

Keywords:

corporate social responsibility, corporate social irresponsibility, social responsibility dilemma, firm value, instrumental stakeholder theory

\footnotetext{
${ }^{6}$ This paper was created in cooperation with the listed co-authors. I was responsible for the literature review, the theoretical foundation, the hypotheses development, the data management, the methodology, and the empirical analysis. My co-responsibilities comprised the positioning, the contribution statement, the conceptual framework, and the implication section.
} 


\subsection{Study 2: Introduction}

Corporate social responsibility (CSR) - firm actions that improve the well-being of stakeholders or society at large (Korschun, Bhattacharya, and Swain 2014; Kotler and Lee 2005) — has become a substantial firm investment. On a positive trajectory, CSR already stands among the top three priorities for half of the Fortune Global 500 companies, with $\$ 20$ billion spent for CSR activities yearly (Economic Policy Group 2015; McKinsey \& Company 2014). These facts align well with the observation that CSR can enhance firm value (Accenture 2010; Luo and Bhattacharya 2006).

As Figure 2 shows, however, corporate social irresponsibility (CSI)—firm actions that hurt the well-being of stakeholders or society at large (Kang, Germann, and Grewal 2016; Strike, Gao, and Bansal 2006)—occurs regularly in the majority of firms that engage in CSR. Alarmingly, in the presence of CSI, stakeholders may interpret CSR activities as insincere (Yoon, Gürhan-Canli, and Schwarz 2006), creating the possibility of damage to firm value (Margolis and Walsh 2003).

Indeed, the potential for a negative interaction between CSR and CSI is a matter of heated debate among practitioners because it could create a social responsibility dilemma: when CSI occurs, both refraining from CSR and engaging in CSR may be undesirable options with respect to their firm value impact. Thus, solving the dilemma is a prerequisite for making unambiguous predictions on the financial implications of CSR efforts.

However, the questions of how and when CSR efforts affect firm performance in the context of CSI represent a major gap in prior research. Most recently, researchers have called for (1) research that captures CSR and CSI as distinct concepts as opposed to the construction of an overall CSR measure that commingles the two (Jayachandran, Kalaignanam, and Eilert 2013; Kang, Germann, and Grewal 2016), (2) differentiating between types of CSR (Basu 
and Palazzo 2008; Mishra and Modi 2016; Wang et al. 2016), and (3) expanding the discussion of CSR's outcomes by clarifying the role of CSI in general and the CSI context in particular (Lin-Hi and Müller 2013). Missing is an integrated response to these calls that will guide CSR efforts of firms that are involved in CSI.

Figure 2: Share of All Firms that Engage in CSR and Faced CSI

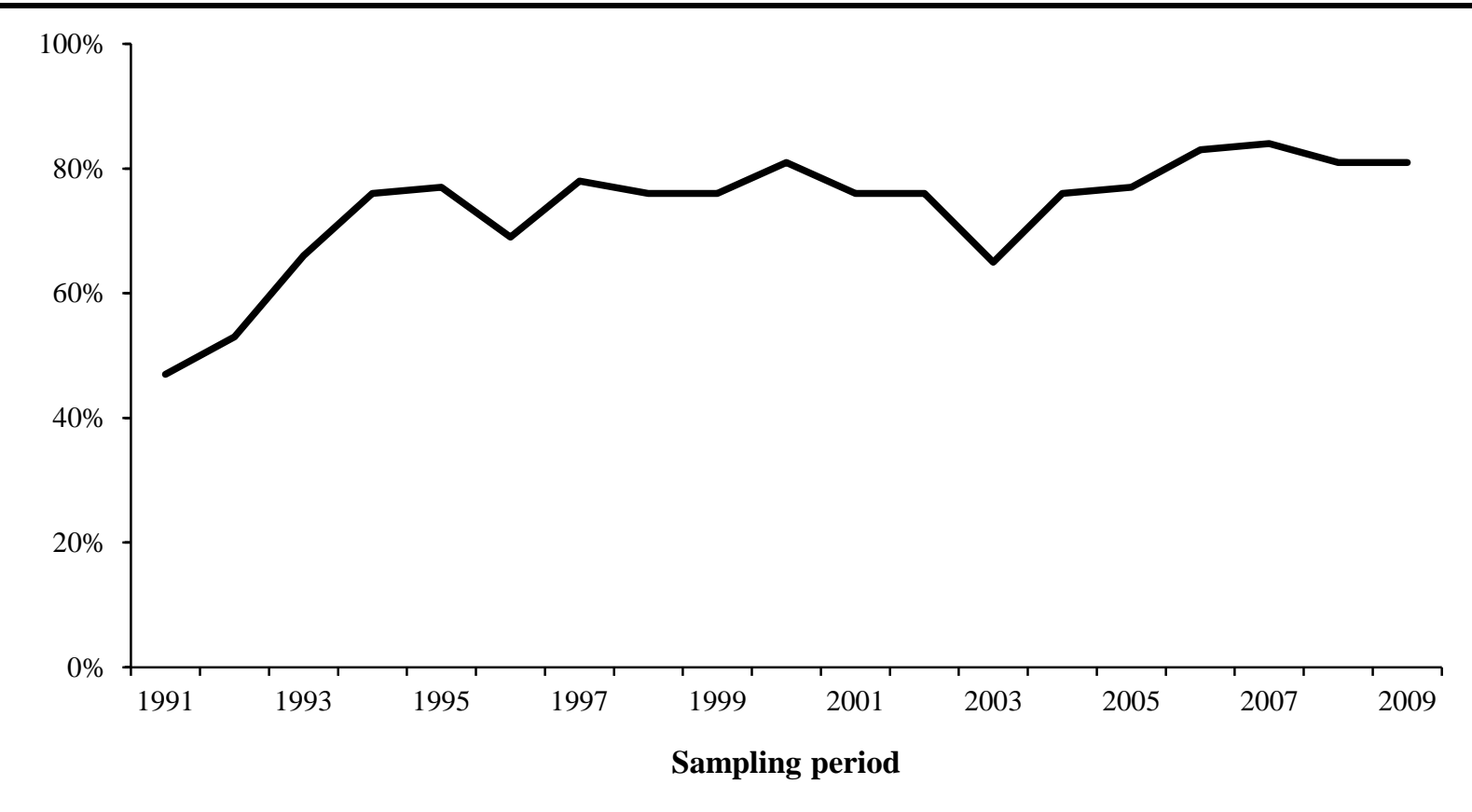

Notes: The sample contains all firm observations from the Kinder, Lydenberg, and Domini database used for Study 2a. Specifically, the sample contains firm observations with CSI and without CSI.

To close this gap, we ask three research questions: (1) Does the occurrence of CSI affect the firm value effects of CSR? If so, (2) can CSR types be distinguished that differ in their firm value effects when CSI is present? And (3) do these effects depend on CSI contexts?

We draw on instrumental stakeholder theory (IST; Jones 1995) as a theoretical starting point for answering these questions. Accordingly, CSR helps to establish trusting stakeholder relationships that positively affect a firm's financial performance. However, 
opportunistic behavior like CSI may lead stakeholders to cut back or even reverse their positive evaluation of CSR, possibly harming firm value (Barnett 2007; Schuler and Cording 2006). Hence, at first glance, CSR may be a questionable or even risky undertaking in the face of CSI. However, we suggest that such a concern results from an overly broad conceptualization of CSR as a monolithic construct that does not account for different types of CSR engagements.

Both CSR and CSI can be further delineated according to the thematic domains they address (Mishra and Modi 2016). We build on such a fine-grained understanding to derive two CSR options for firms with CSI: CSR that relates to the same domains affected by CSI (SD-CSR) and CSR that taps into other domains not affected by CSI (OD-CSR). While this distinction itself is straightforward, the decision of which CSR type (if any) should be prioritized is not clear for managers. When CSI is present, $11 \%$ of firms prefer to allocate CSR investments exclusively to SD-CSR, 38\% opt to conduct OD-CSR only, $22 \%$ engage in both types of CSR, and $29 \%$ do not engage in any CSR at all. ${ }^{7}$ We seek to provide a theoretically driven answer by pinpointing that while SD-CSR indicates inconsistent firm behavior (as moral values conveyed by CSR activities clash with bad deeds), OD-CSR represents consistent behaviors within domains. Therefore, in line with IST, we hypothesize that the two types have different implications for stakeholder relationships and might well differ in their firm value effects in general and across different CSI contexts in particular.

Table 5 distinguishes this study from the few studies that have disentangled CSR and CSI and that have focused on their firm value effects (Jayachandran, Kalaignanam, and Eilert 2013; Kang, Germann, and Grewal 2016). In general, this study is the first to focus on the

\footnotetext{
${ }^{7}$ These numbers refer to the sample described in Study $2 b$ (see also Figure 5).
} 
role of CSI with respect to CSR efforts' firm value implications, which relate to conceptual, theoretical and managerial contributions.

Conceptually, first, the study adds new evidence that reinforces recent calls to capture CSR and CSI as distinct constructs (Jayachandran, Kalaignanam, and Eilert 2013; Kang, Germann, and Grewal 2016). In particular, we show that the occurrence of CSI reduces the firm value effect of CSR. The presence of such an interaction means that combining CSR and CSI in an overall measure is at best an oversimplification and at worst erroneous. Second, we take this effect as a starting point for differentiating CSR types as to whether they relate to domains affected by CSI (SD-CSR vs. OD-CSR). The differentiation we present extends the work of researchers who have initiated the disaggregation of CSR into separate domains (Jayachandran, Kalaignanam, and Eilert 2013; Mishra and Modi 2016). Our distinction is unique, however, in that it goes beyond the pragmatic separation of CSR domains and distinguishes CSR types conceptually.

Theoretically, we advance the fundamental debate about whether CSR aligns with shareholder wealth maximization (Luo and Bhattacharya 2006) by demonstrating that, all else equal, SD-CSR does not affect firm value while OD-CSR enhances firm value. The results are meaningful given that IST has been questioned by studies that do not find CSR effects on firm value while not differentiating between CSR types (e.g., Mishra and Modi 2016). Specifically, our results support the arguments put forward by IST while emphasizing that IST needs to be applied more carefully by distinguishing different CSR activities when theorizing about firm value implications.

Finally, practitioners should enthusiastically embrace the study's findings, which confirm that thoroughly adjusting CSR efforts with the firm's CSI pattern solves the CSR dilemma outlined above. The study's findings facilitate managerial CSR decision making in 
the face of CSI by classifying CSR engagement relative to CSI and they save managers of CSI-affected firms from misreading potentially beneficial CSR activities as harmful and vice versa. In addition, by showing that the effectiveness of SD- and OD-CSR is moderated by CSI contextual factors (CSI proneness and CSI externalization), this research presents concrete, context-specific strategies for firms' engagement in CSR in the light of CSI. 
Table 5: Studies that Focus the Effects of CSR and CSI on Firm Value

\begin{tabular}{|c|c|c|c|}
\hline & $\begin{array}{c}\text { Jayachandran, Kalaignanam, } \\
\text { and Eilert (2013) }\end{array}$ & $\begin{array}{c}\text { Kang, Germann, and Grewal } \\
(\mathbf{2 0 1 6})\end{array}$ & This Study \\
\hline $\begin{array}{l}\text { Consideration of an interaction } \\
\text { between CSR and CSI }\end{array}$ & $x$ & $x$ & $\checkmark$ \\
\hline Consideration of CSR types & $\checkmark$ & $\times$ & $\checkmark$ \\
\hline $\begin{array}{l}\text { Consideration of CSI contextual } \\
\text { factors }\end{array}$ & $x$ & $x$ & $\checkmark$ \\
\hline Key objective & $\begin{array}{l}\text { Comparison of the effects of } \\
\text { (product and environmental) CSR } \\
\text { and CSI on firm value. }\end{array}$ & $\begin{array}{l}\text { Simultaneous examination of the } \\
\text { links between CSR, CSI, and firm } \\
\text { value. }\end{array}$ & $\begin{array}{l}\text { Examination of the role of CSI for the CSR- } \\
\text { firm value link. Focusing on the firm value } \\
\text { effects of CSR types SD-CSR and OD-CSR. } \\
\text { Exploring the role of CSI contextual factors } \\
\text { for the link between CSR types and firm } \\
\text { value. }\end{array}$ \\
\hline Key finding & $\begin{array}{l}\text { (Product) CSI's negative effects } \\
\text { on firm value outruns (product) } \\
\text { CSR's positive effects on firm } \\
\text { value. }\end{array}$ & $\begin{array}{l}\text { Only two relationships are } \\
\text { significant: CSR enhances firm value } \\
\text { and CSI enhances CSR. }\end{array}$ & $\begin{array}{l}\text { The presence of CSI plays an important role in } \\
\text { shaping the effects of CSR on firm value. } \\
\text { Whether SD-CSR and OD-CSR are beneficial } \\
\text { for driving firm value in the face of CSI } \\
\text { depends on the CSI context. }\end{array}$ \\
\hline Key implications for future research & $\begin{array}{l}\text { Separate CSR and CSI measures } \\
\text { should be preferred over one } \\
\text { overall CSR measure. CSR } \\
\text { should be further disaggregated } \\
\text { as to the domains addressed. } \\
\text { Contextual factors need more } \\
\text { attention. }\end{array}$ & $\begin{array}{l}\text { Separate CSR and CSI measures are } \\
\text { preferable to one overall measure. } \\
\text { The effect of CSR on firm value } \\
\text { should be examined while controlling } \\
\text { for CSI. }\end{array}$ & $\begin{array}{l}\text { CSR, CSI and their interaction should be } \\
\text { accounted for. Researchers should distinguish } \\
\text { between SD-CSR and OD-CSR as both have } \\
\text { differential performance implications. CSI } \\
\text { contextual factors should receive more } \\
\text { attention. }\end{array}$ \\
\hline
\end{tabular}




\subsection{Study 2: An Instrumental Stakeholder Theory Perspective on CSR}

We build our theorizing on stakeholder theory (Freeman 1984), which is the most established theoretical framework applied in CSR research (Barnett 2007; Homburg, Stierl, and Bornemann 2013). A central tenet of stakeholder theory is that the firm can be viewed as a nexus of implicit or explicit contracts with its stakeholders-groups or individuals that can affect or are affected by the achievement of the firm (Freeman 1984). Consequently, firms should consider the expectations and claims of not only shareholders but all relevant stakeholders (e.g., customers, employees, community) in their decision making (Donaldson and Preston 1995; Jones 1995).

The instrumental strand of stakeholder theory makes the case for a positive impact of CSR on the firm's financial well-being (Donaldson and Preston 1995). Instrumental stakeholder theory (IST) suggests that CSR helps to establish competitive advantage through trusting stakeholder relationships (Barnett 2007; Jones 1995). Trust has been described as confidence in someone's reliability and integrity (Morgan and Hunt 1994) and includes the conviction that someone behaves with ethical correctness (Greenwood and van Buren 2010). CSR signals a firm's trustworthiness because it allows insights into a firm's value system and character and indicates that the firm cherishes social issues and stakeholder welfare (Brown and Dacin 1997; Jones and Murrell 2001). Thus, CSR influences what stakeholders can expect from a relationship with the firm and whether the firm is worthy of the stakeholders' engagement and support. In sum, CSR has the potential to increase trust within stakeholder relationships, eventually driving firm outcomes including firm value (Homburg, Stierl, and Bornemann 2013; Vlachos et al. 2008).

While IST predicts a positive relationship between CSR and firm value, empirical research has drawn an ambiguous picture of CSR's financial outcomes. Various studies 
provide evidence for a positive relationship (e.g., Hull and Rothenberg 2008), no relationship (e.g., Servaes and Tamayo 2013), and a negative relationship between CSR and financial performance (e.g., Wright and Ferris 1997).

We contend that one reason for the conflicting findings on CSR might be that most researchers assume that both CSR and CSI aggregate to an overall CSR measure. However, several scholars note that CSR and CSI display distinct patterns of firm action that might barely be accounted for when calculating a measure that simply subtracts CSI scores from CSR scores (Mattingly and Berman 2006; Strike et al. 2006). A rarely mentioned aspect of IST suggests that the avoidance of opportunism is crucial for establishing trusting stakeholder relationships through CSR (Jones 1995). Because CSI hurts stakeholders' interests, it indicates the firm's opportunism and therefore potentially hinders CSR's effectiveness in establishing the firm's trustworthiness. IST therefore implies that CSR and CSI may interact, which we discuss in greater detail in Study 2a which answers the general question of whether CSR's firm value effect differs across firms that are involved in CSI.

Another reason for the conflicting findings, however, might be that the majority of prior studies do not differentiate between different CSR engagements. However, given IST's indication that CSR may be less effective (or even counterproductive) for enhancing firm value when CSI is present, a crucial question is how firms should engage in CSR to enhance financial outcomes despite the presence of CSI. Therefore, we examine different options for engaging in CSR in the face of CSI in Study $2 b$. 


\subsection{Study 2a: The Role of CSI for Firm Value Effects of CSR}

\subsubsection{Study 2a: CSR and CSI}

To capture firm value effects of CSR in the face of CSI, we need to disentangle the two variables rather than using an overall approach to capturing them. We define CSR as firm actions that improve the well-being of stakeholders or society at large (Korschun, Bhattacharya, and Swain 2014; Kotler and Lee 2005; Mishra and Modi 2016). The term CSI, in contrast, subsumes firm actions that hurt the well-being of stakeholders or society at large (Kang, Germann, and Grewal 2016; Strike, Gao, and Bansal 2006).

\subsubsection{Study 2a: The Interactive Effect of CSR and CSI on Firm Value}

The general expectation put forward by IST suggests that CSR increases firm value owing to more trusting, stronger stakeholder relationships. ${ }^{8}$ Both IST and recent theorizing further suggest that stakeholders use CSI as a cue for interpreting and evaluating CSR, pointing to a potential interaction between the two variables. Schuler and Cording (2006) theorize that stakeholders evaluate CSR against the knowledge of other socially relevant actions (e.g., CSI). Similarly, Barnett (2007) has proposed that stakeholders react differently to CSR depending on their perception of the firm's character. CSI represents a negative deviation from the behavioral norm that is "diagnostic of the true underlying character of the target being evaluated" (Mishina et al. 2012, p. 463). In turn, CSI may indicate a potential lack of morality and opportunism on the part of the firm (Godfrey, Merrill, and Hansen 2009). These arguments imply that the counterevidence on the firm's morality and values offered by CSI leads stakeholders to view CSR as inconsistent behavior that results in the perception that the

\footnotetext{
${ }^{8}$ Given that the main effect of CSR on firm value has received sufficient evidence in prior empirical research (e.g., Margolis and Walsh 2003), we do not formulate a hypothesis for it.
} 
firm's CSR engagement is insincere (Yoon, Gürhan-Canli, and Schwarz 2006) and in turn reduces the firm's trustworthiness in the eyes of stakeholders (Barnett 2007; Schuler and Cording 2006). In accordance with IST, CSR is then less effective or even counterproductive for enhancing firm value. Formally:

$\mathrm{H}_{1}$ : The positive effect of CSR on firm value is weaker for firms with CSI.

\subsubsection{Study 2a: Data and Variables}

\section{Data Sample}

If $\mathrm{H}_{1}$ holds true, we should find a negative interaction effect between CSR and CSI. To test this, we merge data from two sources. To measure variables that capture CSR and CSI, we draw on the Kinder, Lydenberg, and Domini (KLD) database, which is widely used in CSR studies recently published in top-tier journals (e.g., Mishra and Modi 2016; Servaes and Tamayo 2013). KLD extensively covers firms' socially relevant actions that are substantial and noteworthy in their impact on stakeholders and society by relying on independent experts that rate information from multiple publicly available sources, such as the Securities and Exchange Commission filings surveys, financial statements, articles in the press and in academic journals, and government reports. Starting in 1991, the KLD database today contains yearly ratings for more than 3,000 of the largest U.S. firms and reflects all important U.S. industries.

Beyond these general advantages, the KLD database has two characteristics that make it highly germane to our research. First, the database provides a differentiation of strengths and concerns that allows for the separate examination of CSR and CSI (Strike, Gao, and Bansal 2006). Second, the KLD database covers several strengths and concerns across all 
important domains (corporate governance, employee relations, diversity, environment, product, community and human rights).

All KLD indicators are subject to binary coding. For example, for the work/life benefits strength indicator, KLD assigns a " 1 " when the company has outstanding employee benefits or other programs addressing work/life concerns such as childcare, elder care, or flextime, and " 0 " if otherwise. For the retirement benefits concern indicator, KLD assigns a "1" when the company has either a substantially underfunded defined benefit pension plan or an inadequate retirement benefits program, and " 0 " if otherwise. The complete list of indicators appears in the Appendix 1.

We use firm observations between 1991 and 2009 to build our initial sample based on KLD data. ${ }^{9}$ We derive the remaining variables from Compustat. We match the initial KLD sample with Compustat data and remove all cases for which Compustat data are not available. We end up with 17,345 firm-year observations including 3,041 firms.

\section{Variable Construction}

We construct two variables from KLD: CSR and CSI occurrence. For the CSR variable, given that the number of indicators varies across domains and years, we adapt the scaling procedure from prior research (Servaes and Tamayo 2013). We first scale the number of strengths with a KLD rating of 1 for a firm within each domain by the maximum possible number of strengths within the domain in the respective year. The resulting scales range between 0 and 1 for each domain. We then sum these scaled numbers of strengths across the seven domains, resulting in a measure that is anchored by 0 and 7 . CSI occurrence is

\footnotetext{
${ }^{9}$ Owing to the substantial measurement modifications KLD undertook after 2009, this time period is the longest researchers have examined so far. In fact, to the best of our knowledge, only one study considers a comparable time frame (Kang, Germann, and Grewal 2016).
} 
measured as a dummy variable that equals 1 if the firm had at least one concern and 0 if otherwise. $^{10}$

We derive the remaining variables from Compustat. We measure firm value as Tobin's q, which is the most widely accepted firm value measure in the marketing, management, and finance literature (Chauvin and Hirschey 1993; Rao, Agarwal, and Dahlhoff 2004; Servaes and Tamayo 2013). Tobin's q is the ratio of the market value of a firm to the replacement value of a firm's assets. As its calculation is based on stock market price, Tobin's q is a forward-looking measure that indicates long-term profitability by reflecting expectations of the firm's future cash flows and growth opportunities (Bharadwaj, Bharadwaj, and Konsynski 1999). Tobin's q is most appropriate for this study because theory predicts that CSR affects firm value by establishing trusting stakeholder relationships, which requires a long-term horizon. CSR's effects are therefore expected to unfold via long-term profitability rather than short-term profitability (e.g., return on assets, current cash flows; Jayachandran et al. 2013). Moreover, in contrast to other firm value metrics, Tobin's q is adjusted for market risk and is not sensitive to accounting conventions, which guarantees comparability across industries (Anderson, Fornell, and Mazvancheryl 2004). We follow other marketing studies (e.g., Rao et al. 2004) and construct Tobin's q for each firm observation according to Chung and Pruitt (1994) as shown in Equation (1). ${ }^{11}$

Further, we include a comprehensive set of control variables that potentially affect firm value: research and development $(R \& D)$ intensity, advertising intensity, financial leverage, firm size, and industry concentration. Controlling for R\&D intensity is important, as R\&D investments extend to product and process innovations that influence the firm's

\footnotetext{
${ }^{10}$ Please note that we are interested in whether the CSR effect differs across firms with or without CSI, not in whether the amount of CSI plays a role. However, we also calculate the total number of concerns as an alternative measure for CSI and replicate the results in the analysis section using this measure.

${ }^{11} \mathrm{We}$ winsorize the variable firm value at the $1 \%$ level to avoid biased effects due to extreme observations in our data set (Servaes and Tamayo 2013).
} 
productivity (McWilliams and Siegel 2000). Advertising intensity enhances sales and brand equity but also influences visibility of the firm and its actions (Conchar, Crask, and Zinkhan 2005; Servaes and Tamayo 2013). We calculate R\&D intensity and advertising intensity as the ratio of the respective spending to the book value of total assets of a firm (Luo and Bhattacharya 2009). Financial leverage is important to control for, as it indicates a firm's strategic flexibility and responsiveness to unforeseen events (Kurt and Hulland 2013). We gauge financial leverage as the ratio of long-term debt to the book value of the total assets of the firm. We control for firm size because it might entail higher vulnerability to CSI, and we measure firm size as the logarithm of the number of employees (Bharadwaj, Bharadwaj, and Konsynski 1999). To account for competition effects that influence market power and longterm profitability, we control for industry concentration, operationalized as the Herfindahl index (Kurt and Hulland 2013). Finally, we also include year dummies to control for time effects on firm value (Jayachandran, Kalaignanam, and Eilert 2013). Table 6 summarizes the variables, their measurement, and literature support. We report descriptives and correlations in Table 7. 
Table 6: Measurement and Literature Support

\begin{tabular}{|c|c|c|c|}
\hline Variable & Study & Measurement & Literature Support \\
\hline \multicolumn{4}{|l|}{ Key variables } \\
\hline Firm value & $\begin{array}{l}\text { Studies } 2 \mathrm{a} \\
\text { and } 2 \mathrm{~b}\end{array}$ & Tobin's q & Rao et al. (2004) \\
\hline CSR & Study $2 \mathrm{a}$ & $\begin{array}{l}\text { Sum of strengths; scaled for each domain } \\
\text { separately by the maximum possible number } \\
\text { of strengths }\end{array}$ & $\begin{array}{l}\text { Servaes and Tamayo } \\
\text { (2013) }\end{array}$ \\
\hline SD-CSR & Study $2 b$ & $\begin{array}{l}\text { Sum of strengths in domains with at least } \\
\text { one concern; scaled for each domain } \\
\text { separately by the maximum possible number } \\
\text { of strengths }\end{array}$ & $\begin{array}{l}\text { Based on Servaes } \\
\text { and Tamayo (2013) }\end{array}$ \\
\hline OD-CSR & Study $2 b$ & $\begin{array}{l}\text { Sum of strengths in domains without } \\
\text { concerns; scaled for each domain separately } \\
\text { by the maximum possible number of } \\
\text { strengths }\end{array}$ & $\begin{array}{l}\text { Based on Servaes } \\
\text { and Tamayo (2013) }\end{array}$ \\
\hline \multicolumn{4}{|c|}{ Moderator variables } \\
\hline CSI occurrence & Study $2 \mathrm{a}$ & $\begin{array}{l}\text { Dummy variable with } 1 \text { for firm } \\
\text { observations with at least one concern, and } 0 \\
\text { for firm observation without concern }\end{array}$ & Godfrey et al. (2009) \\
\hline CSI proneness & Study $2 b$ & $\begin{array}{l}\text { Average number of concerns across a firm's } \\
\text { industry; scaled by the maximum possible } \\
\text { number of concerns }\end{array}$ & Own measure \\
\hline $\begin{array}{l}\text { CSI } \\
\text { externalization }\end{array}$ & Study $2 b$ & $\begin{array}{l}\text { Ratio between the number of concerns in a } \\
\text { firm's institutional environment domains } \\
\text { and the overall number of concerns }\end{array}$ & $\begin{array}{l}\text { Adapted from } \\
\text { Mattingly and } \\
\text { Berman (2006) }\end{array}$ \\
\hline \multicolumn{4}{|c|}{ Control variables } \\
\hline R\&D intensity & $\begin{array}{l}\text { Studies } 2 \mathrm{a} \\
\text { and } 2 \mathrm{~b}\end{array}$ & $\begin{array}{l}\text { R\&D spending divided by book value of } \\
\text { total assets }\end{array}$ & $\begin{array}{l}\text { Luo and } \\
\text { Bhattacharya (2009) }\end{array}$ \\
\hline $\begin{array}{l}\text { Advertising } \\
\text { intensity }\end{array}$ & $\begin{array}{l}\text { Studies } 2 \mathrm{a} \\
\text { and } 2 \mathrm{~b}\end{array}$ & $\begin{array}{l}\text { Advertising spending divided by book value } \\
\text { of total assets }\end{array}$ & $\begin{array}{l}\text { Luo and } \\
\text { Bhattacharya (2009) }\end{array}$ \\
\hline $\begin{array}{l}\text { Financial } \\
\text { leverage }\end{array}$ & $\begin{array}{l}\text { Studies } 2 \mathrm{a} \\
\text { and } 2 \mathrm{~b}\end{array}$ & $\begin{array}{l}\text { Long-term debt divided by book value of } \\
\text { total assets }\end{array}$ & $\begin{array}{l}\text { Kurt and Hulland } \\
\text { (2013) }\end{array}$ \\
\hline Firm size & $\begin{array}{l}\text { Studies } 2 \mathrm{a} \\
\text { and } 2 \mathrm{~b}\end{array}$ & Natural log of the number of employees & $\begin{array}{l}\text { Bharadwaj et al. } \\
\text { (1999) }\end{array}$ \\
\hline $\begin{array}{l}\text { Industry } \\
\text { concentration }\end{array}$ & $\begin{array}{l}\text { Studies } 2 \mathrm{a} \\
\text { and } 2 \mathrm{~b}\end{array}$ & Herfindahl index & $\begin{array}{l}\text { Kurt and Hulland } \\
\text { (2013) }\end{array}$ \\
\hline CSI intensity & Study $2 b$ & $\begin{array}{l}\text { Sum of concerns; scaled by the maximum } \\
\text { possible number of concerns }\end{array}$ & $\begin{array}{l}\text { Servaes and Tamayo } \\
(2013)\end{array}$ \\
\hline CSI severity & Study $2 \mathrm{~b}$ & $\begin{array}{l}\text { Ratio between the number of firm's major } \\
\text { concerns and the overall number of concerns }\end{array}$ & Own measure \\
\hline
\end{tabular}


Table 7: Descriptive Statistics and Correlations of Variables in Study 2a Sample

\begin{tabular}{|c|c|c|c|c|c|c|c|c|c|c|}
\hline Variable & $\mathbf{M}$ & SD & 1. & 2. & 3. & 4. & 5. & 6. & 7. & 8. \\
\hline 1. Firm value & 1.61 & 1.24 & 1 & & & & & & & \\
\hline 2. CSR & .27 & .35 & .065 & 1 & & & & & & \\
\hline 3. CSI occurrence & .77 & .42 & -.060 & .068 & 1 & & & & & \\
\hline 4. R\&D intensity & .04 & .09 & .255 & -.013 & -.012 & 1 & & & & \\
\hline 5. Advertising intensity & .02 & .05 & .120 & .050 & -.039 & -.049 & 1 & & & \\
\hline 6. Financial leverage & .20 & .21 & -.158 & -.051 & .032 & -.083 & -.017 & 1 & & \\
\hline 7. Firm size & 1.68 & 1.79 & -.130 & .345 & .124 & -.327 & .044 & .091 & 1 & \\
\hline $\begin{array}{l}\text { 8. Industry } \\
\text { concentration }\end{array}$ & .06 & .06 & -.027 & -.045 & .003 & -.174 & .071 & -.030 & .136 & 1 \\
\hline
\end{tabular}

Notes: Correlations greater than or equal to $|.01|$ are statistically significant $(p<.05$, two-tailed).

\subsubsection{Study 2a: Analysis and Results}

\section{Analysis Approach}

We follow related studies and employ a linear mixed model (Groening, Mittal, and Zhang 2016; Jayachandran, Kalaignanam, and Eilert 2013). Linear mixed models account for dependence within firms and heterogeneity across firms respectively by splitting the overall error variance into within-firms and between-firms variance components. More specifically, linear mixed models allow modeling fixed effects that refer to the marginal mean firm response and random effects that reflect a conditional mean firm response capturing firm variation (Fitzmaurice, Laird, and Waire 2011).

The model needs to answer the question of whether CSR's firm value effect differs across firms that are involved in CSI, as expected from $\mathrm{H}_{1}$. Consequently, we formulate the following equation: 
(3) Firm value $_{\text {it }}=\mu+\beta_{1} \times \mathrm{CSR}_{\mathrm{it}}+\beta_{2} \times \mathrm{CSI}_{\mathrm{it}}+\beta_{3} \times \mathrm{CSR}_{\mathrm{it}} \times \mathrm{CSI}_{\mathrm{it}}$

$$
\begin{aligned}
& +\beta_{4} \times \mathrm{R} \& \mathrm{D}_{\mathrm{it}}+\beta_{5} \times \mathrm{AD}_{\mathrm{it}}+\beta_{6} \times \mathrm{LEV}_{\mathrm{it}}+\beta_{7} \times \mathrm{SIZE}_{\mathrm{it}} \\
& +\beta_{8} \times \mathrm{CONC}_{\mathrm{it}}+\sum_{\mathrm{t}} \alpha_{\mathrm{t}} \mathrm{TIME}_{\mathrm{t}}+\zeta_{\mathrm{i}}+\varepsilon_{\mathrm{it}},
\end{aligned}
$$

where $\mathrm{i}=$ firm; $\mathrm{t}=$ observation year; $\mu=$ overall constant CSR $=$ overall $\mathrm{CSR} ; \mathrm{CSI}=$ CSI occurrence; $R \& D=R \& D$ intensity; $A D=$ advertising intensity; $L E V=$ financial leverage; SIZE = firm size; $\mathrm{CONC}=$ industry concentration; TIME = year dummies accounting for year-specific effects. The equation also considers $\zeta=$ firm-specific random effect capturing unobserved firm heterogeneity (constant across years with zero population mean and a variance $\sigma_{\zeta}^{2}$ over firms). Unobserved firm characteristics may explain variance differences across the firms' CSR approaches. For instance, organizational cultures or leadership styles can entail various CSR approaches. Failing to consider this unobserved heterogeneity across firms results in omitted variables bias - the under- or overestimation of effects because one or more important variables are missing (Jacobson 1990). Finally, $\varepsilon$ is the residual component, specific to each firm at each year (with zero population mean and a variance $\sigma_{\varepsilon}^{2}$ over firms and years).

Endogeneity. Equation (3) does not address the fact that CSR can be driven by firmspecific omitted factors that vary between years. For instance, CSR actions may be driven by changes within the firm unknown to the researcher that affect a firm's financial performance in a given year (e.g., changes in the executive board composition to include more talent). In such cases, CSR correlates with the error term causing endogeneity and in turn produces biased estimates. To correct for such endogeneity potential, we include Gaussian copulas in our model estimation (Park and Gupta 2012). The outstanding advantage of Gaussian copulas is that they represent an instrument-free approach that circumvents the problems of finding 
strong instrumental variables (Rossi 2014), which is why the approach has become very popular in recent marketing research (e.g., Burmester et al. 2015; Datta et al. 2015). Gaussian copulas capture the correlation of the endogenous variables and the error term by modeling their joint distribution on the basis of the observed data. They generate consistent parameter estimates even when the assumed normal distribution of the error term is not present (Park and Gupta 2012). We construct the copula term for CSR as follows:

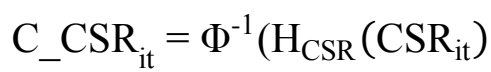

where $\Phi^{-1}$ is the inverse of the normal cumulative distribution function and $\mathrm{H}\left(\mathrm{CSR}_{\mathrm{it}}\right)$ represents the empirical distribution of the CSR variable. We add C_CSR it $_{\text {as }}$ a further control variable to Equation (3).

\section{Hypothesis Testing}

Prior to calculating the interactions and running the model, we mean-center all continuous independent variables to facilitate interpretability (Aiken and West 1991). To test for multicollinearity, we inspect the correlations between the independent variables (see Table 7) and the variance inflation factors (VIFs). The maximum correlation is .35 , which is below the threshold of .8 (Judge et al. 1988). The maximum VIF is 7.58, which is below 10 (Hair et al. 2010). We conclude that multicollinearity does not pose a threat to the results. We also test the usefulness of Gaussian copulas, which hinges on the non-normality of the variables. The Shapiro-Wilk test provides information on the non-normality of variables and confirms nonnormality of the potentially endogenous variable $\mathrm{CSR}\left(\mathrm{W}_{\mathrm{CSR}}=.85, p<.01\right)$.

We report two models in Table 8. Model 1 does not include an interaction between CSR and CSI occurrence, but Model 2 does. The fit measures suggest that adding the interaction improves model fit. We therefore interpret Model 2. The model shows that CSR 
has a positive and significant effect on firm value, as expected on the basis of both IST arguments and prior findings. Further, the model shows that the effect of the interaction between CSR and CSI occurrence on firm value is negative and significant $(\beta=-.38, p<$ .05 ), lending support for $\mathrm{H}_{1}{ }^{12}$ The remaining effects are in line with prior research (e.g., Lee and Grewal 2004; Rao et al. 2004), bolstering the validity of the model.

\subsubsection{Study 2a: Discussion}

The results of Study 2a show that CSI negatively moderates the firm value effect of CSR. This finding supports our theorizing that stakeholders may devalue CSR in the face of CSI, eventually leading to less trusting, weaker stakeholder relationships and lower firm value for firms with CSI. This finding suggests that CSR deserves deepened empirical consideration when CSI occurs. However, as has been the norm in most prior research (e.g., Hull and Rothenberg 2008; Kang, Germann, and Grewal 2016), in Study 2a we adopt an undifferentiated measure of CSR. Yet, managers of firms involved in CSI are keen to find ways to contribute to society through CSR while still being financially rewarded rather than punished for doing so despite the presence of CSI. Likewise, CSR research has raised the questions of how and when doing well can be aligned best with doing good (Barnett 2007; Basu and Palazzo 2008). In Study 2b, we therefore examine different options for engaging in CSR in the face of CSI.

\footnotetext{
${ }^{12}$ When we replace the binary CSI occurrence measure by an alternative CSI measure that captures the total number of concerns and rerun the analysis, all other effects remain stable. The interaction effect when using the alternative measure of CSI is likewise negative $(\beta=-.87, p<.05)$.
} 
Table 8: Moderating Effect of CSI for the CSR-Firm Value Relationship

\begin{tabular}{|c|c|c|c|c|c|c|c|}
\hline \multirow[b]{2}{*}{ Independent Variable } & \multirow[b]{2}{*}{$\begin{array}{l}\text { Hypothesis } \\
\text { (Expected } \\
\text { Sign) }\end{array}$} & \multicolumn{3}{|c|}{ Model 1} & \multicolumn{3}{|c|}{ Model 2} \\
\hline & & Coef. & & Sig. & Coef. & & Sig. \\
\hline Constant & & 1.71 & $(.04)$ & $* *$ & 1.70 & $(.04)$ & $* *$ \\
\hline $\begin{array}{l}\text { CSR } \\
\text { CSI } \\
\text { CSR } \times \text { CSI occurrence }\end{array}$ & $\mathrm{H}_{1}(-)$ & $\begin{array}{r}.25 \\
-.01\end{array}$ & $\begin{array}{l}(.05) \\
(.02)\end{array}$ & $* *$ & $\begin{array}{r}.38 \\
-.02 \\
-.14\end{array}$ & $\begin{array}{l}(.08) \\
(.02) \\
(.07)\end{array}$ & $\begin{array}{l}* * \\
*\end{array}$ \\
\hline \multicolumn{8}{|l|}{ Control variables } \\
\hline $\begin{array}{l}\text { R\&D intensity } \\
\text { Advertising intensity } \\
\text { Financial leverage } \\
\text { Firm size } \\
\text { Industry concentration } \\
\text { C_CSR }\end{array}$ & & $\begin{array}{r}2.13 \\
1.55 \\
-.31 \\
-.17 \\
.26 \\
-.06\end{array}$ & $\begin{array}{l}(.34) \\
(.35) \\
(.09) \\
(.01) \\
(.17) \\
(.01)\end{array}$ & $\begin{array}{l}* * \\
* * \\
* * \\
* * \\
* *\end{array}$ & $\begin{array}{r}2.13 \\
1.54 \\
-.31 \\
-.17 \\
.28 \\
-.06\end{array}$ & $\begin{array}{l}(.35) \\
(.32) \\
(.09) \\
(.01) \\
(.18) \\
(.01)\end{array}$ & $\begin{array}{l}* * \\
* * \\
* * \\
* *\end{array}$ \\
\hline $\begin{array}{l}\sigma_{\zeta} \\
\sigma_{\varepsilon}\end{array}$ & & $\begin{array}{l}.95 \\
.70\end{array}$ & $\begin{array}{l}(.01) \\
(.01)\end{array}$ & $\begin{array}{l}* * \\
* *\end{array}$ & $\begin{array}{l}.94 \\
.70\end{array}$ & $\begin{array}{l}(.01) \\
(.01)\end{array}$ & $\begin{array}{l}* * \\
* *\end{array}$ \\
\hline $\begin{array}{l}\text { Log likelihood } \\
\text { Wald chi-square } \\
\text { Akaike information } \\
\text { criterion }\end{array}$ & & $\begin{array}{r}-21, \\
2, \\
43,\end{array}$ & $\begin{array}{l}733.24 \\
701.75 \\
526.48\end{array}$ & $* *$ & $\begin{array}{r}-21 \\
2 \\
43\end{array}$ & $\begin{array}{l}30.07 \\
82.86 \\
22.15\end{array}$ & $* *$ \\
\hline $\mathrm{N}$ & & & 17,345 & & & 7,345 & \\
\hline
\end{tabular}

$* p<.05 ; * * p<.01$.

Notes: Coefficients are unstandardized. Standard errors are in parentheses. For the analysis, we use bootstrap standard errors with 200 repetitions (Burmester et al. 2015; Park and Gupta 2012). Time dummies are included in the model but not reported. To avoid a large reduction of sample size owing to firms' non-disclosure of advertising and R\&D spending in the Compustat database, we included two separate dummy variables that equal 1 if advertising (R\&D) spending information is disclosed and 0 if respective information is not disclosed (Luo and Bhattacharya 2009). 


\subsection{Study 2b: Firm Value Effects of Different CSR Activities in the Presence of CSI}

\subsubsection{Study 2b: Engaging in CSR in the Face of CSI}

SD-CSR and OD-CSR. In Study 2a, the argumentation focused on the overall effectiveness of CSR and suggested that the occurrence of CSI impairs stakeholder perceptions of the firm's trustworthiness and thus diminishes the positive impact of doing good owing to the counterevidence of doing harm. In Study 2b, we adopt a more fine-grained perspective and argue that in the face of CSI, stakeholders do not necessarily question every CSR engagement to the same degree. Rather, we suggest that on the basis of comparable information stakeholders primarily evaluate CSR actions with respect to their (in)consistency with CSI and the firm's trustworthiness, eventually leading to different firm value effects.

In elaborating on different information offered via CSR and CSI, prior research argues that stakeholders evaluate CSR and CSI with respect to the different possible thematic domains or categories in which these activities are embedded (Jayachandran, Kalaignanam, and Eilert 2013; Mishra and Modi 2016). Particularly when firm actions in different informational domains are not readily comparable, categorization processes will be triggered since a category-specific perspective reduces complexity and uncertainty for stakeholders when evaluating CSR and CSI, enhancing the accuracy of stakeholder expectations and predictability of a firm's future behavior (Schoorman, Mayer, and Davis 2007). CSR scholars view employee relations, diversity, human rights, corporate governance, product, environment, and community relations as such distinct thematic categories or domains (Sen and Bhattacharya 2001). According to categorization research, stakeholders assign CSR and CSI activities to these domains on the basis of the higher order attributes that characterize these domains (Rosch and Mervis 1975). For instance, stakeholders would categorize firm 
actions such as the implementation of occupational or operational safety and health programs (i.e., CSR) and downsizing the workforce (i.e., CSI) as belonging to the domain of employee relations because both represent employee topics.

However, prior research implies that processing domain-specific information not only shapes the separate evaluation of CSR and CSI but additionally provides insights on how CSR and CSI interplay within domains. Particularly, CSI demonstrates opportunism and a lack of morality in one domain and therefore may influence the interpretation of CSR in the same domain. If CSR and CSI activities share higher order attributes that are tied to the same category (i.e., domain), stakeholders perceive high levels of inconsistency between CSR and CSI. Thus, whether CSR and CSI overlap in terms of the addressed domain is of crucial importance for stakeholders' trust perceptions. Consideration of CSI may determine whether stakeholders are able to create a coherent picture of the firm's identity and morality when they evaluate CSR activities (Janney and Gove 2011). Indeed, initial experimental evidence suggests that the thematic relatedness between CSR activities and the firm's negative societal impacts enhances the perception of insincere motives for CSR (Yoon, Gürhan-Canli, and Schwarz 2006). Building on such arguments, our conceptualization aligns with the theorizing that stakeholders consider the domain overlap with CSI when they evaluate CSR actions, because it provides information on the (in)consistency of firm behavior and the firm's trustworthiness.

We therefore distinguish two types of CSR by their domain overlap with CSI. SDCSR (same domain CSR) embraces firm actions that improve the well-being of stakeholders or society at large in the same domain(s) affected by CSI. In contrast, OD-CSR (other domain CSR) embraces firm actions that improve the well-being of stakeholders or society at large in the domain(s) not affected by CSI. As an example of a CSR action that qualifies as SD-CSR, 
the outdoor clothing and gear provider Patagonia contributed to environmental protection with programs such as the World Trout Initiative (i.e., CSR in the environmental domain) but was also criticized for processing chemicals that are harmful to the environment (i.e., CSI in the environmental domain; Patagonia 2013). As an example of a socially desirable action that qualifies as OD-CSR, Wal-Mart contributed to the environment through energy-reduction initiatives and by offering environmentally friendly products (i.e., CSR in the environment domain), but was also criticized for dubious labor practices that had negative outcomes for employees (i.e., CSI in the employee domain; Aston 2009). ${ }^{13}$ We next discuss the firm value implications of SD-CSR and OD-CSR.

\subsubsection{Study 2b: Firm Value Effects of CSR Activities}

SD-CSR relates to domain(s) in which the firm behaves socially irresponsibly. When stakeholders evaluate SD-CSR against their knowledge about CSI, they experience a conflict as to how the CSR activity should be interpreted. The firm's good deeds clash with bad deeds in the same domain, indicating contradictory moral values and arousing stakeholder perceptions of inconsistent firm behavior (Janney and Gove 2011). These perceptions of inconsistency not only alienate stakeholders as to what is the appropriate interpretation of SD-CSR, they may even trigger stakeholders to interpret such engagements as insincere and hypocritical (Wagner, Lutz, and Weitz 2009; Yoon, Gürhan-Canli, and Schwarz 2006). Owing to the resulting lack of credibility of SD-CSR, we therefore propose that SD-CSR countervails the development of strong, trusting stakeholder relationships and in turn reduces the firm's future financial prospects. Hence, all else being equal, we expect a negative effect of SD-CSR on firm value. We hypothesize:

\footnotetext{
${ }^{13}$ For ease of illustration, we assume that neither of the exemplary firms engaged in any other CSR or CSI activities.
} 
$\mathrm{H}_{2}$ : SD-CSR has a negative impact on firm value.

In contrast, OD-CSR refers to domains in which the firm raised no red flag through CSI. OD-CSR does not give rise to an informational conflict when stakeholders evaluate it against the informational background marked by CSI. As CSR activities and CSI fall into different domains, stakeholders do not perceive OD-CSR as inconsistent behavior because the bad deeds do not contradict the moral values reflected by such CSR activities. Rather, OD-CSR draws an unambiguous picture of the firm's interest in enhancing social welfare in the respective domains and thus leads to clear stakeholder interpretations regarding what to expect from the firm (Vlachos et al. 2008; Webb and Mohr 1998). In line with the premises of IST, we therefore suggest that OD-CSR leads to trusting stakeholder relationships that induce higher levels of firm value. Consequently, we expect a positive effect of OD-CSR on firm value. Thus:

$\mathrm{H}_{3}$ : OD-CSR has a positive impact on firm value.

\subsubsection{Study 2b: The Role of CSI Context}

CSI proneness and CSI externalization. We suggest that the effects of SD-CSR and OD-CSR depend on contextual factors. Given that the key interest of this study is on CSR's firm value effects in the face of CSI, factors that characterize the CSI context have the potential to further influence when SD-CSR and/or OD-CSR are more or less financially beneficial, providing managerial guidance. We consider CSI context variables on the industry- and firmlevel.

Representing an industry-level contextual factor, CSI proneness is an industry's susceptibility for irresponsible behavior. High CSI proneness means that the average level of 
CSI among the firms in an industry is high and therefore suggests that CSI is more likely to arise owing to industry-inherent pitfalls than to the individual firm's lack of morality.

Representing a firm-level contextual factor, CSI externalization is the degree to which CSI transpires in the firm's institutional environment as compared to the firm's task environment. ${ }^{14}$ The greater the CSI externalization, the more CSI extends into the firm's institutional environment and the less it takes place in the firm's task environment. Because the institutional environment sets the norms and rules for proper social conduct toward society at large, firm actions in this area are particularly diagnostic of the principles and values that guide the firm's business (Handelman and Arnold 1999). In this sense, high CSI externalization indicates that the firm systematically transgresses norms that are well established in society.

Moderating effects of CSI proneness. SD-CSR signals an ambiguous morality of the firm and stakeholders may perceive such CSR engagement as inauthentic, which eventually reduces firm value owing to weakened stakeholder relationships. However, in CSI-prone industries, CSI occurs frequently. Therefore, firms in such industries have more touch points with stakeholder concerns for social and environmental issues (Peretz, Bohm, and Jasienczyk 1997), drawing particular attention to stakeholder expectations to compensate for the negative societal impacts (Banerjee, Iyer, and Kashyap 2003; Brammer and Pavelin 2006). On the basis of such an industrial background, stakeholders are more likely to judge SD-CSR as an imperative rather than as an indication of a lack of morality and inconsistent firm behavior. The harmful effects of SD-CSR for stakeholder relationships vanish and firm value is less likely to suffer. Likewise, CSI proneness increases stakeholders' awareness that firms in such

\footnotetext{
${ }^{14}$ The task environment is the source of resource exchanges that enable a firm to meet its demands and goals (Handelman and Arnold 1999; Mattingly and Berman 2006). The institutional environment is the source of normative expectations that are based on social and cultural systems of meaning. The classification of firm behavior as occurring in either the firm's task or institutional environment is equivalent to the distinction between firm behavior toward primary or secondary stakeholders (Godfrey, Merrill, and Hansen 2009).
} 
risk-loaded industries cannot fully acquit themselves of CSI. Stakeholders eventually interpret SD-CSR as the firm's efforts to demonstrate its responsiveness to their negative impact, which leads to more positive stakeholder evaluations and competitive advantage through stronger stakeholder relationships, attenuating SD-CSR's negative effects on firm value. We hypothesize the following:

$\mathrm{H}_{4}$ : The negative effect of SD-CSR on firm value is weaker when CSI proneness is high.

Further, we suggest that the positive effect of OD-CSR CSR on firm value is higher in CSI-prone industries. Those industries are inherently associated with regular negative societal impact, which is why firms in a such industries typically have less incentive to enhance stakeholder welfare in the first place since the risk of failing with such initiatives is high (Leonidou, Katsikeas, and Morgan 2012). However, if firms seek to achieve this goal, they must make extraordinary efforts to establish a reputation for being socially responsible given the adverse conditions in "bad" industries. OD-CSR then offers the firm a unique opportunity to demonstrate that it is willing to make this extra effort to counter the bad image of the industry the firm operates in. Given that going the extra mile is well established as a means to positively surprise stakeholders by demonstrating that the firm has genuine interest in being responsible (Schepers et al. 2012), OD-CSR's potential to strengthen stakeholder relationships is accentuated, enabling the firm to reap more financial benefits in the long run. We thus postulate the following:

$\mathrm{H}_{5}$ : The positive effect of OD-CSR on firm value is stronger when CSI proneness is high. 
Moderating effects of CSI externalization. We theorized that SD-CSR lacks credibility among stakeholders, weakening stakeholder relations and consequently firm value. Through high CSI externalization, the firm's negative impact permeates the broader society, seemingly sacrificing societal welfare for profits. Such an unfavorable interpretation of the firm's wrong-doings calls into question the moral character and integrity of the firm and its actions (Godfrey, Merrill, and Hansen 2009). Against this background, stakeholders interpret SDCSR as an attempt to direct their attention away from a lack of morality. In turn, they assess CSR activities even more critically, which amplifies perceptions of insincerity for SD-CSR. The resulting harm for stakeholder relationships results in a more negative impact of SD-CSR on firm value when CSI externalization is high. Therefore, we hypothesize:

$\mathrm{H}_{6}$ : The negative effect of SD-CSR on firm value is stronger when CSI externalization is high.

Finally, we assume that the positive effect of OD-CSR on firm value is weaker in the presence of high CSI externalization. As discussed above, OD-CSR draws an unambiguous picture of the firm's interest in enhancing social welfare in the respective domains because it is not associated with CSI in these domains. When CSI primarily occurs in morally loaded, institutional domains, despite the normative pressure to refer to institutional norms, stakeholders find the cause of CSI to lie in a lack of morality rather than external factors (Yoon, Gürhan-Canli, and Schwarz 2006). In the context of high CSI externalization, stakeholders thus view the firm's good deeds with skepticism and they are less likely to take OD-CSR at face value - that is, as an unambiguous interest in enhancing social welfare. Stakeholders are more likely to interpret OD-CSR as the firm's attempt to whitewash a lack of morality, which reduces the authenticity of OD-CSR engagement. We therefore suggest 
that for high CSI externalization, OD-CSR loses its potency for strengthening stakeholder relationships and results in a less positive impact on firm value. We thus hypothesize:

$\mathrm{H}_{7}$ : The positive effect of OD-CSR on firm value is weaker when CSI externalization is high.

\subsubsection{Study 2b: Data and Variables}

\section{Data Sample}

Since the key interest of Study $2 \mathrm{~b}$ lies in examining different CSR activities of firms that are involved in CSI, we need to define a more focused sample than that in Study 2a. Critically, to test the theorizing that stakeholders judge CSR in the context of CSI, we need to ensure that CSI became public before stakeholders evaluated CSR. Therefore, starting with the sample described in Study 2a, we include all observations where a firm had at least one CSI concern in the previous year. We end up with 13,411 firm observations including 2,682 firms, which accounts for $77 \%$ of the observations considered in the Study 2a sample.

\section{Variable Construction}

We construct the dependent variable firm value as in Study 2a. As to CSR and CSI, however, Study $2 b$ requires different variables, which we describe next. We measure these variables using the strength and concern items that KLD offers across domains as is the standard in research that uses KLD data (e.g., Strike et al. 2006). Further, we adapt the measurement procedure from prior research (Servaes and Tamayo 2013).

For SD-CSR, we consider strengths in the domain(s) in which a firm had at least one concern in the previous year. We scale the number of the binary strength indicators with a value of 1 for a firm within each of the CSI-inflicted domains by the maximum possible 
number of strengths within each of these domains, resulting in a scale that ranges between 0 and 1 in each domain. We then sum these strength scales for each firm year across the CSIinflicted domains to obtain the SD-CSR measure. Given that the maximum number of domains is 7 , the scale is anchored by 0 and 7 . We used the equivalent procedure to construct OD-CSR, but we use only strengths in the domain(s) in which a firm had no concern in the previous year. We scale the number of strengths for a firm within each CSI-free domain by the maximum possible number of strengths within these domains. We sum the strengths for each firm year across the relevant domains to obtain the OD-CSR measure (anchored by 0 and 7).

Next, we consider two moderator variables that further describe the firm's CSI. To measure CSI proneness, we scale the total number of concerns with a value of 1 for each firm by the maximum possible number of concerns in a year and take the average of these values for the firm's industry based on two-digit SIC codes. To measure CSI externalization, we take the ratio between the number of a firm's concerns in domains referring to the institutional environment and the firm's overall number of concerns. ${ }^{15}$

We measured the control variables R\&D intensity, advertising intensity, financial leverage, firm size, and industry concentration exactly as in Study 2a. However, we also considered additional controls: CSI intensity and CSI severity, both captured in the previous year to align with the other CSI-related measures. To construct CSI intensity, we scale the number of concerns for a firm by the maximum possible number of concerns. Next, to measure CSI severity we treat concerns that include substantial fines and civil penalties as

\footnotetext{
${ }^{15}$ As is the norm (e.g., Godfrey et al. 2009; Luo et al. 2015), we use Mattingly and Berman's (2006) domain classification and treat the environment, human rights, and community domains as the firm's institutional environment (i.e., "secondary" domains) and the employee, corporate governance, diversity, and product domains as a firm's task environment (i.e., "primary" domains).
} 
major concerns ${ }^{16}$ (Germann et al. 2014) and measure CSI severity as the ratio between the number of major concerns and the overall number of concerns per firm. Table 6 provides an overview of variable constructions. Table 9 contains descriptive statistics of the variables and their correlations.

\subsubsection{Study 2b: Analysis and Results}

\section{Analysis Approach}

For the same reasons as in Study 2a, we estimate a linear mixed model to examine the firm value effects of different types of CSR activities for firms that are involved in CSI. However, we need to adjust Equation (3) to account for the CSR types and the moderating effects as predicted in $\mathrm{H}_{2}-\mathrm{H}_{7}$. We specify the following equation:

$$
\begin{aligned}
\text { Firm value }_{\mathrm{it}}= & \omega+\gamma_{1} \times \mathrm{SD}_{\mathrm{it}}+\gamma_{2} \times \mathrm{OD}_{\mathrm{it}} \\
& +\gamma_{3} \times \mathrm{PRON}_{\mathrm{it}}+\gamma_{4} \times \mathrm{SD}_{\mathrm{it}} \times \mathrm{PRON}_{\mathrm{it}}+\gamma_{5} \times \mathrm{OD}_{\mathrm{it}} \times \mathrm{PRON}_{\mathrm{it}} \\
& +\gamma_{6} \times \mathrm{EXT}_{\mathrm{it}}+\gamma_{7} \times \mathrm{SD}_{\mathrm{it}} \times \mathrm{EXT}_{\mathrm{it}}+\gamma_{8} \times \mathrm{OD}_{\mathrm{it}} \times \mathrm{EXT}_{\mathrm{it}} \\
& +\gamma_{9} \times \mathrm{R}_{\mathrm{it}}+\gamma_{10} \times \mathrm{AD}_{\mathrm{it}}+\gamma_{11} \times \mathrm{LEV}_{\mathrm{it}}+\gamma_{12} \times \mathrm{SIZE}_{\mathrm{it}} \\
& +\gamma_{13} \times \mathrm{CONC}_{\mathrm{it}}+\gamma_{14} \times \mathrm{INT}_{\mathrm{it}}+\gamma_{15} \times \mathrm{SEV}_{\mathrm{it}}+\sum_{\mathrm{t}} \delta_{\mathrm{t}} \mathrm{TIME}_{\mathrm{t}}+\delta_{\mathrm{i}}+\mathrm{v}_{\mathrm{it}}
\end{aligned}
$$

where i, t, R\&D, AD, LEV, SIZE, CONC, and TIME are the same as in Equation (3) and $\omega, \delta$, and $v$ have equivalent meaning as $\mu, \zeta$, and $\varepsilon$ in Equation (3); $\mathrm{SD}=\mathrm{SD}-\mathrm{CSR}$; $\mathrm{OD}=$ OD-CSR; PRON = CSI proneness $;$ EXT = CSI externalization; INT = CSI intensity; SEV = CSI severity.

Endogeneity. As in Study 2a, we calculated Gaussian copulas for SD-CSR and for

\footnotetext{
${ }^{16}$ Major concerns are hazardous waste and regulatory problems in the environment domain; product safety, marketing/contracting concern and antitrust in the product domain; health and safety concern in the employee relations domain; controversies in the diversity domain.
} 
OD-CSR. Formally:

(6)

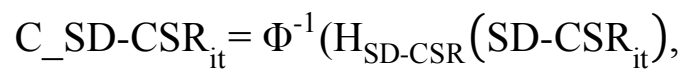

$$
\text { C_OD-CSR }{ }_{\mathrm{it}}=\Phi^{-1}\left(\mathrm{H}_{\mathrm{OD}-\mathrm{CSR}}\left(\mathrm{OD}-\mathrm{CSR}_{\mathrm{it}}\right)\right. \text {, }
$$

where $\Phi^{-1}$ and $\mathrm{H}$ have meaning equivalent to Equation (4). We add the resulting terms C_SD-CSR it $_{\text {and }}$ C_OD-CSR it to Equation (5).

Sample selection. As the objectives of Study $2 \mathrm{~b}$ require a sample that consists of only firms that are involved in CSI, we need to control for sample selection bias. ${ }^{17}$ To do so, we employed the two-step procedure developed by Heckman (1976). In a first step, we ran a random-effects probit model to estimate a firm's probability of being involved in CSI, using firm size, return on assets (ROA), and industry dummies as predictors (Sullivan, Haunschild, and Page 2007). Firm size is an important driver of a firm's CSI probability because large firms have more complex business processes that complicate the management of stakeholder relationships. ROA is a meaningful predictor because striving for higher short-term profits is often a reason for CSI. We account for industry dummies because some industries naturally face a higher probability of CSI occurrence. The results of the random-effects model are shown in Table 10. In a second step, we used the probit estimates to calculate the inverse Mills ratio by dividing the probability density function by the cumulative distribution function of the standard normal distribution. We add the inverse Mills ratio as control variable in Equation (5).

\footnotetext{
${ }^{17}$ We compared average book value of total assets of firm observations with CSI with average total assets of firm observations without CSI. Significant differences in every year underline the need to correct for sample selection bias.
} 
Table 9: Descriptive Statistics and Correlations of Variables in Study 2b Sample

\begin{tabular}{|c|c|c|c|c|c|c|c|c|c|c|c|c|c|c|}
\hline Variable & $\mathbf{M}$ & SD & 1. & 2. & 3. & 4. & 5. & 6. & 7. & 8. & 9. & 10. & 11. & 12. \\
\hline 1. Firm value & 1.57 & 1.21 & 1 & & & & & & & & & & & \\
\hline 2. SD-CSR & .10 & .22 & -.029 & 1 & & & & & & & & & & \\
\hline 3. OD-CSR & .19 & .26 & .120 & .209 & 1 & & & & & & & & & \\
\hline 4. CSI proneness & .06 & .03 & -.102 & .177 & .008 & 1 & & & & & & & & \\
\hline 5. CSI externalization & .19 & .30 & -.147 & .194 & .089 & .327 & 1 & & & & & & & \\
\hline 6. R\&D intensity & .04 & .08 & .270 & -.026 & .019 & -.099 & -.163 & 1 & & & & & & \\
\hline 7. Advertising intensity & .01 & .04 & .108 & -.017 & .082 & -.066 & -.033 & -.038 & 1 & & & & & \\
\hline 8. Financial leverage & .20 & .21 & -.108 & -.008 & -.077 & .108 & .077 & -.095 & -.011 & 1 & & & & \\
\hline 9. Firm size & 1.80 & 1.81 & -.111 & .324 & .277 & .084 & .228 & -.341 & .050 & .085 & 1 & & & \\
\hline 10. Industry concentration & .06 & .06 & -.029 & -.011 & -.056 & .076 & -.063 & -.191 & .078 & -.020 & .132 & 1 & & \\
\hline 11. CSI intensity & .08 & .06 & -.110 & .546 & .022 & .405 & .335 & -.102 & -.041 & .073 & .392 & .009 & 1 & \\
\hline 12. CSI severity & .20 & .30 & -.103 & .206 & .055 & .226 & .290 & -.163 & -.012 & .106 & .351 & .004 & .314 & 1 \\
\hline
\end{tabular}

Notes: Correlations greater than or equal to $|.019|$ are statistically significant $(p<.05$, two-tailed). 
Table 10: Estimation of a Firm's Probability for CSI

\begin{tabular}{lrrr}
\hline Independent Variable & Coef. & & Sig. \\
\hline Constant & .73 & $(.07)$ & $* * *$ \\
ROA & -.32 & $(.10)$ & $* * *$ \\
Firm size & .22 & $(.02)$ & $* * *$ \\
Industry dummies & & & \\
Agriculture, forestry, and fishing & 1.38 & $(.63)$ & $* *$ \\
Mining & .47 & $(.07)$ & $* * *$ \\
Construction & .26 & $(.34)$ & \\
Manufacturing & .13 & $(.08)$ & $*$ \\
Transportation, communications, & .20 & $(.10)$ & $*$ \\
electric, gas and sanitary service & & & \\
Wholesale trade & -.15 & $(.17)$ & \\
Retail trade & -.30 & $(.12)$ & $* *$ \\
Finance, insurance, and real estate & .13 & $(.16)$ & \\
Public administration & 1.24 & $(.55)$ & $* *$ \\
Wald chi-square & & 218.83 & $* * *$ \\
N & & 17,345 & \\
\hline
\end{tabular}

$* p<.10 ; * * p<.05 ; * * * p<.01$.

Notes: Standard errors are in parentheses. We treat services as the reference category. 


\section{Hypotheses Testing}

Prior to calculating the interactions and running the models, we mean-center all independent variables (Aiken and West 1991). To test for multicollinearity, we inspect the correlations between the explanatory variables (see Table 9) and the VIFs. The maximum correlation is .55 , which is below .8 (Judge et al. 1988). The maximum VIF is 3.56 , which is well below 10, indicating that multicollinearity does not pose a threat to the results (Hair et al. 2010). We also test the usefulness of Gaussian copulas that hinges on the non-normality of the variables, which is necessary for identification purposes. The Shapiro-Wilk test confirms that SD-CSR and OD-CSR are non-normally distributed $\left(\mathrm{W}_{\mathrm{SD}-\mathrm{CSR}}=.80, p<.00 ; \mathrm{W}_{\mathrm{OD}-\mathrm{CSR}}=.87, p<.00\right)$.

Table 11 shows the results for both Model 1 as a main-effect-only model and Model 2 that additionally includes the moderated effects, which improves model fit. Model 2's findings demonstrate that SD-CSR has no significant effect on firm value $(\gamma=-.10, p>.10)$, and thus we reject $\mathrm{H}_{2}$. In contrast, the results provide support for $\mathrm{H}_{3}$, because OD-CSR has a positive and significant impact on firm value $(\gamma=.41, p<.01) .{ }^{18}$

Regarding the moderator hypotheses, the results show that the interaction between SD-CSR and CSI proneness has a positive and significant effect on firm value $(\gamma=3.57, p<$ .01 ), in support of $\mathrm{H}_{4}$. The analysis results further suggest that CSI proneness positively and significantly moderates OD-CSR's effect on firm value $(\gamma=2.67, p<.05)$. Thus, $\mathrm{H}_{5}$ is also supported. However, we find no significant effect of the interaction between SD-CSR and CSI externalization on firm value $(\gamma=.24, p>.10)$, and thus we reject $\mathrm{H}_{6}$. Further, the findings indicate that CSI externalization negatively and significantly moderates the effect of OD-CSR on firm value $(\gamma=-.18, p<.05)$, in support of $\mathrm{H}_{7}$.

\footnotetext{
${ }^{18}$ Although KLD tracks publicly available and socially influential firm behavior, the publicity of the firm and its actions could affect our results. We therefore reran our analysis with interactions between the CSR types and advertising intensity as proxy for firm publicity (Rinallo and Basuroy 2009). The effects of the CSR types remained stable while the interactions were not significant, suggesting that publicity does not affect our results.
} 
Regarding the remaining effects in the model, CSI intensity has a (moderately) significant negative impact on firm value, which corresponds to the recent finding by Kang, Germann, and Grewal (2016) suggesting that more CSI is bad as it weakens stakeholder relationships and thus lowers firm value. ${ }^{19}$ In line with our theorizing that high CSI externalization indicates that the firm systematically transgresses ethical rules that are well established in society, CSI externalization has a negative and significant impact on firm value.

\section{Additional Analysis}

Floodlight analysis of moderating effects. We performed floodlight analysis to offer additional insight on the significant interaction effects. Floodlight analysis involves testing the effects of the independent variables on the dependent variable at numerous values across the observed range of the moderating variable (Spiller et al. 2013). We estimate parameters of the direct effects of CSR types on firm value for the observed range of the moderating variables using increments of .02. The beta estimates are plotted in Figures 3 and 4 along with the $95 \%$ confidence interval band.

Alarmingly, Figure 3, Panel A shows that when CSI proneness is lower than approximately .04, SD-CSR has a significant negative impact on firm value. Beyond that point, where the upper confidence interval band crosses the x-axis, SD-CSR has no impact on firm value. From approximately.14, where the lower confidence interval band crosses the xaxis, the effect becomes significantly positive. Thus, SD-CSR may yield either negative

\footnotetext{
${ }^{19}$ Alternatively for CSI intensity, we control for CSI history—a firm's cumulative CSI incidents in the last three years - to account for the possibility that a firm is a repeat offender. To estimate CSI history, we used a decay measure estimated on the baseline sample as follows:

CSI history $\mathrm{it-1}_{1}=1 / 1$ CSI intensity it-1 $_{1}+1 / 2$ CSI intensity it-2 $_{2}+1 / 3$ CSI intensity ${ }_{\text {it-3 }}$ (Shiu 2016). The CSI history variable yields a similar effect as the CSI intensity control $(\beta=-.21, p<.10)$. All other effects remain stable. We thank an anonymous reviewer for this suggestion.
} 
effects, no effect, or positive effects on firm value, depending on the level of CSI proneness. Further, Figure 3, Panel B shows that OD-CSR has a significant positive effect on firm value for the entire observed range of CSI proneness (because the upper and lower confidence bands are both well beyond the x-axis) and that the positive effect increases with increasing levels of CSI proneness. Figure 4 shows that OD-CSR has a significant positive effect on firm value that also appears for the entire range of CSI externalization, but the positive effect decreases with increasing levels of CSI externalization. 
Table 11: Effects of CSR Types on Firm Value

\begin{tabular}{|c|c|c|c|c|c|c|c|}
\hline \multirow[b]{2}{*}{ Independent Variable } & \multirow[b]{2}{*}{$\begin{array}{c}\text { Hypotheses } \\
\text { (Expected Signs) }\end{array}$} & \multicolumn{3}{|c|}{ Model 1} & \multicolumn{3}{|c|}{ Model 2} \\
\hline & & Coef. & & Sig. & Coef. & & Sig. \\
\hline Constant & & 1.11 & $(.06)$ & $* * *$ & 1.11 & $(.06)$ & $* * *$ \\
\hline \multicolumn{8}{|l|}{ CSR types } \\
\hline $\begin{array}{l}\text { SD-CSR } \\
\text { OD-CSR }\end{array}$ & $\begin{array}{l}\mathrm{H}_{2}(-) \\
\mathrm{H}_{3}(+)\end{array}$ & $\begin{array}{r}-.02 \\
.40\end{array}$ & $\begin{array}{l}(.08) \\
(.08)\end{array}$ & $* * *$ & $\begin{array}{r}-.10 \\
.41\end{array}$ & $\begin{array}{l}(.08) \\
(.07)\end{array}$ & $* * *$ \\
\hline \multicolumn{8}{|c|}{ Moderators and interactions } \\
\hline $\begin{array}{l}\text { CSI proneness } \\
\text { SD-CSR } \times \\
\text { CSI proneness }\end{array}$ & $\mathrm{H}_{4}(+)$ & .45 & $(.46)$ & & $\begin{array}{r}.27 \\
3.57\end{array}$ & $\begin{array}{l}(.44) \\
(1.02)\end{array}$ & $* * *$ \\
\hline $\begin{array}{l}\text { OD-CSR } \times \\
\text { CSI proneness }\end{array}$ & $\mathrm{H}_{5}(+)$ & & & & 2.67 & $(1.27)$ & $* *$ \\
\hline $\begin{array}{l}\text { CSI externalization } \\
\text { SD-CSR } \times \\
\text { CSI externalization }\end{array}$ & $\mathrm{H}_{6}(-)$ & -.15 & $(.03)$ & $* * *$ & $\begin{array}{r}-.13 \\
.24\end{array}$ & $\begin{array}{l}(.03) \\
(.15)\end{array}$ & $* * *$ \\
\hline $\begin{array}{l}\text { OD-CSR } \times \\
\text { CSI externalization }\end{array}$ & $\mathrm{H}_{7}(-)$ & & & & -.18 & $(.09)$ & $* *$ \\
\hline \multicolumn{8}{|l|}{ Control variables } \\
\hline R\&D intensity & & 2.63 & $(.24)$ & $* * *$ & 2.63 & $(.25)$ & $* * *$ \\
\hline Advertising intensity & & 1.54 & $(.42)$ & $* * *$ & 1.56 & $(.42)$ & $* * *$ \\
\hline Financial leverage & & -.23 & $(.09)$ & $* * *$ & -.23 & $(.08)$ & $* * *$ \\
\hline Firm size & & -.02 & $(.02)$ & & -.02 & $(.02)$ & \\
\hline Industry concentration & & -.39 & $(.20)$ & ** & -.38 & (.19) & ** \\
\hline CSI intensity & & -.31 & (.19) & * & -.35 & (.21) & * \\
\hline CSI severity & & -.01 & $(.03)$ & & -.00 & $(.03)$ & \\
\hline Inverse Mills ratio & & 2.11 & $(.25)$ & $* * *$ & 2.08 & $(.24)$ & $* * *$ \\
\hline C_SD-CSR & & -.02 & $(.01)$ & & -.01 & $(.01)$ & \\
\hline C_OD-CSR & & -.08 & $(.01)$ & $* * *$ & -.08 & $(.01)$ & $* * *$ \\
\hline$\sigma_{\delta}$ & & .89 & $(.01)$ & $* * *$ & .89 & $(.01)$ & $* * *$ \\
\hline$\sigma_{v}$ & & .67 & $(.01)$ & $* * *$ & .67 & $(.01)$ & $* * *$ \\
\hline Log likelihood & & -16 & 435.29 & & -16 & 425.22 & \\
\hline Wald chi-square & & & 079.18 & $* * *$ & &, 528.47 & $* * *$ \\
\hline $\begin{array}{l}\text { Akaike information } \\
\text { criterion }\end{array}$ & & & 942.59 & & & 930.44 & \\
\hline $\mathrm{N}$ & & & 13,411 & & & 13,411 & \\
\hline
\end{tabular}

$* p<.10 ; * * p<.05 ; * * * p<.01$.

Notes: Coefficients are unstandardized. Standard errors are in parentheses. For the analysis, we use bootstrap standard errors with 200 repetitions (Burmester et al. 2015; Park and Gupta 2012). Time dummies are included in the model but not reported. To avoid a large reduction of sample size owing to firms' nondisclosure of advertising and R\&D spending in the Compustat database, we included two separate dummy variables that equal 1 if advertising $(R \& D)$ spending information is disclosed and 0 if respective information is not disclosed (Luo and Bhattacharya 2009). 
Figure 3: Moderating Role of CSI Proneness for CSR Types

\section{A: Moderating Effect of CSI Proneness for SD-CSR}

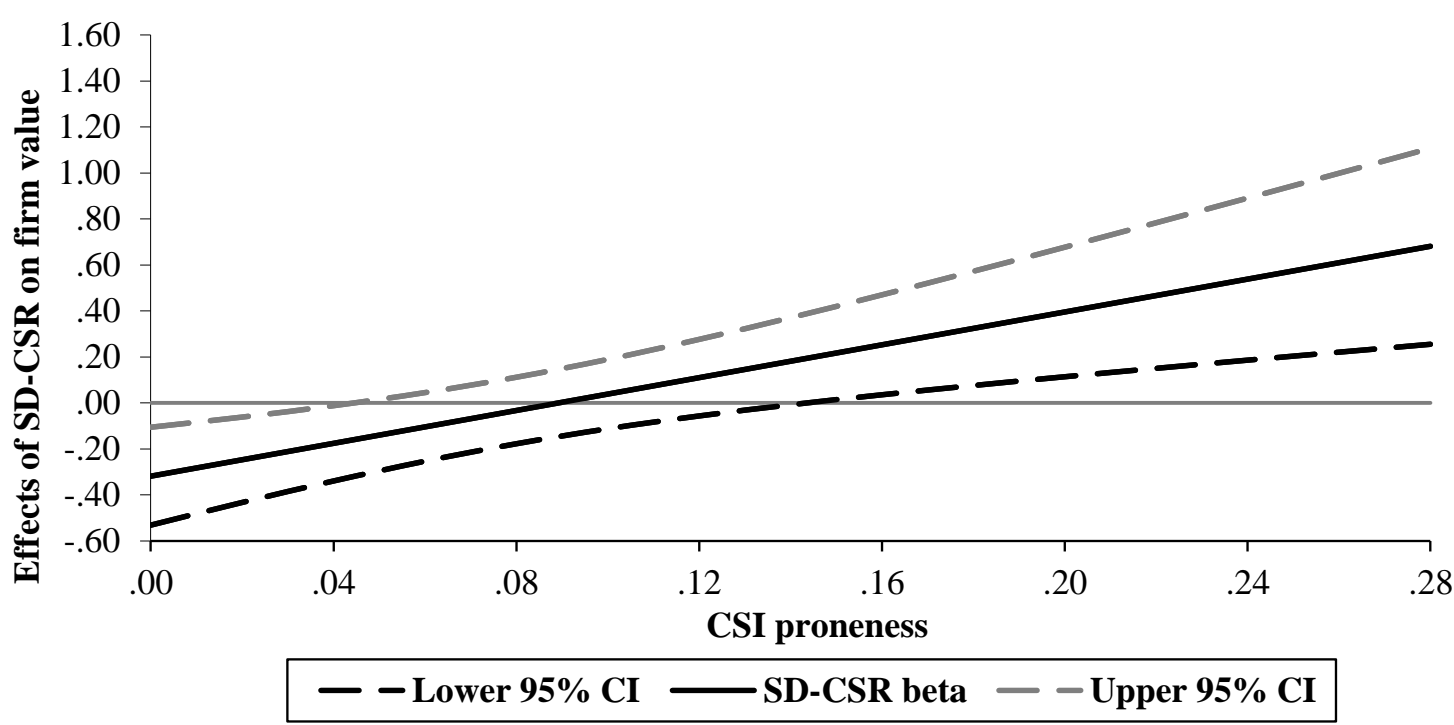

B: Moderating Effect of CSI Proneness for OD-CSR

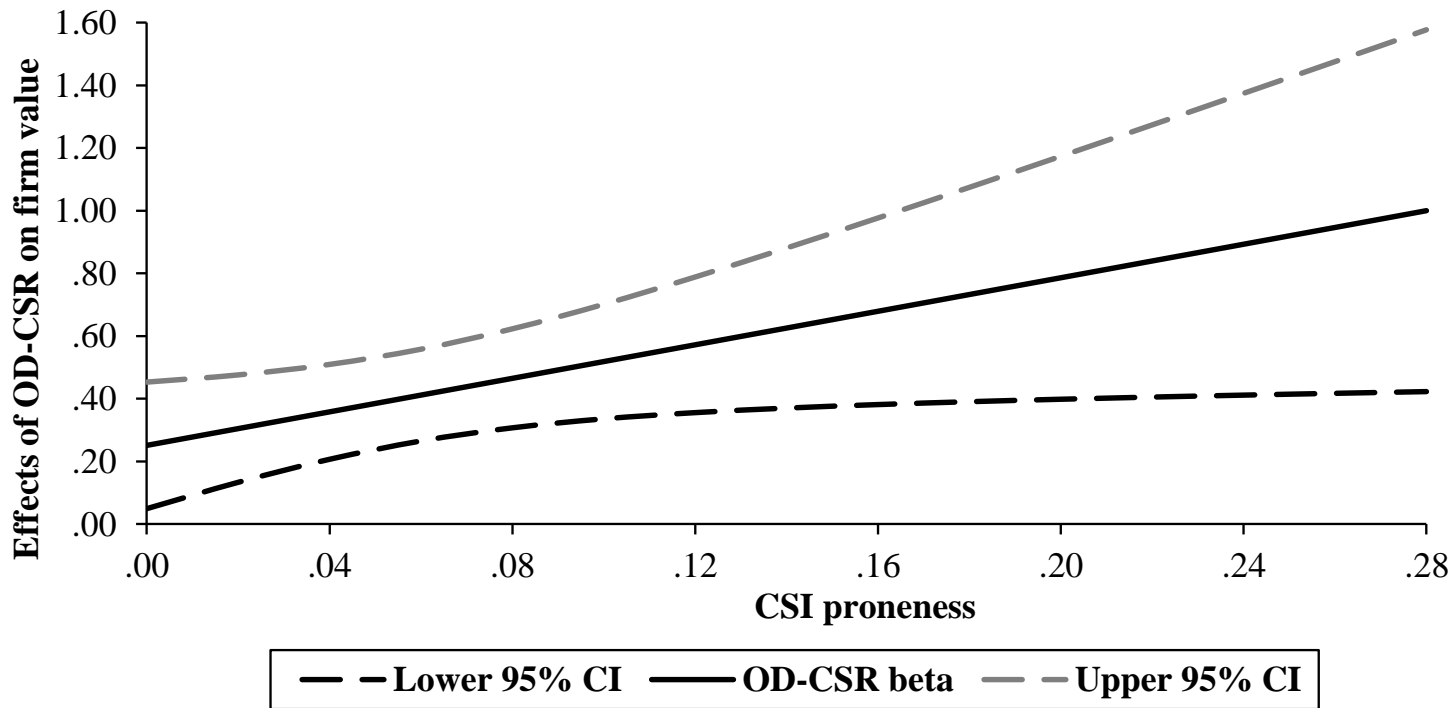

Notes: The effects of CSR types on firm value shown in the graphs are based on the estimates of the floodlight analysis. For ease of understandability, we retransformed the mean-centered values of CSI proneness. 


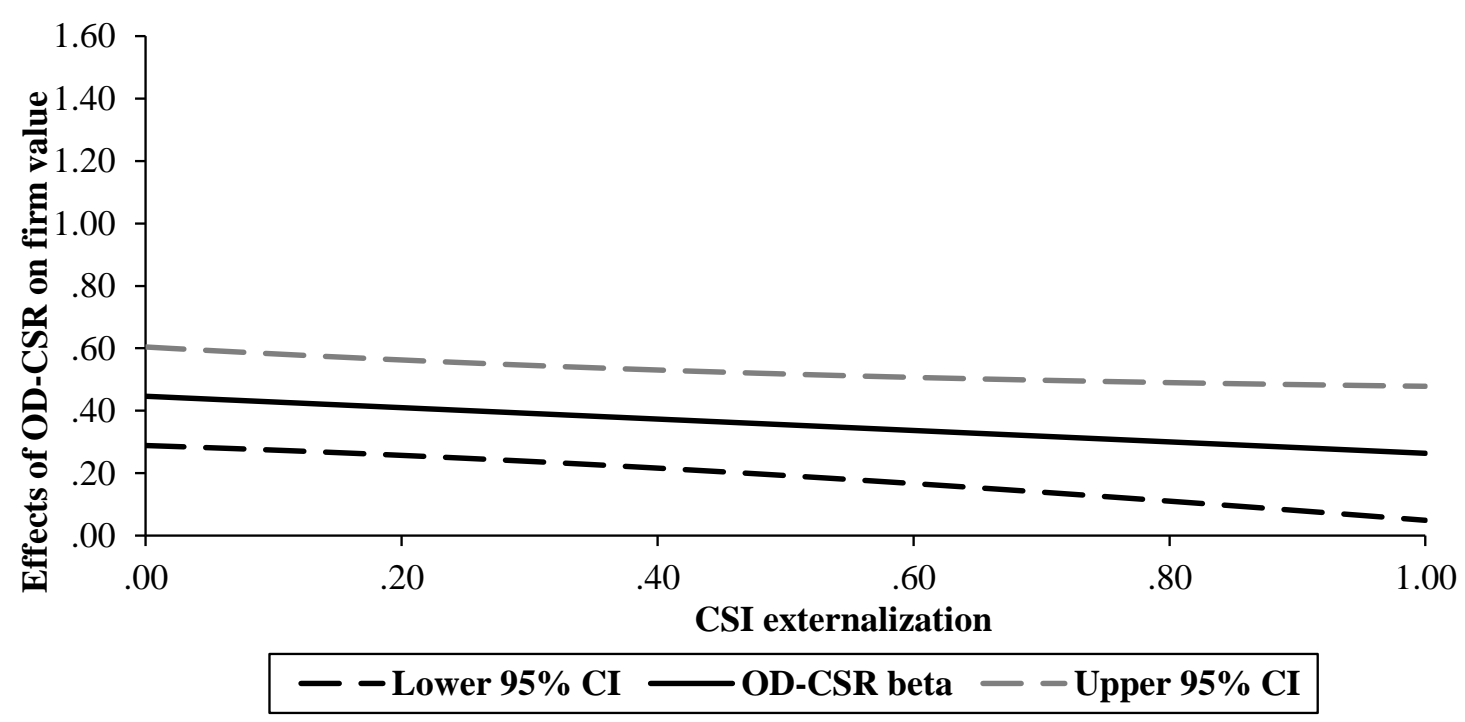

Notes: The effect of OD-CSR on firm value is based on the estimates of the floodlight analysis. For ease of understandability, we retransformed the mean-centered values of CSI externalization.

Robustness checks. To further enhance the validity of the findings, we conducted holdout sample validation. Given that the purpose of the model is descriptive or normative rather than predictive, we aim to demonstrate estimation consistency rather than prediction accuracy (Ebbes, Papies, and Van Heerde 2011). We split our sample into a holdout sample that involves the last four years and an estimation sample that involves the remaining earlier periods. We then estimate the model for the estimation sample and we predict the Tobin's q values for both samples on the basis of these estimates. We evaluate the relative estimation versus holdout sample performance by comparing correlation coefficients between the observed and predicted Tobin's q values of both samples. We find a correlation of .31 (.44) for the holdout sample (estimation sample), which indicates that model estimates produce consistent results regardless of the sampled time period. 
Further, by measuring all concerns in binary terms, KLD does not explicitly allow differentiation of less severe concerns from more severe concerns. Please note that we introduced the control variable CSI severity to address this problem, based on whether concerns included substantial fines and civil penalties. However, in addition, to enhance confidence that the results are not driven by the severity of specific CSI incidents, we selected a sample with firms that faced at least one minor CSI incident and recalculated SDCSR and OD-CSR, CSI intensity and CSI externalization based solely on minor CSI incidents. We then reran the analysis, offering a more conservative test of the theorizing. All results remained the same.

\subsubsection{Study 2b: Discussion}

Building on the finding of Study 2 a that CSR is financially devalued when CSI occurs, Study $2 \mathrm{~b}$ delivers insight on how firms should engage in CSR in such contexts. Bolstering notions in CSR research that the financial performance effects of CSR are not uniform (Barnett 2007), the results of Study $2 b$ demonstrate that distinguishing between SD-CSR and OD-CSR with respect to CSI context helps to disentangle the positive, neutral, and negative firm value effects of doing good. Study 2 b shows that under certain circumstances, managers indeed face a dilemma when engaging in CSR in the context of CSI, but adjusting the CSR with CSI pattern helps solve the dilemma.

\subsection{Study 2: Discussion}

In this study, we elaborate on the role of CSI and CSI context in creating firm value effects of CSR initiatives. We first theorize and demonstrate that CSI is accompanied by decreased financial returns for CSR. We then make a conceptual differentiation between distinct approaches to engage in CSR (i.e., SD-CSR and OD-CSR) when CSI occurs. We show that 
SD-CSR has no effect on firm value, but all else equal, OD-CSR significantly enhances firm value. However, the results also point to the important role of CSI context, as they demonstrate that the choice between SD-CSR and OD-CSR can be decisive for whether CSR engagement is beneficial, has no effect on firm value, or even becomes harmful. These results come with important implications for researchers and practitioners.

\section{Theoretical Implications}

This study has several interesting implications for CSR researchers. These implications are conceptual and theoretical in nature.

Conceptually, although only a few studies have actually examined the two constructs in parallel (e.g., Jayachandran et al. 2013), previous research emphasizes that CSR and CSI are distinct constructs that should not be commingled in an overall CSR construct (Kang, Germann, and Grewal 2016). We provide an initial empirical backing for these recommendations. The significant interaction effect between CSR and CSI on firm value implies that commingling CSR and CSI into one measure leads to neglecting undesirable cross-over effects and thus may draw an overly positive picture of CSR's firm value implications. A more straightforward implication of our study is that researchers should not only examine CSI and CSR as distinct constructs in parallel but should also consider that the firm value effects of CSR activities interact with CSI.

Further, by deriving CSR types on the basis of whether they address domains affected by CSI, we pursue the spirit of the scarce but seminal research that has offered a conceptually founded differentiation of CSR ( e.g., primary vs. secondary CSR enagagement; Godfrey et al. 2009). Such an approach to CSR differentiation is helpful because it avoids the perils of extremes while exploiting their benefits. 
On the one end, researchers have focused on an undifferentiated CSR measure that blends all CSR activities into one construct (e.g., Servaes and Tamayo 2013). However, such an aggregated measure reduces the richness of the data and implies that more effective CSR activities can cancel out less effective activities, masking potential differences between them (Rowley and Berman 2000). On the other end, studies have disaggregated CSR activities with respect to the CSR domains addressed, but these studies often do not find significant effects of the CSR domains on firm value (Jayachandran, Kalaignanam, and Eilert 2013; Mishra and Modi 2016). Scholars assert that some CSR domains, for instance the environment and community domains, are not easy for stakeholders to identify and interpret (Jayachandran et al. 2013; Wang et al. 2008). Thus, a lack of significant effects might result from an overly disaggregated view that cognitively overwhelms stakeholders when they have to evaluate CSR engagement for a multitude of single domains. A conclusion can be that, while still distinguishing CSR types, these differentiations should follow conceptual rather than pragmatic considerations and establish a moderately aggregated level to capture the theoretical aspect that drives stakeholders' CSR evaluations.

As we can show that SD-CSR and OD-CSR differ substantially in their firm value implications, we encourage further research to think of other conceptual differentiations between a firm's CSR engagements such as, for instance, differentiations based on their alignment with a firm's product offering, a firm's marketing strategy, or a firm's overall philosophy.

With regard to theory, this study has two implications that bolster the appropriateness of IST by spotlighting aspects of IST that researchers have scarcely considered. First, the arguments we have put forward, together with the empirical findings, help to establish IST as a useful theory not only for explaining the main effect of CSR on financial performance 
(which has been the focus of prior IST applications) but also for understanding how CSR and CSI interact. IST suggests that a firm's ability to establish trusting stakeholder relationships through CSR is influenced by stakeholders' perception of opportunistic firm behavior (Jones 1995). Given that CSI can be perceived as opportunistic firm behavior, by showing that CSI and CSR interact significantly we offer initial empirical evidence for this largely overlooked tenet of IST.

Likewise, IST suggests that CSR types can differ in their potential to establish trusting firm-stakeholder relationships that boost a firm's financial performance (Jones 1995), but remains silent as to the CSR types this applies to. By theorizing on (in)consistency perceptions of stakeholders within the IST framework, we are able to identify two such CSR types: SD-CSR and OD-CSR. Given that both engagements have unique financial implications, the results increase the managerial relevance of considerations that are based upon IST.

We also respond to calls to advance the understanding of the contingency factors in the CSR-financial performance link (Luo and Bhattacharya 2006, 2009). Our results extend current research on the contingency factors of CSR by establishing the important role of CSI context (e.g., CSI proneness and CSI externalization) and thus help to foster the contingency perspective in the CSR-financial performance link.

Lastly, our results extend the findings of Kang, Germann, and Grewal (2016). In that study, the authors showed that CSR is a fruitless endeavor for offsetting CSI in general. By disaggregating CSR types and considering CSI context, our investigation reveals that CSR only works if it taps into another domain than CSI or if it is directed at CSI-prone industries. Overall, our results deliver first answers to the recently raised questions in CSR research as to how and when CSR contributes to the firm's bottom line (Mishra and Modi 2016). 


\section{Managerial Implications}

Practical evidence of CSR failures shows that CSR actions are often ineffective or even backfire because, despite the firm's best intentions, their meanings to stakeholders are not well thought through (Browne and Nuttall 2013). Particularly, firms with CSI face hard times because their subsequent CSR engagements may lead to unfavorable stakeholder reactions (Lynn 2015). Indeed, we show that this concern is warranted as the occurrence of CSI diminishes the ability of CSR to enhance firm value. A direct implication is that managers should not view their CSR engagements as isolated from CSI occurrence because stakeholders do not do so.

However, the results also indicate that not throwing all CSR activities into one pot can help managers to allocate resources to CSR engagements that are financially rewarded rather than punished in light of CSI. Specifically, we suggest that managers classify their CSR engagement into SD-CSR and OD-CSR. From a managerial point of view, deciding between the two is not trivial. For instance, managers may argue that stakeholders expect SD-CSR as compensation or may perceive it as a hypocritical attempt to wash away the firm's sins, with opposing implications for firm value. Similar considerations can be made for OD-CSR. Across the sample period, Figure 5 demonstrates that for managers, whether SD-CSR or ODCSR is more beneficial is not at all intuitive. Alarmingly, the majority of firms made suboptimal or even detrimental decisions: $11 \%$ of firms have prioritized SD-CSR, $22 \%$ have engaged in both CSR types, and $29 \%$ have decided not to engage in any CSR at all. Only a minority of these firms (38\%) engaged in financially beneficial OD-CSR.

The study further reveals that considering CSI context can change the appropriateness of the choice of CSR type(s) discussed above. Our findings suggest that managers should keep an eye on their industry's CSI level. When the firm's industry peers are tainted by CSI, 
the firm is in the rare situation of being financially rewarded from stakeholders for both SDCSR and OD-CSR. For our sample, this holds true for "problem industries" such as metal mining, tobacco products, agricultural production crops, and petroleum refining industries. While these industries often worry about potential skepticism when engaging in CSR activities, our results actually indicate that they have the highest freedom to choose a CSR activity as both SD-CSR and OD-CSR pay off, albeit to different degrees. On the flip side, in industries with low CSI proneness (e.g., personal services, educational services, or engeneering, accounting, research, and management), managers should be aware that SDCSR becomes dangerous and backfires on firm value. Firms in industries with moderate CSI proneness (e.g., chemicals and allied products, or industrial and commercial machinery and computer equipment) cannot expect to be financially rewarded for SD-CSR. However, they also need not fear that such engagements will conflict with financial goals. Overall, SD-CSR is a risky undertaking that can result in positive or negative firm value consequences as well as no consequences, and thus should be very well thought through.

Our study further suggests that OD-CSR is a promising investment in every context. While managers certainly need to adjust their expectations regarding the financial reward of OD-CSR up- or downwards depending upon context, they can be sure of gaining a positive reward by engaging in OD-CSR. With higher CSI proneness managers can expect leveraged financial effects for OD-CSR. When CSI externalization is high, OD-CSR's firm value effect shrinks. 


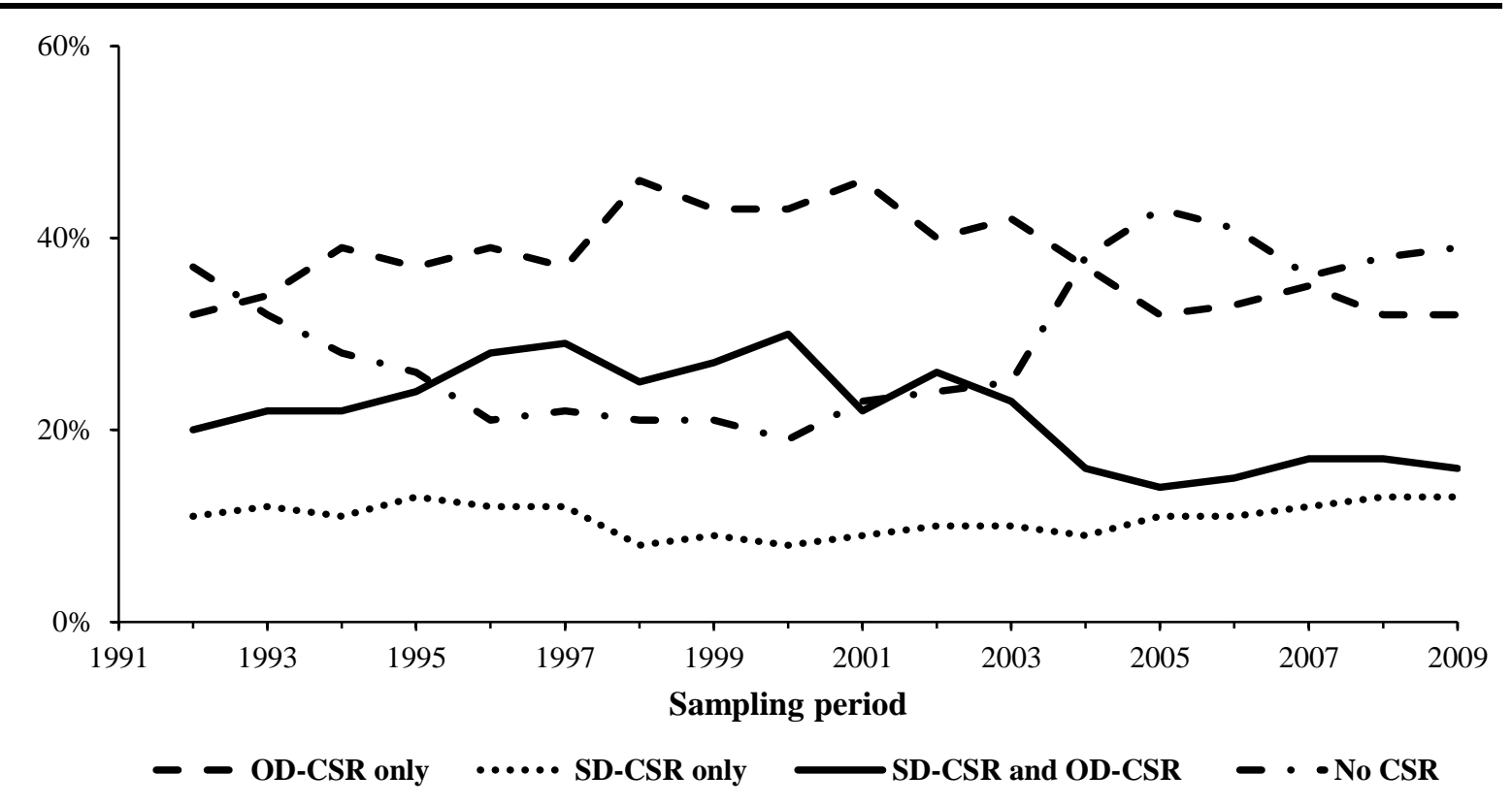

Notes: The sample contains all firm observations from the Kinder, Lydenberg, and Domini database used for Study $2 b(N=13,411)$. Specifically, the sample only contains firm observations with CSI.

\section{Limitations and Future Research}

While our research sheds new light on the CSR-firm value relationship, it has certain limitations that provide avenues for future research. Although the findings are fairly consistent with our theoretical framework, like all other CSR research that uses secondary data to focus on the firm value effects of CSR, we did not directly test the underlying theoretical mechanism (e.g., Godfrey et al. 2009; Jayachandran et al. 2013). While there is initial evidence for such mechanism (Homburg, Stierl, and Bornemann 2013), future research could use experimental and survey methods to test the theoretical mechanism that underlies our argumentation more explicitly. Further, while the KLD data serve as the de facto standard for capturing CSR and CSI in research and are unique in providing ratings of strengths and concerns across the most important domains and across a long time period (Strike, Gao, and 
Bansal 2006), the significant advantages come at a price. For instance, the binary measures offered by KLD do not allow for differentiation between items in terms of their social

relevance. We are the first to address this issue by controlling for CSI severity and by replicating the results while excluding major concerns. However, future research should propose alternative ways to deal with this challenge. Lastly, we note that our sample comprises only publicly held firms, which are naturally confronted with pressure from shareholders and the public to manage CSR.

\section{Conclusion}

In the presence of CSI, CSR engagement can be perceived as insincere, which could create a social responsibility dilemma for practitioners: both refraining from CSR and engaging in CSR may be ill-advised in terms of firm value effects. The findings of our study indicate that managers indeed face such dilemma in some contexts and that this dilemma can be solved by differentiating between SD-CSR and OD-CSR and by considering the CSI context. The results hold value for both firms and society. Firms benefit from the findings because the results show that even in the face of CSI, aligning doing good with doing well is possible. Society gains from the findings because it benefits from firms' continuous CSR efforts. 



\section{Firm Value Effects of Different CSR Types: The Role of Strategic Emphasis}

(with Hauke Wetzel and Maik Hammerschmidt) ${ }^{20}$

To be submitted to Journal of Marketing Research.

A prior version of the manuscript is published as:

Firm Value Effects of Stakeholder Welfare Protection and Enhancement: The Role of Marketing Levers, in: Proceedings of the 45th EMAC Conference, Oslo, Norway, 2016.

Keywords:

corporate social responsibility, value appropriation, value creation, strategic emphasis, firm value

\footnotetext{
${ }^{20}$ This paper was created in cooperation with the listed co-authors. I was responsible for the literature review, the contribution statement, the conceptual framework, the theoretical foundation, the hypotheses development, the data management, the methodology, the empirical analysis, and the implication section. My coresponsibilities comprised the positioning of the paper.
} 


\subsection{Study 3: Introduction}

Corporate social responsibility (CSR) — firm action that links to the fulfillment of stakeholder or societal obligations (Brown and Dacin 1997; Sen and Bhattacharya 2001) — has become an integral part of business ranking among the top three CEO priorities (McKinsey \& Company 2014) and CEOs view consumers as the most important stakeholder group affecting how CSR is managed (Accenture 2010). These facts align well with a nearly-universal consumer demand for CSR. According to a recent global survey, around $90 \%$ of consumers would buy products from a socially responsible firm and also stop buying products of an irresponsible firm (Cone 2015). Importantly, consumers are not only influenced by whether the firm considers their own interests, they also look at whether the firm behaves socially responsible towards other stakeholders such as employees, communities, or society at large (e.g., Sen and Bhattacharya 2001). How CSR engagement affects consumer behavior is key for explaining shareholders' valuation of CSR (Schuler and Cording 2006; Servaes and Tamayo 2013).

However, managers often lack guidance of appropriate CSR activities that lead to favorable shareholder evaluation. Together with the large variety of possibilities to engage in CSR, firms often create a mixture of uncoordinated CSR activities that provide no benefits to consumers and thereby hamper the greatest opportunities to benefit business (Porter and Kramer 2006). For distinguishing CSR activities, two key dimensions have emerged in literature constituting different types of CSR. One dimension refers to whether CSR fulfills societal obligations by contributing to the well-being of society (i.e., doing good) or by preventing harm (i.e., avoiding bad; Lin-Hi and Müller 2013). Another dimension refers to whether CSR is targeted at primary stakeholders (e.g., employees) or secondary stakeholders (e.g., communities; Clarkson 1995; Godfrey, Merrill, and Hansen 2009). To avoid that CSR becomes an unproductive hodgepodge of some of those activities, firms are under increased 
pressure to decide on the right CSR initiatives. As a guidepost for informing this decision, a firm's marketing strategy seems to be a very obvious and natural candidate because a firm's branding and innovation efforts can help to accentuate the benefits that consumers receive from CSR engagement (Luo and Bhattacharya 2006). Although aligning CSR with a firm's marketing strategy is pivotal, a McKinsey survey among CEOs reveals that half of the CEOs fail to integrate CSR decisions into marketing strategy (Bielak, Bonini, and Oppenheim 2007).

Given this lack, the goal of this research is to arm firms with knowledge on which type of CSR engagement aligns best with their marketing strategy. Due to restricted firm resources, the trade-off between value creation (i.e., development of new products through R\&D) and value appropriation (i.e., brand building through advertising) has frequently been regarded as an important strategic task in marketing (Josephson, Johnson, and Mariadoss 2015; Mizik and Jacobson 2003). This trade-off between value creation and value appropriation has been coined as strategic emphasis (SE; Mizik and Jacobson 2003). Therefore, in this study we examine the moderating role of a firm's SE for firm value effects of distinct CSR types. For differentiating CSR types, we draw on the two dimensions introduced above separately and hence consider obligation-based CSR types (i.e., doing good and avoiding bad) and stakeholder-based CSR types (i.e., primary CSR and secondary CSR). Importantly, we also differentiate CSR types by combining both dimensions leading to a more granular, integrative approach for CSR differentiation.

Our general theorizing suggests that shareholders' valuation of CSR depends upon the associated agency costs for CSR due to an eventual managerial misallocation of firm resources (Friedman 1970) and the benefits that CSR creates for consumers (Homburg, Stierl, and Bornemann 2013). We further argue that a firm's SE is pivotal for determining whether 
the consumer benefits from CSR outweigh the agency costs for CSR and thus whether the CSR types examined in this research influence firm value positively or negatively.

By accounting for multiple sources of endogeneity in our econometric model, the results reveal that, irrespective of the approach used for differentiating CSR types, none of the CSR types has a significant main effect on firm value. Concerning the moderation of SE, we find significant effects for doing good and avoiding bad but no effects for primary and secondary CSR. When we examine CSR types distinguished by both dimensions simultaneously, we only find significant moderating effects of SE for doing good activities addressing secondary stakeholders (i.e., secondary doing good) and avoiding bad activities targeting primary stakeholders (i.e., primary avoiding bad). In detail, secondary doing good increases firm value when a firm emphasizes value appropriation, whereas firms that focus on value creation are financially better off with primary avoiding bad.

\subsection{Study 3: Literature Review and Contributions}

For more than three decades, the relationship between CSR and financial performance has been subject to intensive examination in scholarly research. Nevertheless, the empirical findings rather leave an ambiguous picture on whether CSR contributes to firm financial performance with evidence for a positive, a neutral, and even a negative relationship (Margolis, Elfenbein, and Walsh 2009; Orlitzky, Schmidt, and Rynes 2003; Wang, Dou, and Jia 2015). Such fragmented evidence rather fuels than relieves the tension between society and business and shatters the belief in a universal CSR-financial performance relationship in which pursuing CSR in general gets financially rewarded in an unconditional fashion (Barnett 2007). Thus, the debate in CSR research has shifted from whether CSR per se aligns financially to which CSR activities pay back and when. For addressing these questions, 
scholars started to examine different CSR types and the pivotal role of marketing strategy as boundary condition for capitalizing on CSR.

Examination of different CSR types. Studies have approached the differentiation of the CSR construct from two perspectives. Recent studies provide seminal insight by distinguishing doing good and doing bad instead to use an overall CSR performance measure in which the latter is subtracted from the former (Kang, Germann, and Grewal 2016). Lin-Hi and Müller (2013) argue that avoiding bad is an "indispensable part of the social responsibility of companies" (p. 1928), and thus conceptual research recommends to explicitly consider avoiding bad beyond doing good (Campbell 2007; Lin-Hi and Müller 2013). Other studies focus on more nuanced CSR facets. While most of this work follows a pragmatic differentiation by merely assigning CSR initiatives to the domains in which they are accomplished (e.g., environmental CSR, charitable CSR; Jayachandran, Kalaignanam, and Eilert 2013; Mishra and Modi 2016), the only well-established conceptually founded classification of CSR refers to distinguishing between primary and secondary stakeholderrelated CSR (Godfrey, Merrill, and Hansen 2009; Luo et al. 2015). To the best of our knowledge, there is no study that integrates both approaches that is the separation between avoiding bad and doing good, along with a differentiation between primary and secondary stakeholder targets.

Marketing-related contingency factors. Several studies consider the role of the marketing function by examining a firm's value creation (i.e., R\&D, innovativeness) and value appropriation efforts (i.e., advertising; Luo and Bhattacharya 2006, 2009). For instance, advertising has been found to be a conditional factor for the influence of CSR on firm value as it ensures the awareness for CSR among customers (Servaes and Tamayo 2013). Furthermore, innovativeness ensures that consumers view CSR as a legitimate firm 
investment enhancing firm value (Luo and Bhattacharya 2006). In their seminal study, Luo and Bhattacharya (2009) find that CSR in tandem with either advertising or R\&D mitigates a firm's idiosyncratic risk while pursuing advertising and R\&D together with CSR increases risk (Luo and Bhattacharya 2009). Aligning with the idea in marketing literature that firms must prioritize between value creation and appropriation due to limited firm resources (Mizik and Jacobson 2003), such finding suggests that a firm should focus either advertising or R\&D for reaping financial benefits from CSR, but it remains unclear which emphasis aligns best with CSR. Taken all findings together, both value creation and value appropriation efforts should positively influence the relationship between CSR and firm value when considered in isolation. However, although the findings of Luo and Bhattacharya (2009) indicate the importance to make trade-offs between value creation (i.e., R\&D) and value appropriation (i.e., advertising), none study has taken a relative view on both and thereby examined whether a firm's trade-off between both interplays with CSR for deriving firm value.

Contributions. To address both gaps in CSR literature, we differentiate CSR types along both conceptual dimensions separately and combined and examine the moderating role of strategic emphasis (i.e., a firm's trade-off between value creation and value appropriation) in the relationship between these CSR types and firm value. We provide several contributions for CSR research.

In general, by showing that SE determines whether CSR has any impact on firm value, our research helps strengthening prior studies' seminal findings on the critical role of the marketing function in the CSR-firm value relationship (Mishra and Modi 2016; Servaes and Tamayo 2013). More specifically, our study extends prior research that has established an (overly) positive picture on the moderating role of value creation and value appropriation. 
By revealing that a wrong strategic emphasis between both can destroy shareholder wealth for some CSR activities, we detect limits for the effectiveness of marketing efforts.

By comparing approaches for the differentiation of CSR, our research gives concrete advice which differentiation approach is more fruitful, and also points to the hazards that some CSR approaches bear. We demonstrate that the choice of the appropriate differentiation approach can be decisive for detecting a moderating relationship at all and for unmasking the precise relationship. Our findings show that a distinction of CSR on a relatively aggregated level between doing good and avoiding or between primary and secondary stakeholderrelated CSR can lead to wrong conclusions on the moderating role of SE. Using a combination of both dimensions to conceptualize CSR types however enables to capture the moderating role of SE for CSR's effectiveness more precisely and thus helps guiding managers' decisions on financially beneficial initiatives, and importantly, helps to avoid wrong or no CSR engagement.

\subsection{Study 3: The Agency Cost and Benefit Perspective on CSR}

Much like the equivocal empirical evidence on the CSR-firm value relationship, literature views CSR's contribution to the bottom line from various opposing theoretical lenses, whereby agency theory and stakeholder theory are the dominant theoretical underpinnings. Both allow viewing CSR from contrary perspectives, either as managerial misallocation of firm resources that result in agency costs or as benefits for consumers that enhance revenuegenerating purchase behaviors (Wang, Dou, and Jia 2015).

Agency cost perspective. According to agency theory (Jensen and Meckling 1976), CSR represents an agency problem. The theory suggests that managers are the agents of shareholders with the primary responsibility to act in shareholders' best interest that is to 
maximize firm value. A conflict of interests and objectives between both parties eventually exists because managers rather follow their own interests and thereby make unprofitable investments (Jensen and Meckling 1976). CSR can serve managers own interests as it improves their own social standing in the community, enhances their self-image, or relieves them from public pressure. As the potential for misuse on the part of managers is high for CSR (Barnett 2007; Mishra and Modi 2016), shareholders may view CSR as an unprofitable investment for managers' own sake that could have been spent for more profitable initiatives (Friedman 1970; McWilliams and Siegel 2001). For shareholders, such perception leads to monitoring managers' actions and decisions, which raises significant costs for shareholders (i.e., agency costs; Wright and Ferris 1997).

Benefit perspective. Contrary to the agency costs perspective, stakeholder theory (Freeman 1984) suggests that by considering the interests of stakeholders, CSR provides certain benefits for stakeholders that increase stakeholders' exchange with the firm which ultimately results in higher firm value (Jones 1995). Although CSR potentially benefits all stakeholders whose support transforms in higher firm value, particularly the impact of CSR on firm value though consumers has been well-researched albeit implicitly. Indeed, the benefits that CSR creates for consumers and the subsequent consumer-related outcomes have been the focus in the majority of CSR studies. The findings of these studies clarify that CSR benefits consumers by establishing trust in the firm and company-customer-identification that both lead to increased customer loyalty, purchase and recommendation behavior (Homburg, Stierl, and Bornemann 2013; Lichtenstein, Drumwright, and Braig 2004; Vlachos et al. 2008). The resulting customer equity is one of the main drivers of shareholder value (Rust, Lemon, and Zeithaml 2004; Schulze, Skiera, and Wiesel 2012; Srinivasan and Hanssens 
2009). Thus, the consumer-related outcomes are key for explaining the beneficial firm value effects of CSR (Servaes and Tamayo 2013) and we focus on consumers.

Net effect of agency costs and consumer benefits. While both theoretical lenses seem contrary and underline the controversy around the firm value effects of CSR, recent research suggests that these theoretical arguments are interwoven in that CSR always entails both agency costs for shareholders and benefits for consumers (Mishra and Modi 2016). Accordingly, CSR has a positive firm value effect when consumer benefits outweigh the agency costs and a negative impact on firm value when consumer benefits are lower than the agency costs. Recent studies however do not find a direct effect of CSR on firm value and they highlight that the marketing function is pivotal to capitalize on CSR. For instance, marketing can ensure the awareness for CSR among consumers and it helps to find out about stakeholder expectations and to respond to their needs with appropriate CSR engagement (Mishra and Modi 2016; Servaes and Tamayo 2013). Hence, the marketing function is the point of matter for whether CSR provides enough consumer benefits to exceed the agency costs. Decisions on the SE between value creation and value appropriation are at the heart of marketing decisions. Thus, we examine the moderating role of SE for firm value effects of CSR. As recent research found no main effect of CSR on firm value (Mishra and Modi 2016; Servaes and Tamayo 2013), we leave such effect to an empirical question.

\subsection{Study 3: The Role of Strategic Emphasis for Firm Value Effects of CSR Types}

CSR is defined as firm action that links to the fulfillment of stakeholder or societal obligations (Brown and Dacin 1997; Sen and Bhattacharya 2001). Such broad definition of CSR indicates that CSR is a multifaceted construct (Sen, Bhattacharya, and Korschun 2006). While prior research has mostly used a single aggregated CSR measure or has relied on 
examining a single CSR domain (e.g., Hull and Rothenberg 2008; Jayachandran, Kalaignanam, and Eilert 2013), the conflicting findings in the CSR-firm relationship suggest that the conceptualization of CSR as a single construct may be not sufficient to capture the complexity of the CSR-firm value link (Barnett 2007; Wang et al. 2016). From a consumer point of view, it seems natural that some CSR types provide more consumer benefits than others. CSR scholars thus suggest examining the firm value effects of different CSR types (Basu and Palazzo 2008). Importantly, a recent study shows that the marketing function moderates not every CSR engagement in their influence on firm value and thus a differentiation of CSR types makes particularly sense when examining the moderating role of marketing factors (Mishra and Modi 2016). Next, we discuss three CSR differentiation approaches.

\section{Three Approaches for Differentiating CSR}

As discussed in the literature and contribution section, current research suggests differentiating CSR along two dimensions. One dimension refers to how a firm addresses its obligations (Lin-Hi and Müller 2013). Another dimension refers to the different stakeholders that claim these obligations and which are therefore the major targets of the respective engagement (Godfrey, Merrill, and Hansen 2009). We describe the two CSR differentiation approaches that result from considering these dimensions separately and also introduce an integrative approach in which we combine both dimensions. Figure 6 summarizes the three CSR differentiation approaches and the resulting CSR types.

Obligation-based approach. The differentiation of CSR according to the obligationbased approach yields two mutually exclusive CSR types. By informing about how the firm fulfills its obligations to exert a positive impact on society and to minimize its negative impact, CSR refers to doing good or avoiding bad (Lin-Hi and Müller 2013). 
Doing good refers to the firm's discretionary activities that contribute to the wellbeing of stakeholders or society at large (Luo and Bhattacharya 2006; Mishra and Modi 2016). Because such engagement demonstrates the firm's friendliness and generosity (e.g., charitable giving), it transmits the firm's values that are central for a firm's identity. An identity that bases on doing good is enduring and anthropomorphic while the discretionary nature of doing good makes such identity particularly unique and distinct from competitors. All these attributes potentially make the firm a valid target for identification in the mind of consumers (Bhattacharya and Sen 2003; Du, Bhattacharya, and Sen 2007).

Avoiding bad refers to the firm's prevention of social controversies that would harm stakeholders or society at large elsewise (Campbell 2007; Lin-Hi and Müller 2013). Such engagement demonstrates compliance with stakeholder norms (e.g., greenhouse gases of the factories refer to standard values). Barney and Hansen (1994) argue that "an exchange partner worthy of trust is one that will not exploit other's exchange vulnerabilities“(p. 176). As avoiding bad demonstrates that the firm is not opportunistically and is not exploiting stakeholders' vulnerability, it can be a signal for a firm's trustworthiness. Such signals are critical to reduce consumers' potential uncertainty, for example with respect to product quality (Homburg, Stierl, and Bornemann 2013).

Stakeholder-based approach. Research has not only shown that consumers are influenced by CSR engagement that is directed to other stakeholders but also that consumerrelated outcomes vary across the stakeholder targets of CSR (Homburg, Stierl, and Bornemann 2013; Sen and Bhattacharya 2001). Thus, from a consumer perspective, a differentiation of CSR according to the immediate stakeholder targets of CSR is worthwhile. For such stakeholder-based differentiation, stakeholder theory provides a parsimonious and well-established distinction between primary and secondary stakeholders (Clarkson 1995; 
Godfrey, Merrill, and Hansen 2009). Primary stakeholders are those stakeholders that are in an exchange relationship with the firm and without whose the firm cannot maintain business and survive (e.g., consumers, employees, Clarkson 1995). These stakeholder groups have legitimate claims, the power to enforce these claims and their claims are urgent as they call for immediate attention (Mitchell, Agle, and Wood 1997). Secondary stakeholders are stakeholders that are not in a direct transaction relationship with the firm, therefore distant to the firm's core business and not essential for the firm's survival (e.g., environmental and human rights NGO's, local communities; Clarkson 1995). These stakeholders have only legitimate claims but neither power nor urgency to enforce these claims (Mitchell, Agle, and Wood 1997).

The differentiation of CSR by stakeholder targets yields two mutually exclusive CSR types. Primary CSR comprises CSR activities that target primary stakeholders. Such actions demonstrate ethical behavior within the firm's core business operations comprising topics on products and the treatment of employees (Homburg, Stierl, and Bornemann 2013). Secondary CSR refers to CSR activities that target secondary stakeholders. Such actions address goals outside the firm's business operations comprising activities that link to diversity, environmental stewardship, community relations, and human rights (Homburg, Stierl, and Bornemann 2013).

Integrative approach. Combining both dimensions yields four CSR types: primary/secondary doing good and primary/secondary avoiding bad. By combining doing good and avoiding bad with information on the stakeholder targets of the respective engagement, consumers obtain a clearer picture on whether it is worthwhile to identify with or to trust the firm. We suggest that particularly doing good addressing secondary stakeholders (i.e., secondary doing good) helps to trigger customer-company identification 
whereas avoiding bad towards primary stakeholders (i.e., primary avoiding bad) is more meaningful to elicit trust among consumers. We explain our reasoning below.

Secondary doing good refers to a firm's extraordinary and generous engagement that targets secondary stakeholders. Compared to primary stakeholders, secondary stakeholders cannot force the firm to behave in some manner and to satisfy their needs is not immediately important for the firm's business success. Thus, consumers refrain from viewing secondary doing good as the firm's self-interested attempt to induce themselves and other primary stakeholders to engage in behavior favorable for the firm. Instead, they view such engagement as evidence for the firm's voluntary and other-regarding orientation which reveals what the firm sincerely and genuinely values (Godfrey, Merrill, and Hansen 2009; Torres et al. 2012). By addressing secondary stakeholders, a firm thus shapes a more prestigious identity with doing good which more likely triggers the customer-company identification process as compared to engagement towards primary stakeholders (Homburg, Stierl, and Bornemann 2013).

Primary avoiding bad refers to avoiding harm to primary stakeholders. For consumers, primary avoiding bad shows that the firm is not opportunistically in a comparable context, i.e. towards other important business partners. Particularly, such context allows for trust generalizations. By addressing primary stakeholders, avoiding bad thus allows more precise conclusions on the firm's trustworthiness which increases the predictability of future firm behavior among consumers as compared to addressing secondary stakeholders that are not in a direct business relationship with the firm (Homburg, Stierl, and Bornemann 2013).

As one of our goals is to compare these CSR differentiations approaches, we empirically examine the firm value influence of CSR types derived from the three approaches. However, we suppose that a more fine-grained distinction of CSR according to 
the integrative approach yields more precise findings on the moderating role of SE. Given our argumentation above, we suggest that particularly secondary doing good and primary avoiding bad interact with SE in deriving firm value. We thus formulate hypotheses on these CSR types.

Figure 6: Three Approaches to Differentiate CSR

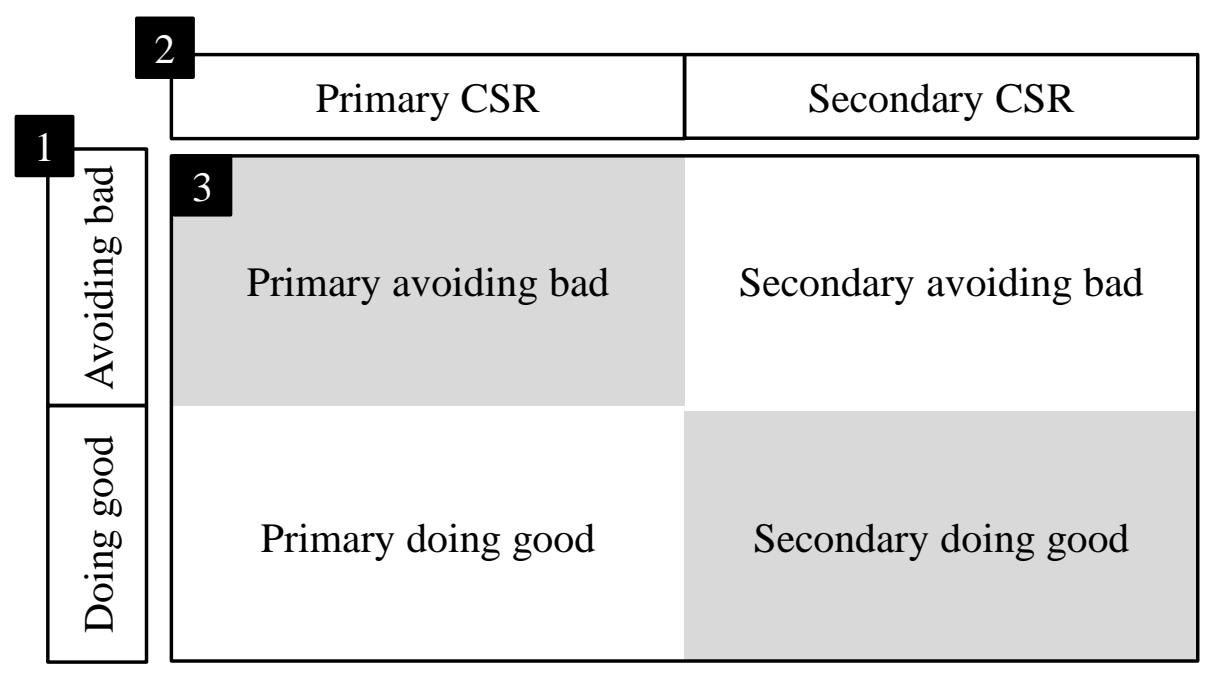

1 Obligation-based approach

2 Stakeholder-based approach

3 Integrative approach 


\section{Strategic Emphasis}

A firm's marketing strategy is shaped by two fundamental components that are value creation and value appropriation. Marketing scholars however suggest that firms rarely balance both components in their strategy (Josephson, Johnson, and Mariadoss 2015). Instead, firms prioritize one component whereby a firm has considerable scope in deciding the extent of emphasizing one over another (Mizik and Jacobson 2003). In keeping with extant literature, we define SE as a firm's trade-off between value creation and value appropriation (Mizik and Jacobson 2003; Swaminathan, Murshed, and Hulland 2008). The continuum of SE is anchored at one end by a focus on value creation and at the other end by a focus on value appropriation.

Value creation is concerned with the provision of superior products or improvements in the production processes which determines the magnitude of a firm's future advantage (Mizik and Jacobson 2003). In marketing literature, value creation is primarily connected to R\&D spending because it represents technical capital that fosters product and process innovations (Currim, Lim, and Kim 2012; Luo and Bhattacharya 2009). Value appropriation is concerned with the extraction of profits from existing products (Mizik and Jacobson 2003). A relevant component of value appropriation is advertising as it establishes barriers of imitation for competitors and thus influences the length of the firm's advantage (Currim, Lim, and Kim 2012; Luo and Bhattacharya 2009). Advertising in the sense of value appropriation is often brand-related as conveying strong brand image and associations helps to differentiate from competitors (Aaker 1991; Joshi and Hanssens 2010; McAlister et al. 2016).

Firms that emphasize value creation relatively more invest in innovative products on a long-term horizon which creates uncertainty in terms of whether the firm launches the new 
product at all, the quality of the new products, and their market success. In the meanwhile, competition may erode the profits from the existing products because the efforts on deploying their value is low (Currim, Lim, and Kim 2012; Mizik and Jacobson 2003). Firms that emphasize value appropriation relatively more focus on capitalizing existing products through conveying brand association. This eventually threatens the firm's longevity because current value may deteriorate due to over-extraction while future trends remain unexplored as the firm invests relatively less in creating new ideas (Gupta et al. 2006).

\section{Moderator Hypotheses}

Secondary doing good and strategic emphasis. Secondary doing good helps to form a prestigious identity which satisfies consumers' need for self-enhancement and self-esteem (Bhattacharya and Sen 2003). Emphasizing value appropriation suggests brand-related advertising in order to differentiate a firm's products from those of competitors. Making brand associations more aware through advertising enhances the likelihood that consumers become aware of the firm and its prestigious identity (Luo and Bhattacharya 2009). Only when identity salience is high, consumers can easily access attractive, self-relevant identity information (Bhattacharya and Sen 2003), compare their own values with those of the company and eventually feel an oneness with the company based on common values which

finally leads to customer-company identification (Sen, Bhattacharya, and Korschun 2006). Moreover, brand-related advertising creates unique brand associations in consumers' memory which form ties to consumers. These ties trigger consumers' cognitive efforts to think about whether own values align with the firm's values transferred by secondary doing good and reinforce the convergence of the value conceptions (Curras-Perez 2009). In other words, brand-related advertising enhances the chance that the values from secondary doing good align with consumers' values which triggers the identification process. Overall, we suggest 
that focusing on value appropriation helps secondary doing good to generate customercompany identification. Thus, a value appropriation focus enables that benefits for consumers outweigh the agency costs associated with secondary doing good leading to increased firm value.

When firms emphasize value creation relatively more in their marketing strategy, they invest in new products and services but do not inform about these products. Thereby, the firm disregards to inform consumers about the benefits and potential hazards of these products (Dutta, Narasimhan, and Rajiv 1999) which increases uncertainty about the performance of the new products (Claudy, Garcia, and Driscoll 2015; Posavac and Brakus 2005). As the functional value of the products is in question and unsure, consumers may give lower consideration to the firm's outstanding generosity towards stakeholders that are even not relevant for the firm's business (Sen and Bhattacharya 2001). Such engagement should fuel consumers' perceptions of misguided firm priorities. In a value creation setting, secondary doing good is not perceived as appropriate firm activity and unlikely to shape a prestigious identity in the mind of consumers and to elicit customer-company identification. In such setting, the identification benefits for doing good should be therefore lower than the agency costs leading to decreased firm value.

$\mathrm{H}_{1}$ : For firms with a SE on value appropriation (creation), secondary doing good increases (decreases) firm value.

Primary avoiding bad and strategic emphasis. For consumers, primary avoiding bad demonstrates that the firm is not acting opportunistically in a comparable context which serves as a precise signal for the firm's trustworthiness (Homburg, Stierl, and Bornemann 2013; Jones 1995). By prioritizing value creation relatively more, firms make substantial investments in new products and services about which consumers may not yet possess 
sufficient information (Mizik and Jacobson 2003). This leads to information asymmetry between firms and consumers. Because the functional benefits, and more importantly, the potential hazards of the product are uncertain, consumers face a higher perceived risk (Claudy, Garcia, and Driscoll 2015; Posavac and Brakus 2005). In such situations, trust is particularly required to reduce exchange uncertainty (Homburg, Stierl, and Bornemann 2013). Hence, consumers increasingly need to rely on cues signaling the firm's trustworthiness because they would indicate that the firm is reliable, competent and integer enough to provide products with sufficient functional benefits and safety standards. Because primary avoiding bad is a precise signal for the firm's trustworthiness, consumers intensively search for such information. The chance that primary avoiding bad indeed yield trust is therefore high in such context. Overall, with a value creation focus, the trust benefit that primary avoiding bad generates may outrun the agency costs associated with primary avoiding bad leading to increased firm value.

Pursuing value appropriation relatively more means to convey brand associations of a strong and trusted brand through advertising. Such brand associations strengthen brand image and quality perceptions, and thus consumers face little uncertainty concerning the performance of the product (Agarwal and Teas 2001). As consumers face smooth sailings on what to expect from the firm's products in a value appropriation setting, cues of trust are less important and thus consumers less likely search for primary avoiding bad as indicator of the firm's competence to produce high quality products. In turn, the chance that consumers draw on primary avoiding bad is low. Overall, by focusing on value appropriation, the trust benefit for consumers is lower than the agency costs associated with primary avoiding bad which leads to decreased firm value. 
$\mathrm{H}_{2}$ : For firms with a SE on value creation (appropriation), primary avoiding bad increases (decreases) firm value.

\subsection{Study 3: Data and Variables}

\section{Data Sources}

In this research, we combine data from two secondary data sources. We use data from the Kinder, Lydenberg, and Domini (KLD) data source to measure firms' socially relevant activities and we use data from the Compustat data source to measure firms' strategic emphasis, firm value and several finance-based control variables.

On an annual basis from 1991 to the present, KLD assesses publically available information on socially relevant activities of the largest publicly traded U.S. firms. Starting with the firms in the Standard \& Poor and the Domini 400 Social Index in 1991, the data source has broadened its scope to the members of the Russell 3000 index and currently contains more than 3,000 firms (Mishra and Modi 2016). By referring to clearly defined screening criteria, KLD ratings are unbiased and objective (Graves and Waddock 1994) and consistent and comparable across firms and industry over time (Groening, Mittal, and Zhang 2016).

The data source provides approximately 80 indicators that represent either strength (i.e., a doing good action) or concern (i.e., a doing bad action) indicators. A rating of "1" indicates the presence and a rating of " 0 " the absence of a strength or concern. These strength and concern indicators are assigned to multiple domains. We follow other studies and interpret KLD's employee, product, diversity, environment, human rights, and community domain as domains capturing socially relevant firm activities (Ailawadi et al. 2014; Chin, Hambrick, and Trevino 2013; Flammer 2015; McWilliams and Siegel 2000; Servaes and 
Tamayo 2013). ${ }^{21}$ Importantly, these domains allow to assign a firm's social behavior to its stakeholder targets (Mattingly and Berman 2006). For example, the work/life benefits strength indicator belongs to the employee domain and KLD assigns a "1" when the company has outstanding employee benefits or other programs addressing work/life concerns such as childcare, elder care, or flextime, and " 0 " if otherwise. For the retirement benefits concern indicator in the employee domain, KLD assigns a "1" when the company has either a substantially underfunded benefit pension plan or an inadequate retirement benefits program, and "0" if otherwise. Besides the prevalence of the KLD ratings for informing investment decisions of institutional investors and portfolio managers, KLD is also the most established data source in the academic management and marketing discipline for measuring CSR (Kang, Germann, and Grewal 2016; Mishra and Modi 2016). The complete list of indicators appears in the Appendix 1.

We use the KLD ratings from 1991 to 2009 as our initial sample. Because KLD has made significant methodological changes in 2010, this observation period avoids biased results (Kang, Germann, and Grewal 2016). After merging KLD data with the relevant data from Compustat and removing missing values, our final sample consists of 3,572 firms and 21,481 firm-year observations.

\section{Variable Construction}

One of our research goals is to compare three approaches to differentiate CSR. We thus integrate in our analysis all CSR types that can be derived based on the three CSR differentiation approaches (see Figure 6). The measurements for these CSR types base on

\footnotetext{
${ }^{21}$ We exclude the corporate governance domain because governance is a controlling mechanism for shareholders to ensure their return on investment, and thus, we do not consider it as socially relevant behavior (Servaes and Tamayo 2013).
} 
KLD data. We also explain how we measure firm value and the relevant control variables by Compustat data.

Doing good and avoiding bad. For measuring doing good, we use KLD's strength indicators in the employee, product, diversity, environment, human rights, and community domain (Servaes and Tamayo 2013). Because the number of indicators varies across domains and years, we scale the number of strengths for a firm within each domain by the maximum possible number of strengths within each domain in the respective year before summing these scaled domain-specific values (Flammer 2013). Because the maximum number of domains is 6, the index ranges from 0 to 6 . Lastly, we divide this index by the number of possible domains to obtain our final measure of doing good that is anchored by 0 and 1 . To construct avoiding bad, we utilize KLD's concern indicators in the same domains as for doing good. We likewise scale the number of concerns for a firm within each domain by the maximum possible number of concerns within each domain in the respective year (Flammer 2013; Servaes and Tamayo 2013). We subtract each scaled domain-specific value from 1 as to capture how many of the maximum possible concerns do not apply to the firm and hence were avoided. Again we sum them to an index ranging from 0 to 6 and divide it by the number of domains. The variable is then anchored by 0 and 1 .

Primary CSR and secondary CSR. We base our measurements of primary CSR and secondary CSR on prior literature. For measuring CSR in general, research has established a net measure between strengths and concerns (e.g., Hull and Rothenberg 2008). For the assignment of the relevant KLD domains according to whether they address primary or secondary stakeholders, we follow other studies and rely on the results of Mattingly and Berman's (2006) factor analysis (Godfrey, Merrill, and Hansen 2009; Luo et al. 2015). Accordingly, the employee and product domain reflect primary stakeholders, and the 
diversity, environment, human rights, and community domain reflect secondary stakeholders. To consider that the number of indicators varies across domains and years, we scale the number of strengths (concerns) within each relevant domain by the maximum possible number of strengths (concerns) within each domain in the respective year. We then subtract the scaled domain-specific concern values from the scaled domain-specific strength values (Deng, Kang, and Low 2013; Flammer 2013). For primary CSR, we only use the strength and concern values for the employees and product domain leading to an index between 0 and 2 . For secondary CSR, we use the strength and concern values for the diversity, environment, human rights, and community domain leading to an index between 0 and 4 . Lastly, to ensure comparability between primary and secondary CSR, we divide each index by the number of used domains to anchor the measurements by 0 and 1 .

Primary/secondary doing good and primary/secondary avoiding bad. For primary (secondary) doing good, we use KLD's strength indicators in the domains that we have identified as referring to primary (secondary) stakeholders. We also use the same domainspecific scaling procedure as for the other measures. Specifically, for primary (secondary) doing good, we scale the number of strengths for a firm within the employee and product (diversity, environment, human rights, and community) domains by the maximum possible number of strengths within each domain in the respective year. We then sum these scaled domain-specific values into an index ranging from 0 to 2 (4) and divide it by the number of used domains to obtain a measure that is anchored by 0 and 1 . For primary (secondary) avoiding bad, we use KLD's concern indicators in the domains that we have identified as referring to primary (secondary) stakeholders and also adopt the usual scaling procedure. In detail, for primary (secondary) doing bad, we scale the number of concerns for a firm in the employee and product (diversity, environment, human rights, and community) domains by 
the maximum possible number of concerns within each domain in the respective year (Deng, Kang, and Low 2013; Flammer 2013; Servaes and Tamayo 2013). We subtract each scaled domain-specific value from 1 and sum them to an index ranging from 0 to 2 (4). Dividing this index by the number of used domains ensures that primary (secondary) avoiding bad is anchored by 0 and 1 .

Firm value. We measure firm value as Tobin's q which is the ratio of the market value of a firm to the replacement value of a firm's assets. Values greater 1 reflect a more effective use of the firm's resources referring to a higher shareholder value, values equally 1 suggest no incremental value for the firm's assets and values lower 1 refer to an inefficient use of the firm's resources (Anderson, Fornell, and Mazvancheryl 2004). Tobin's q is a widely accepted firm value measure in the finance, management, and marketing literature (Bharadwaj, Bharadwaj, and Konsynski 1999; Chauvin and Hirschey 1993; Luo and Bhattacharya 2006) which bases on the idea that the stock market efficiently evaluates a firm's future cash flows and growth opportunities in determining firm value. By including the firm's stock price, Tobin's q is more forward-looking than an accounting measure based on backward-looking data and not biased by different accounting conventions ensuring comparability across firms (Anderson, Fornell, and Mazvancheryl 2004; Bharadwaj, Bharadwaj, and Konsynski 1999; Lee and Grewal 2004). In the context of CSR, such forward looking measure is particularly appropriate as CSR is expected to unfold its impact in the long run (Jayachandran, Kalaignanam, and Eilert 2013). We follow other marketing studies (Groening, Mittal, and Zhang 2016; Jayachandran, Kalaignanam, and Eilert 2013) and construct Tobin's q as shown in Equation (1). We Winsorize firm value at the $1^{\text {st }}$ and $99^{\text {th }}$ percentile to avoid biased effects due to outliers (Servaes and Tamayo 2013). 
Strategic emphasis. To operationalize SE, we use a firm's advertising spending to determine value appropriation and a firm's R\&D spending for value creation. Both advertising and R\&D spending have been established as appropriate proxies for value appropriation and value creation in literature (Josephson, Johnson, and Mariadoss 2015; Swaminathan, Murshed, and Hulland 2008). Based on these proxies, we measure SE as the difference between advertising and $\mathrm{R} \& \mathrm{D}$ spending divided by the book value of total assets. Values greater zero reflect the degree to which a firm focuses relatively more on value appropriation than on value creation in its marketing strategy. Negative scores reflect the degree to which a firm focuses relatively more on value creation than on value appropriation. $^{22}$

Controls. Based on previous empirical research, we incorporate financial leverage, firm size, and industry concentration as control variables in our model (Jayachandran, Kalaignanam, and Eilert 2013; Lee and Grewal 2004). The ratio of long-term debt to the book value of total assets serves as a measure for financial leverage (Luo and Bhattacharya 2009). Firm size is operationalized as the log of the book value of total assets (Servaes and Tamayo 2013). Finally, we control for industry concentration, operationalized as the Herfindahl index for each firm observation using sales for all firms appearing in the Compustat database with the same four-digit SIC code (Kurt and Hulland 2013). Table 12 summarizes the measurement of the variables. Table 13 shows the descriptive statistics of the variables and correlations among these variables.

\footnotetext{
${ }^{22}$ To underline the differences between examining SE and examining advertising and R\&D spending through absolute measures, consider the following example: A firm spends equally on advertising and R\&D and hence the SE measure is zero. By doubling these spending, the SE measure would still be zero while the absolute measures have increased. Thus, SE refers to a firm's prioritization and thus our analysis differs from those that examine the effects of absolute advertising and R\&D spending on firm value (e.g., Joshi and Hanssens 2010).
} 
Table 12: Measurement and Literature Support

\begin{tabular}{|c|c|c|}
\hline Variable & Measurement & Literature Support \\
\hline Firm value & Tobin's q & Lee and Grewal (2004) \\
\hline Doing good & $\begin{array}{l}\text { Sum of strengths scaled for each domain separately by } \\
\text { the maximum possible number of strengths in each } \\
\text { domain; divided by the total number of domains }\end{array}$ & $\begin{array}{l}\text { Adapted from Servaes } \\
\text { and Tamayo (2013) }\end{array}$ \\
\hline Avoiding bad & $\begin{array}{l}\text { Sum of concerns scaled for each domain separately by } \\
\text { the maximum possible number of concerns in each } \\
\text { domain and subtracted from } 1 \text {; divided by the total } \\
\text { number of domains }\end{array}$ & $\begin{array}{l}\text { Adapted from Servaes } \\
\text { and Tamayo (2013) }\end{array}$ \\
\hline Primary CSR & $\begin{array}{l}\text { Difference between strengths and concerns whereby } \\
\text { strengths (concerns) are scaled for each primary } \\
\text { domain separately by the maximum possible number } \\
\text { of strengths (concerns) in each primary domain; } \\
\text { divided by the total number of primary domains }\end{array}$ & $\begin{array}{l}\text { Adapted from Servaes } \\
\text { and Tamayo (2013); } \\
\text { Mattingly and Berman } \\
\text { (2006) }\end{array}$ \\
\hline Secondary CSR & $\begin{array}{l}\text { Difference between strengths and concerns whereby } \\
\text { strengths (concerns) are scaled for each secondary } \\
\text { domain separately by the maximum possible number } \\
\text { of strengths (concerns) in each secondary domain; } \\
\text { divided by the total number of secondary domains }\end{array}$ & $\begin{array}{l}\text { Adapted from Servaes } \\
\text { and Tamayo (2013); } \\
\text { Mattingly and Berman } \\
(2006)\end{array}$ \\
\hline $\begin{array}{l}\text { Primary doing } \\
\text { good }\end{array}$ & $\begin{array}{l}\text { Sum of strengths scaled for each primary domain } \\
\text { separately by the maximum possible number of } \\
\text { strengths in each primary domain; divided by the total } \\
\text { number of primary domains }\end{array}$ & $\begin{array}{l}\text { Adapted from Servaes } \\
\text { and Tamayo (2013); } \\
\text { Mattingly and Berman } \\
\text { (2006) }\end{array}$ \\
\hline $\begin{array}{l}\text { Secondary } \\
\text { doing good }\end{array}$ & $\begin{array}{l}\text { Sum of strengths scaled for each secondary domain } \\
\text { separately by the maximum possible number of } \\
\text { strengths in each secondary domain, divided by the } \\
\text { total number of secondary domains }\end{array}$ & $\begin{array}{l}\text { Adapted from Servaes } \\
\text { and Tamayo (2013); } \\
\text { Mattingly and Berman } \\
\text { (2006) }\end{array}$ \\
\hline $\begin{array}{l}\text { Primary } \\
\text { avoiding bad }\end{array}$ & $\begin{array}{l}\text { Sum of concerns scaled for each primary domain } \\
\text { separately by the maximum possible number of } \\
\text { concerns in each primary domain and subtracted from } \\
1 \text {; divided by the total number of primary domains }\end{array}$ & $\begin{array}{l}\text { Adapted from Servaes } \\
\text { and Tamayo (2013); } \\
\text { Mattingly and Berman } \\
\text { (2006) }\end{array}$ \\
\hline $\begin{array}{l}\text { Secondary } \\
\text { avoiding bad }\end{array}$ & $\begin{array}{l}\text { Sum of concerns scaled for each secondary domain } \\
\text { separately by the maximum possible number of } \\
\text { concerns in each secondary domain and subtracted } \\
\text { from } 1 \text {; divided by the total number of secondary } \\
\text { domains }\end{array}$ & $\begin{array}{l}\text { Adapted from Servaes } \\
\text { and Tamayo (2013); } \\
\text { Mattingly and Berman } \\
\text { (2006) }\end{array}$ \\
\hline $\begin{array}{l}\text { Strategic } \\
\text { emphasis }\end{array}$ & $\begin{array}{l}\text { Advertising spending minus R\&D spending divided } \\
\text { by book value of total assets }\end{array}$ & $\begin{array}{l}\text { Mizik and Jacobson } \\
(2003)\end{array}$ \\
\hline $\begin{array}{l}\text { Financial } \\
\text { leverage }\end{array}$ & Long-term debt divided by book value of total assets & $\begin{array}{l}\text { Luo and Bhattacharya } \\
\text { (2009) }\end{array}$ \\
\hline Firm size & Log of book value of total assets & $\begin{array}{l}\text { Servaes and Tamayo } \\
\text { (2013) }\end{array}$ \\
\hline $\begin{array}{l}\text { Industry } \\
\text { concentration }\end{array}$ & Herfindahl index & $\begin{array}{l}\text { Tuli and Bharadwaj } \\
\text { (2009) }\end{array}$ \\
\hline
\end{tabular}


Table 13: Descriptive Statistics and Correlations

\begin{tabular}{|c|c|c|c|c|c|c|c|c|c|c|c|c|c|c|c|}
\hline Variable & $\mathbf{M}$ & SD & 1. & 2. & 3. & 4. & 5. & 6. & 7. & 8. & 9. & 10. & 11. & 12. & 13. \\
\hline 1. Firm value & 1.69 & 1.38 & 1 & & & & & & & & & & & & \\
\hline 2. Doing good & .04 & .05 & .025 & 1 & & & & & & & & & & & \\
\hline 3. Avoiding bad & .94 & .06 & .126 & -.223 & 1 & & & & & & & & & & \\
\hline 4. Primary CSR & -.04 & .12 & .111 & .260 & .579 & 1 & & & & & & & & & \\
\hline 5. Secondary CSR & -.02 & .08 & .088 & .534 & .506 & .170 & 1 & & & & & & & & \\
\hline 6. Primary doing good & .04 & .08 & .045 & .759 & -.131 & .519 & .204 & 1 & & & & & & & \\
\hline 7. Secondary doing good & .03 & .06 & .005 & .898 & -.226 & .016 & .620 & .395 & 1 & & & & & & \\
\hline 8. Primary avoiding bad & .92 & .10 & .096 & -.245 & .767 & .788 & .050 & -.116 & -.266 & 1 & & & & & \\
\hline 9. Secondary avoiding bad & .95 & .06 & .107 & -.126 & .843 & .199 & .710 & -.096 & -.113 & .302 & 1 & & & & \\
\hline 10. Strategic emphasis & -.03 & .11 & -.203 & .046 & -.046 & -.061 & .038 & -.018 & .076 & -.058 & -.020 & 1 & & & \\
\hline 11. Financial leverage & .19 & .21 & -.106 & -.021 & -.075 & -.100 & -.031 & -.040 & -.002 & -.090 & -.038 & .082 & 1 & & \\
\hline 12. Firm size & 7.16 & 1.66 & -.230 & .450 & -.405 & -.157 & .095 & .295 & .436 & -.395 & -.270 & .261 & .225 & 1 & \\
\hline 13. Industry concentration & .22 & .18 & -.044 & .026 & -.009 & -.003 & .018 & .034 & .014 & -.028 & .011 & .114 & -.051 & -.016 & 1 \\
\hline
\end{tabular}

Notes: Correlations greater than or equal to $|.014|$ are statistically significant $(p<.05$, two-tailed). 


\subsection{Study 3: Analysis and Results}

\section{Analysis Approach}

For comparing the three CSR differentiation approaches, we examine the moderating role of SE for the firm value effects of these CSR types (see Figure 6) and model three equations. The obligation-based approach allows a differentiation between doing good and avoiding bad. The equation comprises the main effects of doing good, avoiding bad and SE, the interactions between each CSR type and SE, and the control variables as predictors of firm value:

$$
\begin{aligned}
\text { Firm value }_{i t}= & \alpha+\beta_{1} \times \mathrm{DG}_{\mathrm{it}}+\beta_{2} \times \mathrm{AB}_{\mathrm{it}}+\beta_{3} \times \mathrm{SE}_{\mathrm{it}}+\beta_{4} \times \mathrm{SE}_{\mathrm{it}} \times \mathrm{DG}_{\mathrm{it}} \\
& +\beta_{5} \times \mathrm{SE}_{\mathrm{it}} \times \mathrm{AB}_{\mathrm{it}}+\beta_{6} \times \mathrm{LEV}_{\mathrm{it}}+\beta_{7} \times \mathrm{SIZE}_{\mathrm{it}}+\beta_{8} \times \mathrm{CONC}_{\mathrm{it}}+\varepsilon_{\mathrm{it}},
\end{aligned}
$$

where $\mathrm{i}=$ firm, $\mathrm{t}=$ year, $\alpha=$ constant, $\mathrm{DG}=$ doing good, $\mathrm{AB}=$ avoiding bad, $\mathrm{SE}=$ strategic emphasis, $\mathrm{LEV}=$ financial leverage, $\mathrm{SIZE}=$ firm size, $\mathrm{CONC}=$ industry concentration, and $\varepsilon=$ residual component.

The stakeholder target-based approach differentiates between primary and secondary CSR. The equation includes the main effects of primary CSR, secondary CSR and SE, the interactions between these CSR types and SE, and the control variables as predictors of firm value:

$$
\begin{aligned}
\text { Firm value }_{\text {it }}= & \Omega+\mu_{1} \times \mathrm{P}_{-} \mathrm{CSR}_{\mathrm{it}}+\mu_{2} \times \mathrm{S}_{-\mathrm{CSR}_{\mathrm{it}}}+\mu_{3} \times \mathrm{SE}_{\mathrm{it}}+\mu_{4} \times \mathrm{SE}_{\mathrm{it}} \times \mathrm{P}-\mathrm{CSR}_{\mathrm{it}} \\
& +\mu_{5} \times \mathrm{SE}_{\mathrm{it}} \times \mathrm{S}_{-\mathrm{CSR}_{\mathrm{it}}}+\mu_{6} \times \mathrm{LEV}_{\mathrm{it}}+\mu_{7} \times \mathrm{SIZE}_{\mathrm{it}}+\mu_{8} \times \mathrm{CONC}_{\mathrm{it}}+\delta_{\mathrm{it}}
\end{aligned}
$$

where i, t, SE, LEV, SIZE, and CONC are the same as in Equation (8). $\Omega$ and $\delta$ have equivalent meaning as $\alpha$ and $\varepsilon$ in Equation (8); P-CSR = primary CSR, S-CSR $=$ secondary CSR. 
The integrative approach where we combine the obligation and stakeholder dimension yields four CSR types: primary doing good, secondary doing good, primary doing bad, and secondary avoiding bad. We model their main effects, their interaction with SE, and the control variables as predictors of firm value as follows:

$$
\begin{aligned}
\text { Firm value }_{i t}= & \psi+\gamma_{1} \times \mathrm{P}-\mathrm{DG}_{\mathrm{it}}+\gamma_{2} \times \mathrm{S}-\mathrm{DG}_{\mathrm{it}}+\gamma_{3} \times \mathrm{P}-\mathrm{AB}_{\mathrm{it}}+\gamma_{4} \times \mathrm{S}-\mathrm{AB}_{\mathrm{it}} \\
& +\gamma_{5} \times \mathrm{SE}_{\mathrm{it}}+\gamma_{6} \times \mathrm{SE}_{\mathrm{it}} \times \mathrm{P}-\mathrm{DG}_{\mathrm{it}}+\gamma_{7} \times \mathrm{SE}_{\mathrm{it}} \times \mathrm{S}-\mathrm{DG}_{\mathrm{it}}+\gamma_{8} \times \mathrm{SE}_{\mathrm{it}} \times \mathrm{P}-\mathrm{AB}_{\mathrm{it}} \\
& +\gamma_{9} \times \mathrm{SE}_{\mathrm{it}} \times \mathrm{S}-\mathrm{AB}_{\mathrm{it}}+\gamma_{10} \times \mathrm{LEV}_{\mathrm{it}}+\gamma_{11} \times \mathrm{SIZE}_{\mathrm{it}}+\gamma_{12} \times \mathrm{CONC}_{\mathrm{it}}+v_{\mathrm{it}}
\end{aligned}
$$

where i, t, SE, LEV, SIZE, and CONC are the same as in Equation (8). $\psi$ and $v$ have equivalent meaning as $\alpha$ and $\varepsilon$ in Equation (8); P-DG $=$ primary doing good, $\mathrm{S}-\mathrm{DG}=$ secondary doing good, $\mathrm{P}-\mathrm{AB}=$ primary avoiding bad, $\mathrm{S}-\mathrm{AB}=$ secondary avoiding bad.

We took several methodological steps to remove endogeneity because such bias is seen as one of the main methodological concerns in the CSR-firm value relationship (Flammer 2015; Garcia-Castro, Ariño, and Canela 2010; Jiao 2010). Endogeneity of CSR in general means that CSR likely correlates with omitted variables that likewise impact a firm's financial performance. Such correlation leads to biased estimates of CSR and a potentially spurious relationship to firm value (Flammer 2015). We thus extend our modeling approach to address multiple endogeneity sources.

Cross-sectional heterogeneity. Cross-sectional heterogeneity refers to differences between firms due to time-invariant firm characteristics (e.g., management characteristics such as leadership style). Such firm characteristics are difficult to measure and to control for but they could correlate with CSR decisions and firm value (e.g., leadership styles affect CSR approaches and firm performance alike) and thus lead to endogeneity bias. To account for these time-invariant unobservable firm characteristics, we estimate Equations (8) - (10) using the fixed effects estimator. Such estimator means technically that each firm observation is 
adjusted by its firm-specific mean which equals the inclusion of firm dummies. Thereby, the fixed effects estimator removes systematic differences between firms. In a consequence, our model caters to explain variation within firm observations, i.e. over time, and thus, omitted time-invariant firm characteristics do not threat our results. ${ }^{23}$

Longitudinal heterogeneity. Longitudinal heterogeneity refers to differences due to year-specific factors which systematically affect every firm. Neglecting such factors can create endogeneity bias (e.g., financial crises affect CSR investments and financial performance). To avoid such bias, we include year-specific fixed effects, i.e., time dummies in Equation (8) - (10) (Groening, Mittal, and Zhang 2016; Jayachandran, Kalaignanam, and Eilert 2013).

Remaining Endogeneity. We also address endogeneity problems that may arise due to unobserved factors specific to a firm in (a) certain year(s) (e.g., change in the CEO board composition towards more talented CEO members affects CSR and financial performance). We address this source of endogeneity with the Gaussian copulas method (Park and Gupta 2012) which has become increasingly popular in marketing research to control for such source of endogeneity (e.g., Burmester et al. 2015; Datta et al. 2015). The Gaussian copulas method is an instrument-free approach and therefore does not depend on the choice of strong instruments for the endogenous variables which are always debatable (Rossi 2014). The main idea behind Gaussian copulas is to model the joint distribution of the endogenous variable and the error term to capture the dependence of both that causes endogeneity (Park and Gupta 2012). We construct Gaussian copula terms for each CSR type. We show the equation exemplarily for doing good and avoiding bad:

\footnotetext{
${ }^{23}$ The industry a firm belongs to is a time-invariant characteristic whose influence is eliminated through the fixed effects estimator. To ensure that our results are not driven by such characteristics is particularly important in our context as advertising and R\&D spending, and therefore a firm's SE, inherently vary between industries (Steenkamp and Fang 2011).
} 
C_ $\mathrm{DG}_{\mathrm{it}}=\Phi^{-1}\left(\mathrm{H}_{\mathrm{DG}}\left(\mathrm{DG}_{\mathrm{it}}\right)\right.$,

$$
\mathrm{C}_{-} \mathrm{AB}_{\mathrm{it}}=\Phi^{-1}\left(\mathrm{H}_{\mathrm{AB}}\left(\mathrm{AB}_{\mathrm{it}}\right),\right.
$$

where $\Phi^{-1}$ is the inverse of the normal cumulative distribution function and $\mathrm{H}(\cdot)$ represents the empirical distribution of the respective variables. We add these terms as control variables in Equation (8). The Gaussian copula terms for primary and secondary CSR are included in Equation (9), and those for primary/secondary doing good and primary/secondary avoiding bad are included in Equation (10).

\section{Testing for the Appropriateness of the Model}

Before we run the final model, we test for the appropriateness of the model. First, we ensured that the fixed effects estimator is appropriate for our purpose. We inspected whether the differences within firms are large enough to provide a sufficient basis for explaining firm variation over time. As a start, we examined whether the number of year observations per firm is large enough. In average, a firm is 6 years in our sample which represents a reasonable time horizon to examine firm variation over time. Moreover, we also examined more specifically whether the CSR types provide enough firm variation over time. We estimated the standard deviation of a firm's CSR types over time and averaged these values across firms. We compare this time-series variation with the cross-sectional variation (Servaes and Tamayo 2013). For instance, the average within firm variation is .03 for doing good and .05 for avoiding bad. We find yearly standard deviations from .04 to .06 for doing good and values between .05 and .06 for avoiding bad. Comparing the relative magnitude indicates enough variability in doing good and avoiding bad. We receive similar values for the other CSR types.

Second, we tested for multicollinearity among our independent variables by 
estimating variance inflation factors (VIFs) after we mean-centered all independent variables. The maximum VIF is 1.91 for Equation (8), 1.80 for Equation (9), and 2.50 for Equation (10), which are all far below 10 (Hair et al. 2010) and indicates that multicollinearity does not pose a threat to our results.

Third, we test the usefulness of Gaussian copulas which hinges on the non-normality of the variables. The Shapiro-Wilk test provides information on the non-normality of variables and confirms that non-normality applies to our main constructs $\left(\mathrm{W}_{\mathrm{DG}}=.86, p<.01\right.$; $\mathrm{W}_{\mathrm{AB}}=.91, p<.01 ; \mathrm{W}_{\mathrm{P}-\mathrm{CSR}}=.96, p<.01 ; \mathrm{W}_{\mathrm{S}-\mathrm{CSR}}=.97, p<.01 ; \mathrm{W}_{\mathrm{P}-\mathrm{DG}}=.94, p<.01 ;$ $\left.\mathrm{W}_{\mathrm{S}-\mathrm{DG}}=.85, p<.01 ; \mathrm{W}_{\mathrm{P}-\mathrm{AB}}=.93, p<.01 ; \mathrm{W}_{\mathrm{S}-\mathrm{AB}}=.95, p<.01\right)$.

\section{Comparative Model Testing}

Across the three CSR differentiation approaches shown in Equation (8) - (10), we compare the results of the main effects of the CSR types, the moderating role of SE, and the model fit. Table 14 shows the results for each CSR differentiation approach in two models, a maineffect-only model and a model that additionally includes the effects for the interaction with SE. Across the CSR differentiation approaches, none CSR type has a significant main effect on firm value (see Model 1a, 2a, 3a). Model 1b shows that doing good and avoiding bad are both significantly moderated by SE. Specifically, doing good is positively moderated by SE and avoiding bad is negatively moderated by SE. However, we do not find that SE significantly moderates primary or secondary CSR in Model 2b. As compared to Model 1b, Model 3b shows that only secondary doing good and primary avoiding is significantly moderated by SE, with a positive interaction effect for secondary doing good and a negative for primary avoiding bad. SE has however no significant moderating influence on primary doing good and secondary avoiding bad. The fit measures suggest favoring the models for the integrative approach which we use for hypotheses testing. 


\section{Hypotheses Testing}

We refer to Model $3 b$ for testing $\mathrm{H}_{1}$ and $\mathrm{H}_{2}$. The results show that the interaction between secondary doing good and SE is significant and positive $(\gamma=12.57, p<.01)$ while the interaction of primary avoiding bad and SE is significant and negative $(\gamma=-3.56, p<.05)$. To comprehensively test $\mathrm{H}_{1}$ and $\mathrm{H}_{2}$, we conduct floodlight analysis which informs about the specific ranges of SE for which the moderating effects are significant (Spiller et al. 2013). We test the effects of secondary doing good (primary avoiding bad) on firm value for the observable range of SE using increments of .20 and plot the beta estimates in Figure 7 along with the $90 \%$ confidence interval band. Important for testing $\mathrm{H}_{1}$ and $\mathrm{H}_{2}$, such graphical illustration shows whether and when the moderating effects eventually turn from positive to negative or vice versa.

For secondary doing good, Figure 7, Panel A suggests that the effect of SE is significant for the entire range except from approximately 0 to .25 . Levels beyond .25 , where the lower confidence interval band crosses the $\mathrm{x}$-axis, reveal a significant positive effect on firm value. As positive values for SE refer to an emphasis on value appropriation, the finding indicates that focusing on value appropriation that goes beyond this level increases firm value for secondary doing good. Values lower than 0 , where the upper confidence interval band crosses the $\mathrm{x}$-axis, however suggest a significantly negative effect on firm value. As negative values indicate an emphasis on value creation, the finding reveal that doing good decreases firm value in such strategic setting. Overall, the findings lend support for $\mathrm{H}_{1}$.

Figure 7, Panel B shows that the moderation effect of SE for primary avoiding bad is significant for the entire range except from approximately -.40 to .30 . Below -.40 the effect of SE is significant and positive on firm value. This suggests that primary avoiding bad increases firm value with an increasing emphasis on value creation, i.e., if the SE variable 
becomes increasingly negative below this threshold. Values of SE higher than .30 have a significantly negative effect on firm value. Therefore, primary avoiding bad decreases firm value when the prioritization of value appropriation increases beyond .30. In sum, the findings reflect what we proposed by $\mathrm{H}_{2}$.

We also inspect the influence of SE on firm value. The main effect of SE is significantly negative and shows that shareholders rather appreciate focusing on value creation. Because R\&D investments are long-term investments that pay off in the future, focusing on such investments might indicate higher cash flows and better growth opportunities to shareholders in the future. Contrary, a focus on value appropriation may rather enhance short-term financial performance measures as such strategic focus yields profits from existing products in the short-run (Gupta et al. 2006; Josephson, Johnson, and Mariadoss 2015). 
Table 14: Moderating Effect of Strategic Emphasis for CSR Types Based on Three Differentiation Approaches

\begin{tabular}{|c|c|c|c|c|c|c|c|c|c|c|c|c|c|c|c|c|c|c|}
\hline \multirow[b]{3}{*}{ Independent Variable } & \multicolumn{6}{|c|}{ Obligation-Based Approach } & \multicolumn{6}{|c|}{ Stakeholder-Based Approach } & \multicolumn{6}{|c|}{ Integrative Approach } \\
\hline & \multicolumn{3}{|c|}{ Model 1a } & \multicolumn{3}{|c|}{ Model 1b } & \multicolumn{3}{|c|}{ Model 2a } & \multicolumn{3}{|c|}{ Model 2b } & \multicolumn{3}{|c|}{ Model 3a } & \multicolumn{3}{|c|}{ Model 3b } \\
\hline & Coef. & & Sig. & Coef. & & Sig. & Coef. & & Sig. & Coef. & & Sig. & Coef. & & Sig. & Coef. & & Sig. \\
\hline Constant & 1.56 & $(.07)$ & $* * *$ & 1.56 & $(.07)$ & $* * *$ & 1.54 & $(.07)$ & $* * *$ & 1.54 & $(.07)$ & $* * *$ & 1.49 & $(.08)$ & $* * *$ & 1.50 & $(.08)$ & $* * *$ \\
\hline $\begin{array}{l}\text { Doing good } \\
\text { Avoiding bad } \\
\text { Doing good } * \text { SE } \\
\text { Avoiding bad } * \text { SE }\end{array}$ & $\begin{array}{r}-.81 \\
-1.56\end{array}$ & $\begin{array}{l}(1.04) \\
(1.31)\end{array}$ & & $\begin{array}{r}-.77 \\
-1.09 \\
15.75 \\
-7.32\end{array}$ & $\begin{array}{l}(1.16) \\
(1.19) \\
(5.78) \\
(3.41)\end{array}$ & $\begin{array}{l}* * * \\
* *\end{array}$ & & & & & & & & & & & & \\
\hline $\begin{array}{l}\text { Primary CSR } \\
\text { Secondary CSR } \\
\text { Primary CSR * SE } \\
\text { Secondary CSR } * \text { SE }\end{array}$ & & & & & & & $\begin{array}{r}-.02 \\
.25\end{array}$ & $\begin{array}{l}(.45) \\
(.71)\end{array}$ & & $\begin{array}{r}.10 \\
.23 \\
-2.64 \\
3.79\end{array}$ & $\begin{array}{l}(.43) \\
(.71) \\
(1.83) \\
(2.55)\end{array}$ & & & & & & & \\
\hline $\begin{array}{l}\text { Primary doing good } \\
\text { Secondary doing good } \\
\text { Primary avoiding bad } \\
\text { Secondary avoiding bad } \\
\text { Primary doing good } * \text { SE }\end{array}$ & & & & & & & & & & & & & $\begin{array}{l}-.86 \\
-.84 \\
-.27 \\
-.97\end{array}$ & $\begin{array}{l}(.78) \\
(1.11) \\
(.60) \\
(.78)\end{array}$ & & $\begin{array}{r}-.59 \\
-1.10 \\
-.07 \\
-.78 \\
3.53\end{array}$ & $\begin{array}{l}(.69) \\
(.95) \\
(.57) \\
(.79) \\
(4.14)\end{array}$ & \\
\hline Secondary doing good $*$ SE & & & & & & & & & & & & & & & & 12.57 & $(4.69)$ & $* * *$ \\
\hline Primary avoiding bad $*$ SE & & & & & & & & & & & & & & & & -3.56 & $(1.79)$ & $* *$ \\
\hline Secondary avoiding bad $* \mathrm{SE}$ & & & & & & & & & & & & & & & & -3.43 & $(3.82)$ & \\
\hline SE & -1.52 & $(.33)$ & $* * *$ & -1.27 & $(.37)$ & $* * *$ & -1.52 & $(.33)$ & $* * *$ & -1.52 & $(.32)$ & $* * *$ & -1.52 & $(.33)$ & $* * *$ & -1.26 & $(.36)$ & $* * *$ \\
\hline Financial leverage & -.46 & $(.11)$ & $* * *$ & -.45 & $(.11)$ & $* * *$ & -.46 & $(.11)$ & $* * *$ & -.45 & $(.11)$ & $* * *$ & -.45 & $(.11)$ & $* * *$ & -.44 & $(.10)$ & $* * *$ \\
\hline Firm Size & -.54 & $(.04)$ & $* * *$ & -.54 & $(.04)$ & $* * *$ & -.54 & $(.04)$ & $* * *$ & -.54 & $(.03)$ & $* * *$ & -.54 & $(.04)$ & $* * *$ & -.54 & $(.03)$ & $* * *$ \\
\hline Industry concentration & -.14 & $(.21)$ & & -.18 & $(.20)$ & & -.13 & $(.21)$ & & -.14 & $(.21)$ & & -.12 & $(.21)$ & & -.16 & $(.21)$ & \\
\hline Wald chi-square & & 018.26 & $* * *$ & & $2,357.40$ & $* * *$ & & 016.56 & $* * *$ & &, 099.80 & $* * *$ & & $2,008.24$ & $* * *$ & & 629.02 & $* * *$ \\
\hline AIC & & 924.48 & & & $5,869.03$ & & & 904.45 & & & 890.88 & & & $6,888.94$ & & & 826.94 & \\
\hline $\mathrm{R}^{2}$ (based on within variance) & & $20.12 \%$ & & & $20.34 \%$ & & & $20.19 \%$ & & & $20.26 \%$ & & & $20.28 \%$ & & & $20.54 \%$ & \\
\hline
\end{tabular}

** $p<.05 ; * * * p<.01$. Notes: Standard errors are in parentheses. We used fixed effects panel estimation and bootstrap standard errors with 200 repetitions (Burmester et al. 2015). Time dummies and Copula terms for each CSR type are included to control for unobserved heterogeneity and endogeneity but not reported. We also included but not reported two separate dummy variables that equal 1 if advertising (R\&D) spending information is disclosed and 0 if respective information is not disclosed 
Figure 7: Moderating Effect of Strategic Emphasis for Secondary Doing Good and Primary Avoiding Bad

\section{A: Moderating Effect of Strategic Emphasis for Secondary Doing Good}

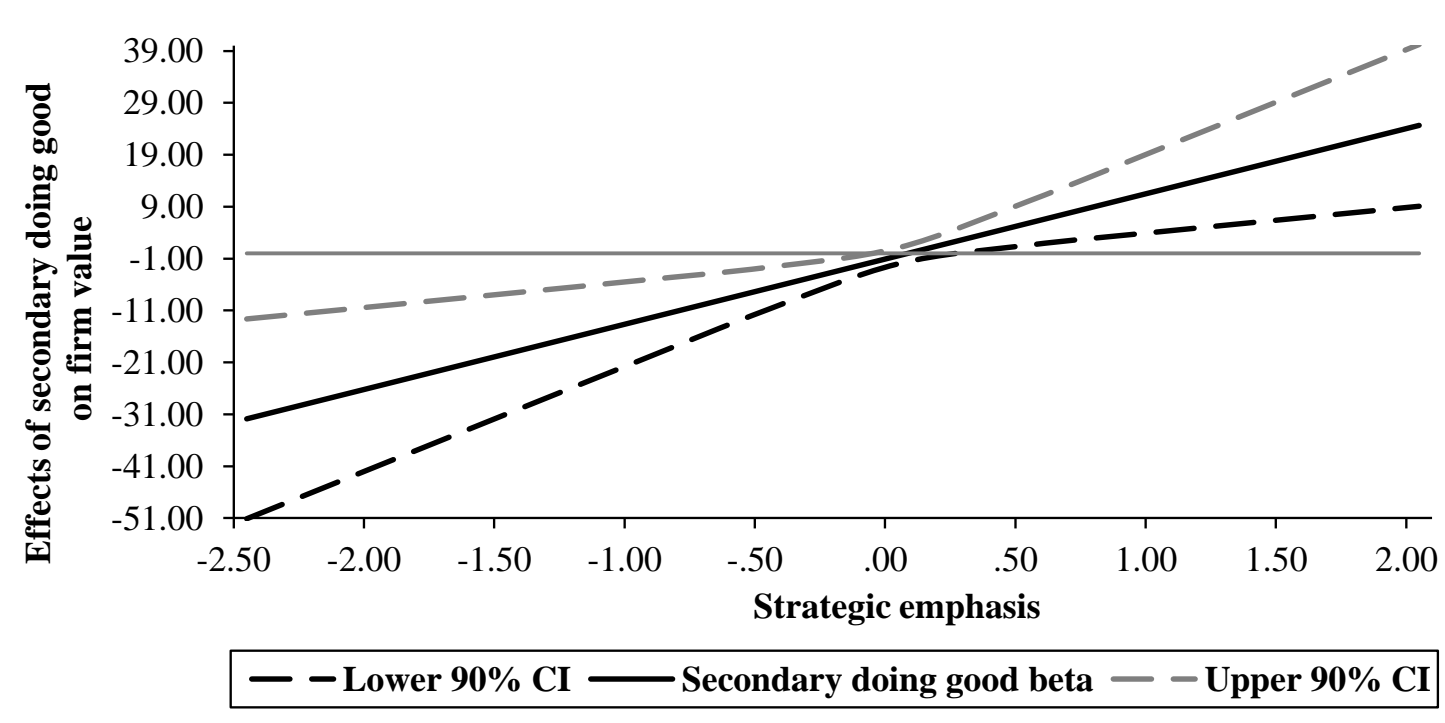

\section{B: Moderating Effect of Strategic Emphasis for Primary Avoiding Bad}

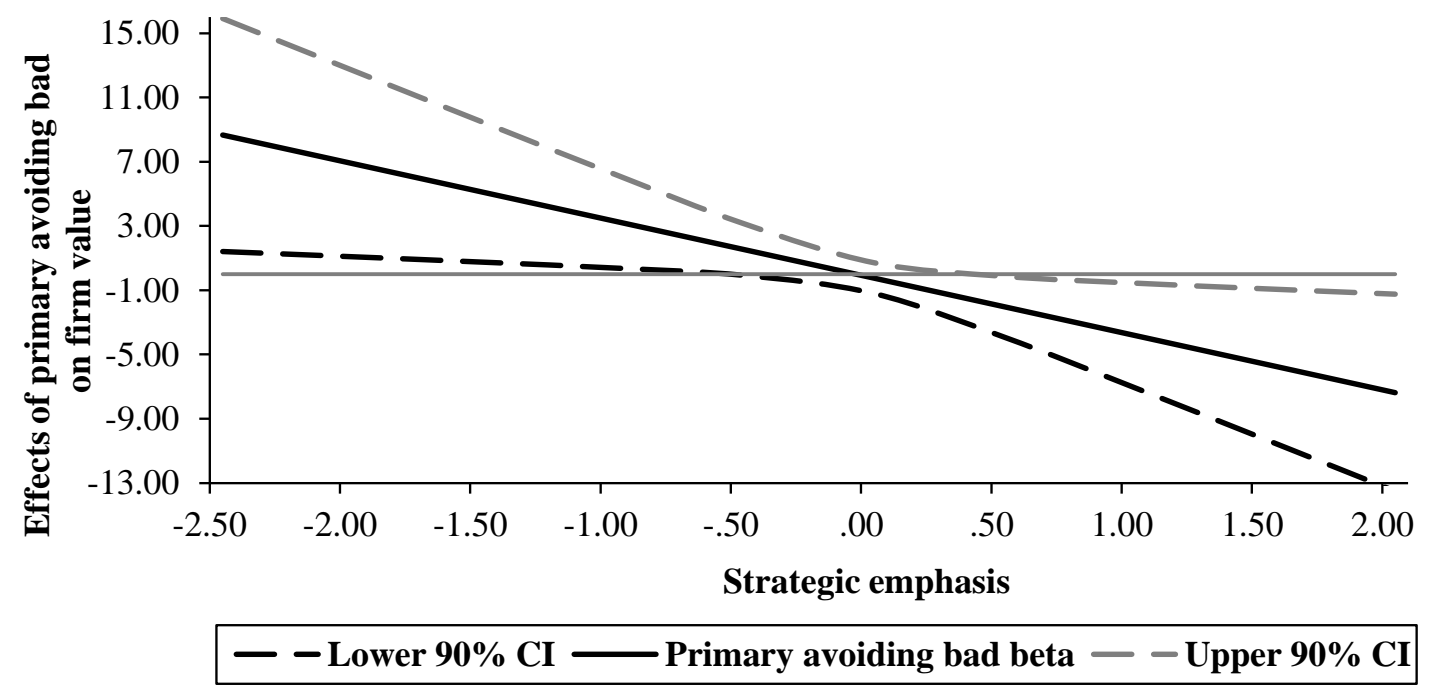

Notes: The effects of secondary doing good and primary avoiding bad on firm value shown in the graphs are based on the estimates of the floodlight analysis. 


\subsection{Study 3: Discussion}

This research focuses on the role that the strategic emphasis between value creation and value appropriation plays for firm value effects of distinct CSR types. For conceptualizing these distinct CSR types, we refer to two CSR dimensions that are most prevalent in research and practice for distinguishing CSR initiatives (Lin-Hi and Müller 2013; Luo et al. 2015). One dimension refers to how a firm addresses its obligations (i.e., doing good and avoiding bad) and the other dimension refers to the targets of the CSR activities (i.e., primary or secondary stakeholders). We theorize and empirically show that among the four CSR types that emerge from combining both dimensions (see Figure 6), only secondary doing good and primary avoiding bad interact with SE in deriving firm value. Such interaction provides insight into whether a firm's emphasis on value creation or value appropriation aligns better with secondary doing good and primary avoiding bad. Interestingly, we find that distinct strategic foci complement these CSR types: Secondary doing good increases (decreases) firm value when a firm emphasizes value appropriation (creation) whereas avoiding bad increases (decreases) firm value when a firm prioritizes value creation (appropriation). To underscore the information content of our integrative approach, we compare the effects of the integrative CSR types to those CSR types that can be derived by the approaches comprising the dimensions separately. The findings of this study come with important implications for researchers and practitioners.

\section{Theoretical Implications}

Recently, the debate in CSR research has shifted from whether CSR aligns with firm value enhancements to which CSR activities pay back and when. For addressing these questions, seminal research has examined different CSR types and the role of the marketing function for 
firm value effects of CSR. By approaching both topics simultaneously, our research shows that the question whether specific CSR types pay back financially is intertwined with the strategic priorities set by the marketing function.

By referring to a rigorous model that accounts for multiple sources of endogeneity, our findings reveal that, across the different approaches to differentiate CSR, no CSR type has a significant main effect on firm value and that SE determines whether CSR has any impact on firm value. These findings generate further support for the pivotal role of marketing for capitalizing on CSR (Mishra and Modi 2016; Servaes and Tamayo 2013), and thus, we recommend going away from exploring direct effects of CSR.

Our research underlines that distinguishing between CSR engagements makes sense for the detection of potentially offsetting moderating effects that would not be revealed when using a single aggregated CSR measure. However, the chosen approach for differentiating CSR types is decisive for whether researchers find a moderating effect at all and whether this effect is precisely captured. Our results show that CSR differentiations according to the stakeholder-based approach are not useful to detect a moderating effect of SE. Using primary and secondary CSR as relatively aggregated measures could falsely lead to assume no moderating influence as opposing moderating effects cancel out each other. Researchers that use the obligation-based approach for differentiating CSR likewise hazard wrong implications. By using doing good and avoiding bad as relatively aggregated measures, a positive (negative) moderating influence could be falsely taken for granted but actually such effect only applies to some facets of the respective engagements, whereas for others no effect exists. Our findings indeed demonstrate the pitfalls of such relatively aggregated, unidimensional CSR measures as we find that only a differentiation of CSR by the integrative approach allows for detecting meaningful moderating effects. Specifically, we find that only 
doing good with a secondary stakeholder focus and avoiding bad with a primary stakeholder focus yields significant firm value effects while the direction of these effects is conditional on SE. While a large amount of studies do not differentiate between CSR types at all (e.g., Hull and Rothenberg 2008; Luo and Bhattacharya 2006), we urgently recommend researchers to do so but we also recommend choosing the differentiation approach cautiously. In detail, we recommend future research not to stick to the examination of relatively aggregated CSR types that are based on single dimensions and to use more fine-grained conceptually grounded CSR types instead. Our findings show that only such CSR types unmask the moderating effects precisely.

By empirically detecting a moderating effect of SE for primary avoiding bad, we go beyond mere conceptualizations of avoiding bad (Lin-Hi and Müller 2013) and provide an initial empirical backing for its importance for firm value effects. Our study may help to sensitize research that avoiding bad is a substantial component of a firm's responsibility and hopefully encourages researchers to consider it in future examinations. However, instead of considering the impact of avoiding bad in general (compared to doing good), we recommend a differentiation between primary and secondary avoiding bad.

As we examine trade-offs between value creation and appropriation, we also enhance the understanding of how the marketing function moderates the CSR-firm value relationship. Specifically, for the studies using absolute measures of value appropriation and value creation, we add knowledge on the influence of the relative emphasis between both for the firm value effects of different CSR types (Luo and Bhattacharya 2006, 2009; Mishra and Modi 2016; Servaes and Tamayo 2013). More specifically, while these studies view the contribution of marketing in the CSR-firm value relationship consistently positive, our findings suggest potential boundary conditions for this impact as we find that SE can also 
destroy shareholder wealth for some CSR types. For instance, our results indicate that the positive interaction effect between CSR and advertising intensity on firm value found by Servaes and Tamayo (2013) could be enhanced or diminished depending on whether secondary doing good or primary avoiding bad constitutes the CSR engagement and whether firms spend relatively less (more) on R\&D at the same time. We therefore suggest that prior studies' results on the role of marketing in the CSR-firm value relationship should be revisited in the light of our findings. Future research should also consider a relative view on value creation and appropriation but ideally should apply this view for evaluating different CSR types.

\section{Managerial Implications}

CSR literature has taught managers that marketing as being most influential on consumers helps to capitalize from CSR (Luo and Bhattacharya 2006; Mishra and Modi 2016; Servaes and Tamayo 2013). Scholars even appeal that for CSR to be successful "it is all about marketing" (Bhattacharya 2009). Though, firms often engage in CSR activities for which consumers do not see any benefits because it does not align with their marketing decisions. From a marketing strategy perspective, the trade-off between value creation and value appropriation represents an important marketing decision that affects consumers and their evaluation of CSR in turn. For managers, this research delivers valuable insight into which CSR engagement suits their SE between value creation and value appropriation best.

A clear implication of our study is that for decision making on CSR managers should have an eye on more specific marketing decisions, i.e., their SE between value creation and value appropriation. We find that depending on the trade-offs firms make between these two fundamental investments, CSR becomes a double-edged sword. Some CSR engagements pay back financially while some even backfire. More specifically, our findings suggest that firms 
that emphasize value creation should particularly pursue avoiding harm for primary stakeholders as it increases firm value but they should be cautious with making doing good for secondary stakeholders the focus of their CSR initiatives as it decreases firm value. Contrary, firms that put strong emphasis on value appropriation should focus on good deeds for their secondary stakeholders as such engagement is valued by the investor community while primary avoiding bad backfires for such firms.

Importantly, our results also show that these effects only apply to firms with relatively large differences in their value creation and value appropriation efforts, i.e., firms that strongly emphasize one of both. As we have theorized in detail, these firms create a context in which the benefits from secondary doing good and primary avoiding bad become particularly obvious to consumers. SE is however not pivotal for capitalizing on CSR when firms balance value creation and value appropriation efforts. Firms that fall under this umbrella either simultaneously invest in innovations while communicating the brand's point of difference to consumers or they do invest in none of both (McAlister 2016). In the former case, the firm serves consumer needs for innovative products and also creates brand loyalty. Both in tandem may then make the benefits that secondary doing good and primary avoiding bad potentially generate less relevant to consumers. In the latter case, the firm obviously focuses on reducing its costs and thus produces low price products. Because consumers of such products are more price-sensitive, they see CSR engagement as coming at the expenses of low prices and thus they do not value CSR. In sum, our results give managers important advice how to design their CSR program according to their prioritization in marketing strategy. 


\section{Limitations}

Our research is not free from limitations that provide avenues for future research. First, we must acknowledge that a firm's focus could vary between industries. For instance, R\&D spending and innovations are more inherent in high-technology industries and thus firms that operate in these industries may naturally focus more on value creation (Mizik and Jacobson 2003). Such industry-specific influences could potentially affect consumers' evaluation of the CSR types. It would be interesting to make these industry-inherent differences in a firm's SE the focus of investigation when examining the moderating role of SE for CSR. As we are the first study that examines the role of SE in a CSR context, the goal of the study was to provide results that are generalizable across industries. We thus took great care to methodologically eliminate differences that come from the industry a firm belongs to. Second, although our findings are consistent with our theoretical framework, we do not test it explicitly. While there is already some empirical evidence for the benefits that CSR creates for consumers (Homburg, Stierl, and Bornemann 2013), future research could explicitly test the moderating role of SE with experimental and survey data. Third, it is also critical to note that KLD only rates CSR behavior of U.S. firms. Future research could therefore replicate our study using a multi-country sample. 



\section{General Discussion}

The starting point of this dissertation was the lack of consensus in research and practice on whether firms can do well by doing good. Scholarly work on this topic only generates inconclusive findings on the firm value impact of CSR because most studies have taken an undifferentiated view on CSR when examining its firm value implications using a single aggregated CSR measure. Similarly, from a practical lens, the financial rewards from CSR are still difficult to anticipate and thus engaging in the right CSR represents a major challenge for managers. By examining the firm value effects of distinct CSR types from three different perspectives under consideration of contingency factors, this dissertation provides new answers to the question how and when firms can do well by doing good.

\section{Research Implications}

A general conclusion of the three studies is that the firm value effects of CSR are heterogeneous originating from the fact that different CSR types generate different firm value outcomes and/or that the firm value effects of the CSR types vary or even switch directions depending on contingency factors.

Study 1 and Study 2 show that some CSR types contribute to firm value while others have no influence or even backfire on firm value. Study 1 finds contrary firm value effects for the two strategies to engage in CSR as a means for compensating stakeholders for past misconduct (i.e., misconduct-related and misconduct-unrelated compensation). By considering a setting in which CSR and socially irresponsible behavior coincide and firms can decide to employ CSR in the CSI-inflicted domain or other domains, Study 2 likewise reveals that not every CSR activity contributes to firm value. Both studies thus point to the 
importance to distinguish between CSR types because without such differentiation, the heterogeneous firm value implications of CSR are masked.

Across the studies, the findings also reveal that for some CSR types contingency factors are decisive for whether an effect on firm value occurs at all or whether the positive (negative) firm value effect is strengthened or weakened. Study 1 shows that the negative (positive) firm value effect of misconduct-related (misconduct-unrelated) compensation is leveraged by marketing instruments. Study 2 demonstrates that CSI contextual factors strengthen/weaken the positive effect of other-domain CSR. Importantly, the CSI context is pivotal for whether same-domain CSR has any effect on firm value and whether this effect is beneficial or detrimental. Similarly to this finding, Study 3 highlights that the firm value effects of CSR types are strongly intertwined with contingency factors. Across the three CSR approaches that are used for deriving CSR types, no main effect of any of the CSR types exists but some CSR types are moderated by a firm's strategic emphasis between value creation and value appropriation. The findings demonstrate that, alike the differentiation between CSR types, examining contingency factors helps to unmask the heterogeneous firm value implications of CSR.

Overall, the findings of the studies indicate that the firm value implications of the CSR types are intertwined with a firm's context. Future research should thus approach the how- and when-questions simultaneously.

More specifically, the studies' findings suggest that future research should conceptually differentiate CSR types on a medium aggregation level instead of using fully disaggregated, fine-grained differentiations that assign CSR activities to the specific domains in which they are accomplished (e.g., environmental CSR, charitable CSR) or to use a single, fully aggregated CSR measure in which every CSR engagement is commingled. When CSI 
occurs, Study 2 suggests a conceptually founded differentiation of CSR according to the domain overlap with prior CSI. Study 3 shows that a differentiation approach combining the obligation and stakeholder dimension is meaningful to detect precise moderating effects. By comparing multiple CSR differentiation approaches, the study further demonstrates that the chosen differentiation approach can be decisive for whether researchers detect a moderating effect and whether this effect is accurately captured. While focusing on mid-aggregated CSR types is recommended, researchers should however choose their CSR differentiation approach cautiously, as some approaches may hazard wrong implications.

Concerning the contingency factors in the CSR-firm value relationship, the studies' findings suggest that it is worthwhile to further examine marketing- and CSI-related factors. While prior scholarly work has established an overly positive picture on the moderating role of marketing (Mishra and Modi 2016; Servaes and Tamayo 2013), Study 1 and Study 3 are the first that point to the boundaries for the effectiveness of marketing for capitalizing on CSR. Study 2 establishes the pivotal role of CSI context in the CSR-firm value relationship. As the influence of CSI context has been neglected in prior research, future research could take the findings of Study 2 as a starting point to examine other CSI context factors.

\section{Managerial Implications}

For managers, the key implication of the studies is that CSR indeed contributes to firm value, however not every CSR engagement has the potential do so. Managers should thus cautiously choose their CSR engagement. Importantly, their selection should be made under consideration of the specific firm context in which stakeholders' embed their CSR evaluations.

Study 1 shows that managers using CSR as a means for compensating stakeholders for past misconduct should scrutinize whether stakeholders should be made aware that CSR 
is just a reaction to prior misconduct. By drawing attention to misconduct through misconduct-related compensation, stakeholders become aware of the solely reactive nature of these compensation efforts harming firm value in turn. With misconduct-unrelated compensation firms can avoid such an association and thus such efforts enhance firm value. Managers should also take into account that the marketing function has an "accelerator" effect in that advertising and R\&D strengthen the unfavorable (favorable) firm value effects of misconduct-related (misconduct-unrelated) compensation.

Study 2 provides empirical evidence that stakeholders concurrently consider CSR and CSI information when evaluating CSR initiatives. Firms that are inflicted by CSI occurrence and at the same time conduct CSR should classify their CSR engagement with respect to whether CSR activities tap into the same domains as CSI (i.e., same-domain CSR) or not (i.e., other-domain CSR). Such classification helps to identify financially beneficial CSR activities from those that are not. If necessary, managers should adjust their CSR program accordingly. However, such considerations should not be disconnected from CSI context. Managers should particularly keep an eye on the CSI proneness of the firm's industry as in some cases not only other-domain CSR is a financially beneficial endeavor but also samedomain CSR.

Study 3 shows that shareholders evaluate a firm's CSR engagement with respect to a firm's emphasis between value creation and value appropriation. The findings of Study 3 show that firms should classify CSR engagement by how they fulfill societal obligations (i.e., doing good or avoiding bad) together with the stakeholders that are targeted by the CSR engagement (i.e., primary or secondary stakeholders). Depending on the firm's marketing strategic focus, some of the CSR activities that can be derived from such classification enhance firm value, while others backfire. More specifically, the findings suggest that 
managers should focus on doing good activities that target secondary stakeholder when the firm emphasizes value appropriation, whereas firms that focus on value creation are financially better off with avoiding bad activities that target primary stakeholders.

The findings of the three studies give managers concrete recommendations on which CSR activities should be on the agenda given their specific situation: If firms use CSR to compensate stakeholders for past misconduct, managers should consider the findings of Study 1 for maximizing shareholder wealth. Firms that face CSI while also engaging in CSR at the same time should incorporate the findings of Study 2, and firms that focus either on value creation or value appropriation in their marketing strategy should consider the findings of Study 3. Overall, the studies' results help managers to justify investments in CSR and hopefully to convince those that still refrain from CSR. While the focus of this dissertation was the examination how and when doing good leads to doing well, it is worthwhile to mention that, from an ethical and moral point of view, some CSR activities could be just the right thing to do although the financial benefits may stay away. 



\section{Appendix}

Appendix 1: List of KLD Items

\begin{tabular}{|c|c|c|}
\hline Domain & Type & Items \\
\hline \multirow[t]{2}{*}{ Community } & Strengths & $\begin{array}{l}\text { Charitable giving } \\
\text { Innovative giving } \\
\text { Non-US charitable giving } \\
\text { Support for housing } \\
\text { Support for education (added '94) } \\
\text { Indigenous peoples relations (added '00; moved '02) } \\
\text { Volunteer programs (added '05) } \\
\text { Other strength }\end{array}$ \\
\hline & Concerns & $\begin{array}{l}\text { Investment controversies } \\
\text { Negative economic impact } \\
\text { Indigenous peoples relations (added '00; moved '02) } \\
\text { Tax disputes (moved '05) } \\
\text { Other concern }\end{array}$ \\
\hline \multirow[t]{2}{*}{ Corporate governance } & Strengths & $\begin{array}{l}\text { Limited compensation } \\
\text { Ownership strength } \\
\text { Transparency strength (added '05) } \\
\text { Political accountability strength (added '05) } \\
\text { Public policy } \\
\text { Other strength }\end{array}$ \\
\hline & Concerns & $\begin{array}{l}\text { High compensation } \\
\text { Ownership concern } \\
\text { Public policy (added '07) } \\
\text { Accounting concern (added '05) } \\
\text { Transparency concern (added '05) } \\
\text { Political accountability concern (added '05) } \\
\text { Other concern }\end{array}$ \\
\hline \multirow[t]{2}{*}{ Diversity } & Strengths & $\begin{array}{l}\text { CEO } \\
\text { Promotion } \\
\text { Board of directors } \\
\text { Work/Life benefits } \\
\text { Women \& minority contracting } \\
\text { Employment of the disabled } \\
\text { Gay \& lesbian policies (added '95) } \\
\text { Other strength }\end{array}$ \\
\hline & Concerns & $\begin{array}{l}\text { Controversies } \\
\text { Non-Representation } \\
\text { Other concern }\end{array}$ \\
\hline Environment & Strengths & $\begin{array}{l}\text { Beneficial products and services } \\
\text { Pollution prevention } \\
\text { Recycling } \\
\text { Clean energy } \\
\text { Communications (added '96; moved '05) } \\
\text { Management systems }\end{array}$ \\
\hline
\end{tabular}


Appendix 1: List of KLD Items (continued)

\begin{tabular}{|c|c|c|}
\hline Domain & Type & Items \\
\hline Environment & Strengths & $\begin{array}{l}\text { Property, plant, and equipment (ended '95) } \\
\text { Other strength }\end{array}$ \\
\hline Environment & Concerns & $\begin{array}{l}\text { Hazardous waste } \\
\text { Regulatory problems } \\
\text { Ozone depleting chemicals } \\
\text { Substantial emissions } \\
\text { Agricultural chemicals } \\
\text { Climate change (added '99) } \\
\text { Other concern }\end{array}$ \\
\hline \multirow[t]{2}{*}{ Human rights } & Strengths & $\begin{array}{l}\text { Positive record in South Africa ('94-'95) } \\
\text { Indigenous peoples relations strength (added '02) } \\
\text { Labor rights strength (added '02) } \\
\text { Other strength }\end{array}$ \\
\hline & Concerns & $\begin{array}{l}\text { South Africa (ended '94) } \\
\text { Northern Ireland (ended '94) } \\
\text { Burma concern (added '95) } \\
\text { Mexico ('95-'02) } \\
\text { Labor rights concern (added '98) } \\
\text { Indigenous peoples relations concern (added '00) } \\
\text { Other concern }\end{array}$ \\
\hline Product & Strengths & $\begin{array}{l}\text { Quality } \\
\text { R\&D/Innovation } \\
\text { Benefits to economically disadvantaged } \\
\text { Other strength } \\
\text { Product safety } \\
\text { Marketing/Contracting concern } \\
\text { Antitrust } \\
\text { Other concern }\end{array}$ \\
\hline \multirow[t]{2}{*}{ Employee relations } & Strengths & $\begin{array}{l}\text { Union relations } \\
\text { No-Layoff policy (ended '94) } \\
\text { Cash profit sharing } \\
\text { Employee involvement } \\
\text { Retirement benefits strength } \\
\text { Health and safety strength } \\
\text { Other strength }\end{array}$ \\
\hline & Concerns & $\begin{array}{l}\text { Union relations } \\
\text { Health and safety concern } \\
\text { Workforce reductions } \\
\text { Retirement benefits concern (added '92) } \\
\text { Other concern }\end{array}$ \\
\hline
\end{tabular}




\section{References}

Aaker, David A. (1991), Managing Brand Equity, New York: The Free Press.

Accenture (2010), “A New Era of Sustainability," [available at https://www.unglobalcompact.org/docs/news_events/8.1/UNGC_Accenture_CEO_Stud y_2010.pdf].

Agarwal, Sanjeev, and Kenneth R. Teas (2001), "Perceived Value: Mediating Role of Perceived Risk," Journal of Marketing Theory and Practice, 9(4), 1-14.

Aiken, Leona S., and Stephen G. West (1991), Multiple Regression: Testing and Interpreting Interactions, Newbury Park, CA: Sage.

Ailawadi, Kusum L., Scott A. Neslin, Y. Jackie Luan, and Gail Ayala Taylor (2014), "Does Retailer CSR Enhance Behavioral Loyalty? A Case for Benefit Segmentation," International Journal of Research in Marketing, 31(2), 156-67.

Almasy, Steve (2016), "Nestle Recalls Certain Frozen Foods Over Glass Concerns," CNN, [available at http://edition.cnn.com/2016/03/10/us/nestle-digiorno-lean-cuisinestouffers-recall/].

Anderson, Eugene W., Claes Fornell, and Sanal K. Mazvancheryl (2004), "Customer Satisfaction and Shareholder Value," Journal of Marketing, 68(4), 172-85.

Aston, Adam (2009), "Wal-Mart: Making Its Suppliers Go Green,” Bloomberg Businessweek, [available at http://www.businessweek.com/magazine/content/09_21/b4132044814736.htm].

Banerjee, Subhabrata Bobby, Easwar S. Iyer, and Rajiv K. Kashyap (2003), "Corporate Environmentalism: Antecedents and Influence of Industry Type," Journal of Marketing, 67(2), 106-22.

Barnett, Michael L. (2007), "Stakeholder Influence Capacity and the Variability of Financial Returns to Corporate Social Responsibility," Academy of Management Review, 32(3), 794-816.

Barnett, Michael L., and Robert M. Salomon (2012), "Does it Pay to Be Really Good? Addressing the Shape of the Relationship between Social and Financial Performance," Strategic Management Journal, 33(11), 1304-20.

Barney, Jay B., and Mark H. Hansen (1994), "Trustworthiness as a Source of Competitive Advantage,” Strategic Management Journal, 15(Issue Supplement S1), 175-90.

Basu, Kunal, and Guido Palazzo (2008), "Corporate Social Responsibility: A Process Model of Sensemaking," Academy of Management Review, 33(1), 122-36.

Berman, Shawn L., Andrew C. Wicks, Suresh Kotha, and Thomas M. Jones (1999), "Does Stakeholder Orientation Matter? The Relationship between Stakeholder Management Models and Firm Financial Performance," Academy of Management Journal, 42(5), 488-506.

Bharadwaj, Anandhi S., Sundar G. Bharadwaj, and Benn R. Konsynski (1999), "Information Technology Effects on Firm Performance as Measured by Tobin's q," Management 
Science, 45(7), 1008-24.

Bhattacharya, C. B., Daniel Korschun, and Sankar Sen (2011), "What Really Drives Value in Corporate Responsibility?," McKinsey Quarterly, (4), 1-3.

Bhattacharya, C. B., and Sankar Sen (2003), "Consumer-Company Identification: A Framework for Understanding Consumers' Relationship with Companies," Journal of Marketing, 67(2), 76-88.

— (2004), "Doing Better at Doing Good," California Management Review, 47(1), 9-25.

Bhattacharya, C.B. (2009), "Corporate Social Responsibility: It's All About Marketing," The Forbes, [available at http://www.forbes.com/2009/11/20/corporate-social-responsibilityleadership-citizenship-marketing.html].

Bielak, Debby, Sheila M. J. Bonini, and Jeremy M. Oppenheim (2007), "CEOs on Strategy and Social Issues," McKinsey Quarterly, McKinsey \& Company, Inc., [available at http://search.ebscohost.com/login.aspx?direct=true \&db=bth\&AN=27602563\&site=edslive\&authtype $=$ shib].

Boyd, Eric D., Rajesh K. Chandy, and Marcus Cunha (2010), "When Do Chief Marketing Officers Affect Firm Value? A Customer Power Explanation,” Journal of Marketing Research, 47(6), 1162-76.

Brammer, Stephen J., and Stephen Pavelin (2006), "Corporate Reputation and Social Performance: The Importance of Fit," Journal of Management Studies, 43(3), 435-55.

Brown, Tom J., and Peter A. Dacin (1997), "The Company and the Product: Corporate Associations and Consumer Product Responses," Journal of Marketing, 61(1), 68-84.

Browne, John, and Robin Nuttall (2013), "Beyond Corporate Social Responsibility: Integrated External Engagement," McKinsey\&Company, [available at http://www.mckinsey.com/insights/strategy/beyond_corporate_social_responsibility_int egrated_external_engagement].

Burmester, Alexa B., Jan U. Becker, Harald J. van Heerde, and Michel Clement (2015), "The Impact of Pre- and Post-Launch Publicity and Advertising on New Product Sales," International Journal of Research in Marketing, 32(4), 408-17.

Campbell, John L. (2007), "Why Would Corporations Behave in Socially Responsible Ways? An Institutional Theory of Corporate Social Responsibility," Academy of Management Review, 32(3), 946-67.

Chapman, Kenneth J., and Andrew Aylesworth (1999), "Riding the Coat-Tails of a Positive Review: Rave Reviews and Attitude Transfer," Journal of Consumer Marketing, 16(45), 418-41.

Chauvin, Keith W., and Mark Hirschey (1993), "Advertising, R\&D Expenditures and the Market Value of the Firm," Financial Management, 22(1), 128-40.

Chin, M. K., D. C. Hambrick, and L. K. Trevino (2013), "Political Ideologies of CEOs: The Influence of Executives' Values on Corporate Social Responsibility," Administrative Science Quarterly, 58(2), 197-232.

Chung, Kee H., and Stephen W. Pruitt (1994), "A Simple Approximation of Tobin's q," Financial Management, 23(2), 70-74. 
Clarkson, Max B. E. (1995), "A Stakeholder Framework for Analyzing and Evaluating Corporate Social Performance," Academy of Management Review, 20(1), 92-117.

Claudy, Marius C., Rosanna Garcia, and Aidan O. Driscoll (2015), "Consumer Resistance to Innovation-A Behavioral Reasoning Perspective," Journal of the Academy of Marketing Science, 43(4), 528-44.

Collins, Allan M., and Elizabeth F. Loftus (1975), "A Spreading-Activation Theory of Semantic Processing," Psychological Review, 82(6), 407-28.

Conchar, Margy P., Melvin R. Crask, and George M. Zinkhan (2005), "Market Valuation Models of the Effect of Advertising and Promotional Spending: A Review and MetaAnalysis," Journal of the Academy of Marketing Science, 33(4), 445-60.

Cone (2015), “2015 Cone Communications/Ebiquity Global CSR Study,” [available at http://www.conecomm.com/2015-cone-communications-ebiquity-global-csr-study].

Creyer, Elizabeth H., and William T. Jr. Ross (1996), "The Impact of Corporate Behavior on Perceived Product Value," Marketing Letters, 7(2), 173-85.

Curras-Perez, Rafael (2009), "The Role of Self-Definitional Principles in Consumer Identification with a Socially Responsible Company," Journal of Business Ethics, 89(4), 547-64.

Currim, Imran S., Jooseop Lim, and Joung W. Kim (2012), "You Get What You Pay For: The Effect of Top Executives' Compensation on Advertising and R\&D Spending Decisions and Stock Market Return," Journal of Marketing, 76(5), 33-48.

Datta, Hannes, Bram Foubert, and Harald J. Van Heerde (2015), "The Challenge of Retaining Customers Acquired with Free Trials," Journal of Marketing Research, 52(2), 217-34.

Deng, Xin, Jun-Koo Kang, and Buen Sin Low (2013), "Corporate Social Responsibility and Stakeholder Value Maximization: Evidence from Mergers," Journal of Financial Economics, 110(1), 87-109.

Denis, David J., and Timothy A. Kruse (2000), "Managerial Discipline and Corporate Restructuring Following Performance Declines," Journal of Financial Economics, 55(3), 391-424.

Dixon-Fowler, Heather R., Daniel J. Slater, Jonathan L. Johnson, Alan E. Ellstrand, and Andrea M. Romi (2013), 'Beyond 'Does it Pay to be Green?' A Meta-Analysis of Moderators of the CEP-CFP Relationship," Journal of Business Ethics, 112(2), 353-66.

Donaldson, Thomas, and Lee E. Preston (1995), "The Stakeholder Theory of the Corporation: Concepts, Evidence, and Implications," Academy of Management Journal, 20(1), 65-91.

Du, Shuili, C. B. Bhattacharya, and Sankar Sen (2007), "Reaping Relational Rewards from Corporate Social Responsibility: The Role of Competitive Positioning," International Journal of Research in Marketing, 24(3), 224-41.

(2010), "Maximizing Business Returns to Corporate Social Responsibility (CSR): The Role of CSR Communication," International Journal of Management Reviews, 12(1), 8-19.

Dutta, Shantanu, Om Narasimhan, and Surendra Rajiv (1999), "Success in High-Technology Markets: Is Marketing Capability Critical?,” Marketing Science, 18(4), 547-68. 
Ebbes, Peter, Dominik Papies, and Harald J. Van Heerde (2011), "The Sense and Non-Sense of Holdout Sample Validation in the Presence of Endogeneity," Marketing Science, 30(6), 1115-22.

Economic Policy Group (2015), "Business Backs Education: Creating a Baseline for Corporate CSR Spend on Global Education Initiatives," [available at http://businessbackseducation.org/wp-content/uploads/2014/05/BBE-EPG-Report2015.pdf].

Ellen, Pam Scholder, Deborah J. Webb, and Lois A. Mohr (2006), "Building Corporate Associations: Consumer Attributions for Corporate Socially Responsible Programs," Journal of the Academy of Marketing Science, 34(2), 147-57.

Fein, Steven, and James L. Hilton (1994), "Judging Others in the Shadow of Suspicion," Motivation and Emotion, 18(2), 167-98.

Fitzmaurice, Garrett M., Nan M. Laird, and James H. Waire (2011), Applied Longitudinal Analysis, Hoboken, New Jersey: John Wiley \& Sons, Inc.

Flammer, Caroline (2013), "Corporate Social Responsibility and Shareholder Reaction: The Environmental Awareness of Investors," Academy of Management Journal, 56(3), 75881.

(2014), "The Impact of Stakeholder Orientation on Innovation," Management Science, 62(7), 1-38.

(2015), "Does Corporate Social Responsibility Lead to Superior Financial Performance? A Regression Discontinuity Approach," Management Science, 61(11), 2549-68.

Forbes (2008), “CEOs On CSR,” [available at http://www.forbes.com/2008/10/16/ceos-csrcritics-lead-corprespons08-cx_tw_mk_kk_1016ceos.html].

Forehand, Mark R., and Sonya Grier (2003), "When Is Honesty the Best Policy? The Effect of Stated Company Intent on Consumer Skepticism," Journal of Consumer Psychology, 13(3), 349-56.

Freeman, R. Edward (1984), Strategic Management: A Stakeholder Approach, Boston: Pitman.

Friedman, Milton (1970), "The Social Responsibility of Business Is to Increase its Profits," New York Times Magazine, 32-33.

Frooman, Jeff (1997), "Socially Irresponsible and Illegal Behavior and Shareholder Wealth: A Meta-Analysis of Event Studies," Business \& Society, 36(3), 221-49.

Garcia-Castro, Roberto, Miguel A. Ariño, and Miguel A. Canela (2010), "Does Social Performance Really Lead to Financial Performance? Accounting for Endogeneity," Journal of Business Ethics, 92(1), 107-26.

Gentleman, Amelia (2006), "Pesticide Allegations Trip up Coke and Pepsi - Business International Herald Tribune," New York Times.

Godfrey, Paul C., Craig B. Merrill, and Jared M. Hansen (2009), "The Relationship between Corporate Social Responsibility and Shareholder Value: An Empirical Test of the Risk Management Hypothesis," Strategic Management Journal, 30(4), 425-45. 
Graves, Samuel B., and Sandra A. Waddock (1994), "Institutional Owners and Corporate Social Performance," The Academy of Management Journal, 37(4), 1034-46.

Greening, Daniel W., and Daniel B. Turban (2000), "Corporate Social Performance As a Competitive Advantage in Attracting a Quality Workforce," Business \& Society, 39(3), 254-80.

Greenwood, Michelle, and Harry J. van Buren (2010), "Trust and Stakeholder Theory: Trustworthiness in the Organisation-Stakeholder Relationship," Journal of Business Ethics, 95(3), 425-38.

Groening, Christopher, Vikas Mittal, and Yan Zhang (2016), "Cross-Validation of Customer and Employee Signals and Firm Valuation," Journal of Marketing Research, 53(1), 6176.

Gupta, Anil K., Ken G. Smith, Christina E. Shalley, and K. Smith (2006), “The Interplay between Exploration and Exploitation," Academy of Management Journal, 49(4), 693706.

Hair, Joseph F. Jr., William C. Black, Barry J. Babin, and Rolph E. Anderson (2010), Multivariate Data Analysis, Upper Saddle River, NY: Pearson.

Handelman, Jay M., and Stephen J. Arnold (1999), "The Role of Marketing Actions with a Social Dimension: Appeals to the Institutional Environment," Journal of Marketing, 63(3), 33-48.

Harris, Jared, and Philip Bromiley (2007), "Incentives to Cheat: The Influence of Executive Compensation and Firm Performance on Financial Misrepresentation," Organization Science, 18(3), 350-67.

Heckman, James J. (1976), "The Common Structure of Statistical Models of Truncation, Sample Selection, and Limited Dependent Variables and a Simple Estimator for Such Models," Annals of Economic and Social Measurement, 5(4), 475-92.

Hildebrand, Diogo, Sankar Sen, and C.B. Bhattacharya (2011), "Corporate Social Responsibility: A Corporate Marketing Perspective," European Journal of Marketing, 45(9/10), 1353-64.

Hillman, Amy J., and Gerald D. Keim (2001), "Shareholder Value, Stakeholder Management, and Social Issues: What's the Bottom Line?," Strategic Management Journal, 22(2), 125-39.

Homburg, Christian, Marcel Stierl, and Torsten Bornemann (2013), "Corporate Social Responsibility in Business-to-Business Markets: How Organizational Customers Account for Supplier Corporate Social Responsibility Engagement," Journal of Marketing, 77(6), 54-72.

Hull, Clyde Eiríkur, and Sandra Rothenberg (2008), "Firm Performance: The Interactions of Corporate Social Performance with Innovation and Industry Differentiation," Strategic Management Journal, 29(7), 781-89.

Jacobson, Robert (1990), "Unobservable Effects and Business Performance: Reply to the Comments of Boulding and Buzzel," Marketing Science, 9(1), 92-95.

Janney, Jay J., and Steve Gove (2011), "Reputation and Corporate Social Responsibility 
Aberrations, Trends, and Hypocrisy: Reactions to Firm Choices in the Stock Option Backdating Scandal," Journal of Management Studies, 48(7), 1562-85.

Jayachandran, Satish, Kartik Kalaignanam, and Meike Eilert (2013), "Product and Environmental Social Performance: Varying Effect on Firm Performance," Strategic Management Journal, 34(10), 1255-65.

Jensen, Michael C., and William H. Meckling (1976), "Theory of the Firm: Managerial Behavior, Agency Costs and Ownership Structure," Journal of Financial Economics, 3(4), 305-60.

Jiao, Yawen (2010), "Stakeholder Welfare and Firm Value," Journal of Banking and Finance, 34(10), 2549-61.

Johar, Gita Venkataramani, and Michel Tuan Pham (1999), "Relatedness, Prominence, and Constructive Sponsor Identification," Journal of Marketing Research, 36(1), 299-312.

Jones, Ray, and Audrey J. Murrell (2001), "Signaling Positive Corporate Social Performance: An Event Study of Family-Friendly Firms," Business \& Society, 40(1), 59-78.

Jones, Thomas M. (1995), "Instrumental Stakeholder Theory: A Synthesis of Ethics and Economics," The Academy of Management Review, 20(2), 404-37.

Josephson, Brett W., Jean L. Johnson, and Babu J. Mariadoss (2015), "Strategic Marketing Ambidexterity: Antecedents and Financial Consequences," Journal of the Academy of Marketing Science, (2), 1-16.

Joshi, Amit, and Dominique M. Hanssens (2010), "The Direct and Indirect Effects of Advertising Spending on Firm Value," Journal of Marketing, 74(1), 20-33.

Judge, George G., R. Carter Hill, William Griffiths, Helmut Lütkepohl, and Tsoung-Chao Lee (1988), Introduction to the Theory and Practice of Econometrics, Hoboken, NJ: John Wiley \& Sons.

Kang, Charles, Frank Germann, and Rajdeep Grewal (2016), "Washing Away Your Sins? Corporate Social Responsibility, Corporate Social Irresponsibility, and Firm Performance," Journal of Marketing, 20(2), 59-79.

Korschun, Daniel, C.B. Bhattacharya, and Scott D. Swain (2014), "Corporate Social Responsibility, Customer Orientation, and the Job Performance of Frontline Employees," Journal of Marketing, 78(3), 20-37.

Kotchen, Matthew, and Jon J. Moon (2012), "Corporate Social Responsibility for Irresponsibility," The B.E. Journal of Economic Analysis \& Policy, 12(1), Article 55.

Kotler, Philip, and Nancy Lee (2005), Corporate Social Responsibility: Doing the Most Good for Your Company and Your Cause, New York: John Wiley \& Sons.

KPMG (2014), “A New Vision of Value: Connecting Corporate and Societal Value Creation," [available at http://www.kpmg.com/ES/es/ActualidadyNovedades/ArticulosyPublicaciones/Documen ts/a-new-vision-of-value-2014.pdf].

Krasnikov, Alexander, and Satish Jayachandran (2008), "The Relative Impact of Marketing, Research-and-Development, and Operations Capabilities on Firm Performance," Journal of Marketing, 72(4), 1-11. 
Kurt, Didem, and John Hulland (2013), "Aggressive Marketing Strategy Following Equity Offerings and Firm Value: The Role of Relative Strategic Flexibility," Journal of Marketing, 77(5), 57-74.

Lee, Ruby P., and Rajdeep Grewal (2004), "Strategic Responses to New Technologies and Their Impact on Firm Performance," Journal of Marketing, 68(4), 157-71.

Lei, Jing, Niraj Dawar, and Jos Lemmink (2008), "Negative Spillover in Brand Portfolios: Exploring the Antecedents of Asymmetric Effects," Journal of Marketing, 72(3), 11123.

Leonidou, Constantinos N., Constantine S. Katsikeas, and Neil A. Morgan (2012), "'Greening' the Marketing Mix: Do Firms Do It and Does It Pay Off?," Journal of the Academy of Marketing Science, 41(2), 151-70.

Lichtenstein, Donald R, Minette E Drumwright, and Bridgette M Braig (2004), "The Effect of Corporate Social Responsibility on Customer Donations to Corporate-Supported," 68(October), 16-32.

Lin-Hi, Nick, and Karsten Müller (2013), "The CSR Bottom Line: Preventing Corporate Social Irresponsibility," Journal of Business Research, 66(10), 1928-36.

Luo, Xueming (2009), "Quantifying the Long-Term Impact of Negative Word of Mouth on Cash Flows and Stock Prices," Marketing Science, 28(1), 148-65.

Luo, Xueming, and C. B. Bhattacharya (2006), "Corporate Social Responsibility, Customer Satisfaction, and Market Value," Journal of Marketing, 70(4), 1-18.

(2009), “The Debate over Doing Good: Corporate Social Performance, Strategic Marketing Levers, and Firm-Idiosyncratic Risk," Journal of Marketing, 73(6), 198-213.

Luo, Xueming, and Christian Homburg (2007), "Neglected Outcomes of Customer Satisfaction," Journal of Marketing, 71(2), 133-49.

Luo, Xueming, Heli Wang, Sascha Raithel, and Qinqin Zheng (2015), "Corporate Social Performance, Analyst Stock Recommendations, and Firm Future Returns," Strategic Management Journal, 36(1), 123-36.

Lynn, Matthew (2015), “Corporate Social Responsibility Has Become a Racket - and a Dangerous One," The Telegraph, [available at http://www.telegraph.co.uk/finance/newsbysector/industry/11896546/Corporate-SocialResponsibility-has-become-a-racket-and-a-dangerous-one.html].

Maignan, Isabelle, and O. C. Ferrell (2004), "Corporate Social Responsibility and Marketing: An Integrative Framework," Journal of the Academy of Marketing Science, 32(1), 3-19.

Margolis, Joshua D., Hillary A. Elfenbein, and James P. Walsh (2009), "Does It Pay To Be Good...And Does It Matter? A Meta-Analysis of the Relationship Between Corporate Social and Financial Performance," Working Paper.

Margolis, Joshua D., and James P. Walsh (2003), "Misery Loves Companies: Rethinking Social Initiatives by Business," Administrative Science Quarterly, 48(2), 268-305.

Mattingly, J. E. (2015), “Corporate Social Performance: A Review of Empirical Research Examining the Corporation-Society Relationship Using Kinder, Lydenberg, Domini Social Ratings Data," Business \& Society, 54(3), 1-44. 
Mattingly, James E., and Shawn L. Berman (2006), "Measurement of Corporate Social Action: Discovering Taxonomy in the Kinder Lydenburg Domini Ratings Data," Business \& Society, 45(1), 20-46.

McAlister, Leigh, Raji Srinivasan, Niket Jindal, and Albert A. Cannella (2016), “Advertising Effectiveness: The Moderating Effect of Firm Strategy," Journal of Marketing Research, 53(2), 207-24.

McKinsey\&Company (2009), "McKinsey Global Survey Results : Valuing Corporate Social Responsibility," [available at http://www.mckinsey.com/insights/corporate_finance/valuing_corporate_social_respons ibility_mckinsey_global_survey_results].

McKinsey \& Company (2014), “Sustainability’s Strategic Worth: McKinsey Global Survey Results," [available at http://www.mckinsey.com/insights/sustainability/sustainabilitys_strategic_worth_mckin sey_global_survey_results].

McWilliams, Abagail, and Donald Siegel (2000), "Corporate Social Responsibility and Financial Performance: Correlation or Misspecification?," Strategic Management Journal, 21(5), 603-9.

(2001), "Corporate Social Responsibility: A Theory of the Firm Perspective," The Academy of Management Review, 26(1), 117-27.

Menon, Satya, and Barbara E. Kahn (2003), "Corporate Sponsorship of Philanthrophic Activities: When Do They Impact Perception of Sponsor Brand?," Journal of Consumer Psychology, 13(3), 316-27.

Mishina, Yuri, Emily S. Block, and Michael J. Mannor (2012), "The Path Dependence of Organizational Reputation: How Social Judgment Influences Assessments of Capability and Character," Strategic Management Journal, 33(5), 459-77.

Mishra, Saurabh, and Sachin B. Modi (2016), "Corporate Social Responsibility and Shareholder Wealth: The Role of Marketing Capability," Journal of Marketing, 80(1), 26-46.

Mitchell, Ronald K., Bradley R. Agle, and Donna J. Wood (1997), "Toward a Theory of Stakeholder Identification and Salience: Defining the Principle of Who and What Really Counts," The Academy of Management Review, 22(4), 853-86.

Mizik, Natalie, and Robert Jacobson (2003), "Trading Off Between Value Creation and Value Appropriation: The Financial Implications of Shifts in Strategic Emphasis," Journal of Marketing, 67(1), 63-76.

Montgomery, Cynthia A., and Birger Wernerfelt (1988), "Diversification, Ricardian Rents, and Tobin's q," The RAND Journal of Economics, 19(4), 623-32.

Morgan, Robert M., and Shelby D. Hunt (1994), "The Commitment-Trust Theory of Relationship Marketing," Journal of Marketing, 58(3), 20-38.

Morrin, Maureen (1999), "The Impact of Memory Brand Extensions Structures and Retrieval Processes," Journal of Marketing Research, 36(4), 517-25.

Muller, Alan, and Roman Kräussl (2011), "Doing Good Deeds in Times of Need: A Strategic 
Perspective on Corporate Disaster Donations," Strategic Management Journal, 32(9), 911-29.

Orlitzky, Marc, Frank L. Schmidt, and Sara L. Rynes (2003), "Corporate Social and Financial Performance: A Meta-analysis," Organization Studies, 24(3), 403-41.

Park, S., and S. Gupta (2012), "Handling Endogenous Regressors by Joint Estimation Using Copulas," Marketing Science, 31(4), 567-86.

Patagonia (2013), "World Trout Initiative," [available at http://www.patagonia.com/us/patagonia.go?assetid=32942].

Peloza, John, and Jingzhi Shang (2011), "How Can Corporate Social Responsibility Activities Create Value for Stakeholders? A Systematic Review," Journal of the Academy of Marketing Science, 39(1), 117-35.

Peretz, Jean H., Robert A. Bohm, and Philip D. Jasienczyk (1997), "Environmental Policy and the Reduction of Hazardous Waste," Journal of Policy Analysis and Management, 16(4), 556-74.

Porter, Michael E., and Mark R. Kramer (2006), "Strategy \& Society. The Link Between Competitive Advantage and Corporate Social Responsibility," Harvard Business Review, 84(12), 78-92.

Posavac, Steven S., and J. Joško Brakus (2005), “Adoption of New and Really New Products: The Effects of Self-Regulation Systems and Risk Salience," Journal of Marketing Research, 44(2), 251-60.

Pricewaterhouse Coopers (2014), "Business Success Beyond the Short Term: CEO Perspectives on Sustainability," [available at http://www.pwc.com/gx/en/sustainability/ceo-views/assets/pwc-ceo-summarysustainability.pdf].

Rao, Vithala R., Manoj K. Agarwal, and Denise Dahlhoff (2004), "How Is Manifest Branding Strategy Related to the Intangible Value of a Corporation?," Journal of Marketing, 68(4), 126-41.

Rinallo, Diego, and Suman Basuroy (2009), "Does Advertising Spending Influence Media Coverage of the Advertiser ?," Journal of Marketing, 73(6), 33-46.

Roehm, Michelle L., and Alice M. Tybout (2006), "When Will a Brand Scandal Spill Over, and How Should Competitors Respond?," Journal of Marketing Research, 43(3), 36673.

Rogers, William H. (1993), "Regression Standard Errors in Clustered Samples," Stata Technical Bulletin, 13, 19-23.

Rosch, Eleanor, and Carolyn B. Mervis (1975), "Family Resemblances: Studies in the Internal Structure of Categories," Cognitive Psychology, 7, 573-605.

Rossi, Peter E. (2014), "Invited Paper-Even the Rich Can Make Themselves Poor: A Critical Examination of IV Methods in Marketing Applications," Marketing Science, 33(5), 655-72.

Rowley, T., and S. Berman (2000), "A Brand New Brand of Corporate Social Performance," Business \& Society, 39(4), 397-418. 
Rust, Roland T., Katherine N. Lemon, and Valarie A. Zeithaml (2004), "Return on Marketing: Using Customer Equity to Focus Marketing Strategy," Journal of Marketing, 68(1), 109-27.

Schepers, Jeroen, Tomas Falk, Ko D Ruyter, Ad D Jong, and Maik Hammerschmidt (2012), "Principles and Principals: Do Customer Stewardship and Agency Control Compete or Complement When Shaping Frontline Employee Behavior?," Journal of Marketing, 76(6), 1-20.

Schoorman, David F., Roger C. Mayer, and James H. Davis (2007), “An Integrative Model of Organizational Trust: Past, Present, and Future," Academy of Management Review, 32(2), 344-54.

Schuler, Douglas A., and Margaret Cording (2006), "A Corporate Social Performance Corporate Financial Performance Behavioral Model for Consumers," Academy of Management Review, 31(3), 540-58.

Schulze, Christian, Bernd Skiera, and Thorsten Wiesel (2012), "Linking Customer and Financial Metrics to Shareholder Value: The Leverage Effect in Customer-Based Valuation," Journal of Marketing, 76(2), 17-32.

Sen, Sankar, and C. B. Bhattacharya (2001), "Does Doing Good Always Lead to Doing Better? Consumer Reactions to Corporate Social Responsibility," Journal of Marketing Research, 38(2), 225-43.

Sen, Sankar, C. B. Bhattacharya, and Daniel Korschun (2006), "The Role of Corporate Social Responsibility in Strengthening Multiple Stakeholder Relationships: A Field Experiment," Journal of the Academy of Marketing Science, 34(2), 158-66.

Servaes, Henri, and Ane Tamayo (2013), "The Impact of Corporate Social Responsibility on Firm Value: The Role of Customer Awareness," Management Science, 59(5), 1045-61.

Shiu, Yung-Ming (2016), "Does Engagement in Corporate Social Responsibility Provide Strategic Insurance-like Effects?," Strategic Management Journal, forthcoming.

Shrieves, Ronald E., Deborah L. Murphy, and Samuel L. Tibbs (2009), "Understanding the Penalties Associated with Corporate Misconduct: An Empirical Examination of Earnings and Risk," Journal of Financial and Quantitative Analysis, 44(1), 55.

Simmons, Carolyn J., and Karen L. Becker-Olsen (2006), “Achieving Marketing Objectives Through Social Sponsorships," Journal of Marketing, 70(4), 154-69.

Smith, N. Craig (2003), "Corporate Social Responsibility: Whether or How?," California Management Review, 45(4), 52-77.

Spiller, Stephen A., Gavan J. Fitzsimons, John G. Lynch, and Gary H. McClelland (2013), "Spotlights, Floodlights, and the Magic Number Zero: Simple Effects Tests in Moderated Regression," Journal of Marketing Research, 50(2), 277-88.

Srinivasan, Shuba, and Dominique M. Hanssens (2009), "Marketing and Firm Value: Metrics, Methods, Findings, and Future Directions," Journal of Marketing Research, 46(3), 293-312.

Steenkamp, Jan-Benedict E. M., and Eric (Er) Fang (2011), "The Impact of Economic Contractions on the Effectiveness of R\&D and Advertising: Evidence from U.S. 
Companies Spanning Three Decades," Marketing Science, 30(4), 628-45.

Strike, Vanessa M., Jijun Gao, and Pratima Bansal (2006), "Being Good While Being Bad: Social Responsibility and the International Diversification of US Firms," Journal of International Business Studies, 37(6), 850-62.

Suchman, Mark C. (1995), "Managing Legitimacy: Stategic and Institutional Approaches," Academy of Management Review, 20(3), 571-610.

Sullivan, Bilian Ni, Pamela Haunschild, and Karen Page (2007), "Organizations Non Gratae? The Impact of Unethical Corporate Acts on Interorganizational Networks," Organization Science, 18(1), 55-70.

Swaminathan, Vanitha, Feisal Murshed, and John Hulland (2008), "Value Creation Following Merger and Acquisition Announcements: The Role of Strategic Emphasis Alignment," Journal of Marketing Research, 45(1), 33-47.

Torres, Anna, Tammo H. A. Bijmolt, Josep A. Tribó, and Peter Verhoef (2012), "Generating Global Brand Equity Through Corporate Social Responsibility to Key Stakeholders," International Journal of Research in Marketing, 29(1), 13-24.

Tuli, Kapil R., and Sundar G. Bharadwaj (2009), "Customer Satisfaction and Stock Returns Risk," Journal of Marketing, 73(6), 184-97.

UN Global Compact (2016), "The World's Largest Corporate Sustainability Initiative," [available at https://www.unglobalcompact.org/].

Vlachos, Pavlos A., Argiris Tsamakos, Adam P. Vrechopoulos, and Panagiotis K. Avramidis (2008), "Corporate Social Responsibility: Attributions, Loyalty, and the Mediating Role of Trust," Journal of the Academy of Marketing Science, 37(2), 170-80.

Waddock, Sandra (2003), "Myths and Realities of Social Investing," Organization \& Environment, 16(3), 369-80.

Waddock, Sandra A., and Samuel B. Graves (1997), "The Corporate Social Performance Financial Performance Link," Strategic Management Journal, 18(4), 303-19.

Wagner, Tillmann, Richard J. Lutz, and Barton A. Weitz (2009), "Corporate Hypocrisy: Overcoming the Threat of Inconsistent Corporate Social Responsibility Perceptions," Journal of Marketing, 73(6), 77-91.

Wang, Heli, Jaepil Choi, and Jiatao Li (2008), "Too Little or Too Much? Untangling the Relationship Between Corporate Philanthropy and Firm Financial Performance," Organization Science, 19(1), 143-59.

Wang, Heli, and Cuili Qian (2011), "Corporate Philanthropy and Corporate Financial Performance: The Roles of Stakeholder Response and Political Access," Academy of Management Journal, 54(6), 1159-81.

Wang, Heli, Li Tong, Riki Takeuchi, and Gerry George (2016), "Corporate Social Responsibility: An Overview and New Research Directions," Academy of Management Journal, 59(2), 534-44.

Wang, Qian, Junsheng Dou, and Shenghua Jia (2015), “A Meta-Analytic Review of Corporate Social Responsibility and Corporate Financial Performance: The Moderating Effect of Contextual Factors," Business \& Society, 1-39. 
Webb, Deborah J., and Lois A. Mohr (1998), "A Typology of Consumer Responses to CauseRelated Marketing: From Skeptics to Socially Concerned," Journal of Public Policy \& Marketing, 17(2), 226-38.

Wright, Peter, and Stephen P. Ferris (1997), “Agency Conflict and Corporate Strategy: The Effect of Divestment on Corporate Value," Strategic Management Journal, 18(1), 7783.

Yoon, Yeosun, Zeynep Gürhan-Canli, and Norbert Schwarz (2006), "The Effect of Corporate Social Responsibility (CSR) Activities on Companies With Bad Reputations," Journal of Consumer Psychology, 16(4), 377-90. 